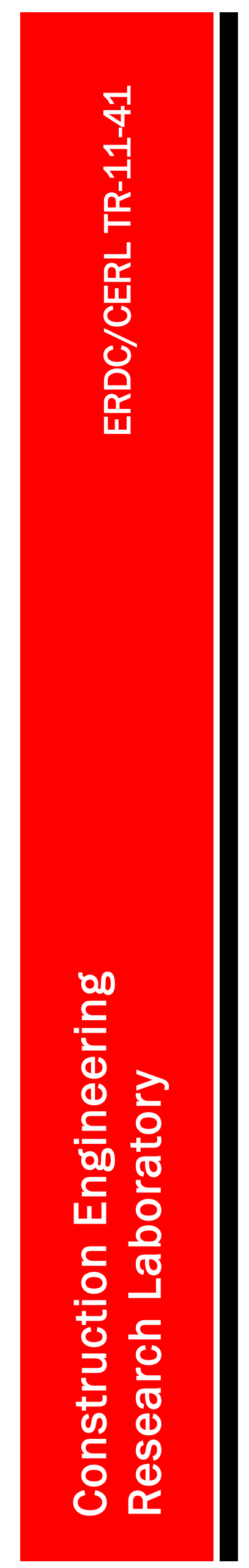

Installation Technology Transfer Program

\title{
Early Design Energy Analysis Using Building Information Modeling Technology
}

Annette L. Stumpf, Hyunjoo Kim, and Elisabeth M. Jenicek

November 2011

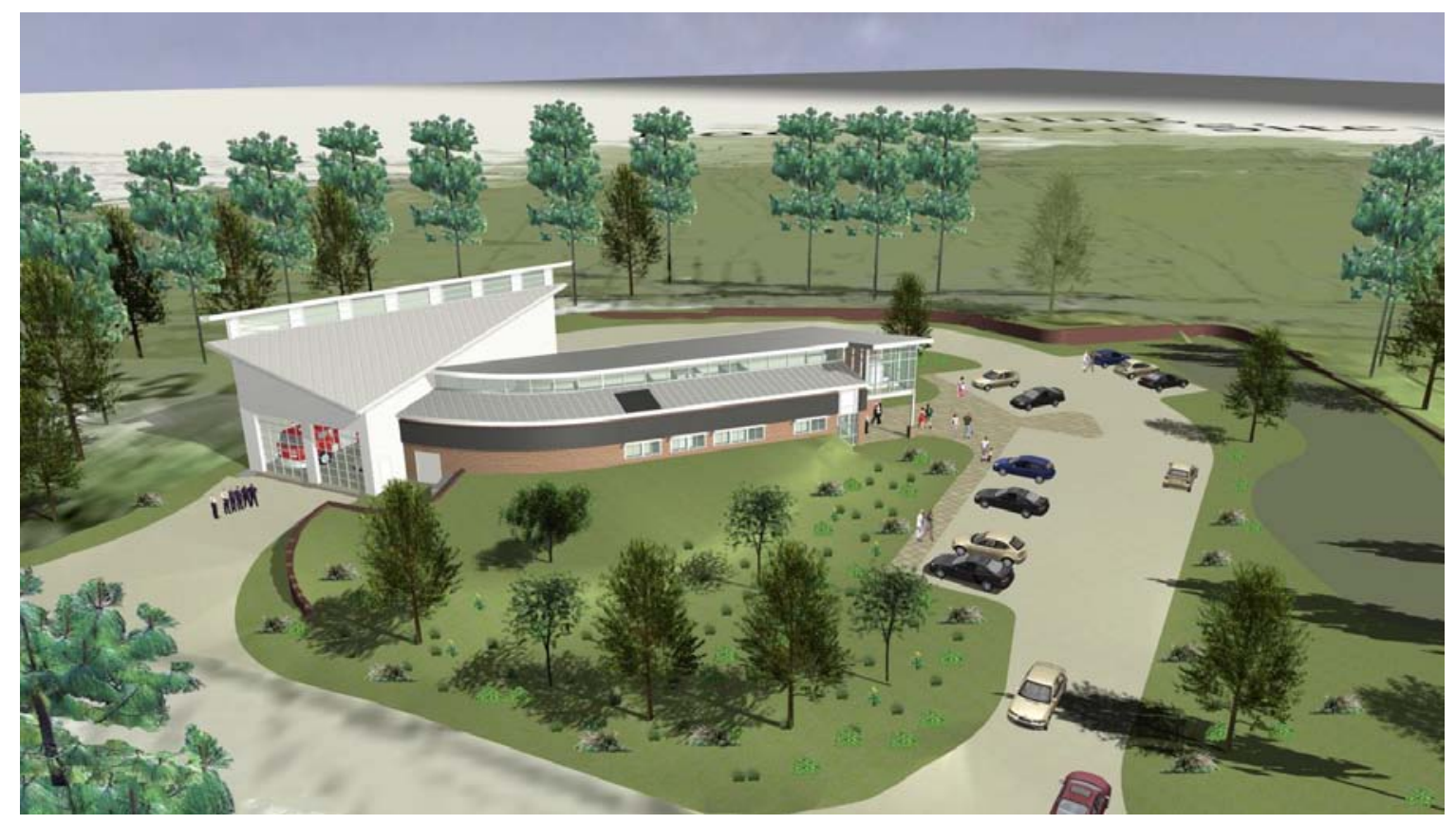





\section{Early Design Energy Analysis Using Building Information Modeling Technology}

Annette L. Stumpf and Elisabeth M. Jenicek

Construction Engineering Research Laboratory

US Army Engineer Research and Development Center

2902 Newmark Dr.

Champaign, IL 61824

Hyunjoo Kim

The Pertan Group

Champaign, IL 61820

Final Report

Approved for public release; distribution is unlimited.

\footnotetext{
Prepared for Office of the Assistant Chief of Staff for Installation Management (ACSIM) 2511 Jefferson Davis Highway

Arlington, VA 22202

Under Project FY09-46, "Early Design Energy Analysis Using BIM”
} 


\begin{abstract}
With the advent of Military Construction (MILCON) Transformation, the responsibility for conducting energy modeling late in the design process falls solely on the Design/ Build contractor or their consultants. This research utilized Building Information Modeling (BIM) for energy analysis during the conceptual design phase. Most building energy analyses are conducted later in the design process by energy analysts. This report describes a process of exploring different energy saving alternatives in early design using 3D-CAD (computer-aided design)/ BIM technology. This project investigated the feasibility of exporting a gbXML file from a BIM model for use in Green Building Studio, a computer-based energy analysis tool. The goal was to assess the applicability of this technology during a planning or early design charrette in order to identify energy saving measures equal to or exceeding the $30 \%$ energy-saving requirement over the ASHRAE baseline. This type of tool could potentially be used early in the project life cycle to evaluate alternative energy design schemas as part of an integrated whole-building design process.
\end{abstract}




\section{Table of Contents}

List of Figures and Tables.........................................................................................................

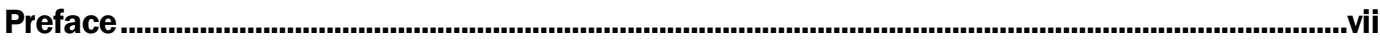

Unit Conversion Factors ........................................................................................................................ ix

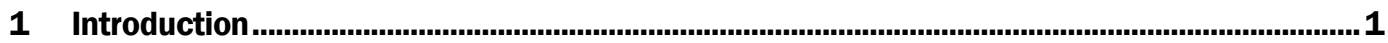

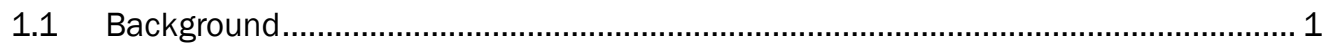

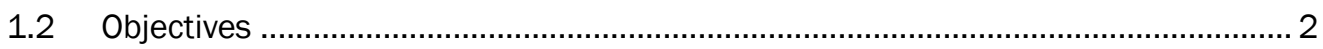



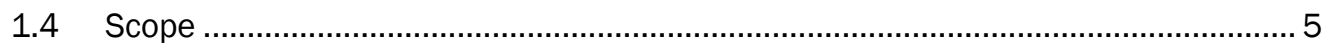

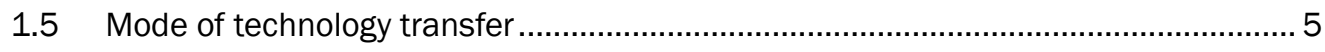

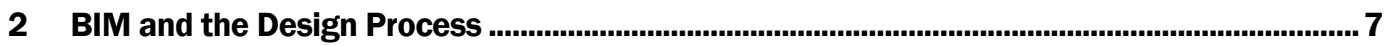

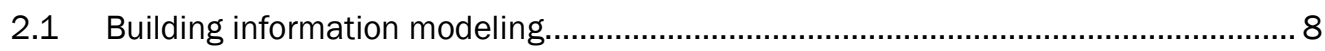



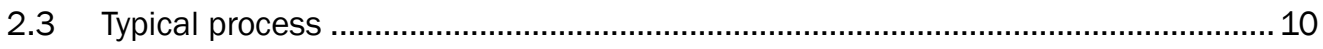

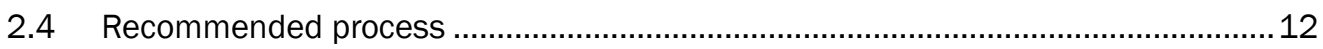

2.5 CAD/BIM tools that work with Green Building Studio ${ }^{\circledR}$ and export gbXML



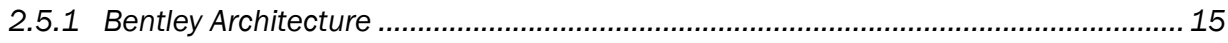

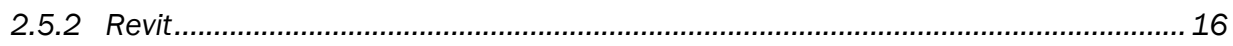

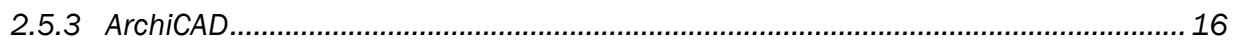

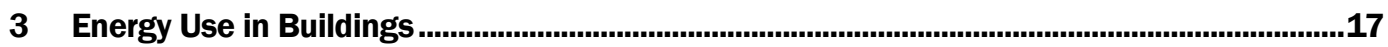

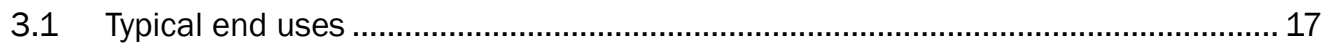

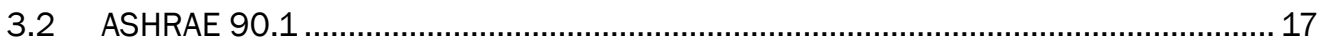

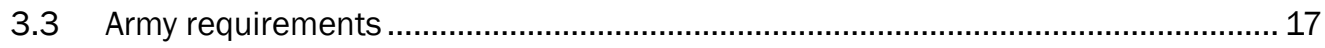

3.4 Building construction (MCA) requirements and standards..................................... 18

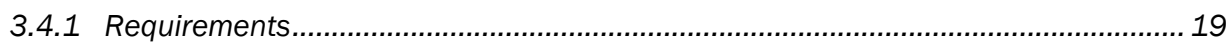

3.4.2 Integrated design and project delivery team members...........................................20



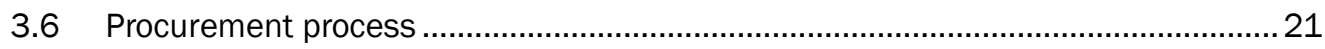

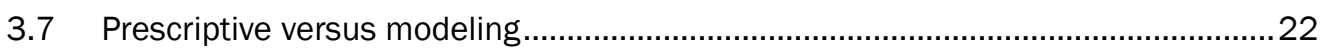

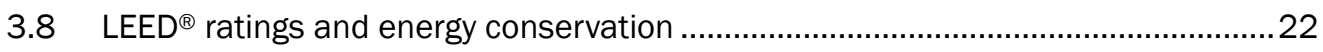

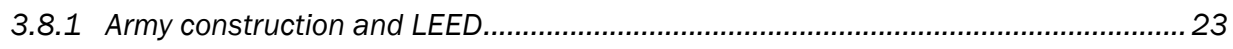

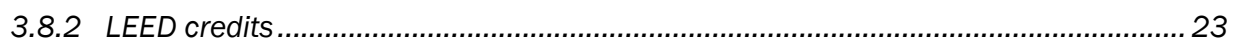

3.8.3 Design/build submittal requirements............................................................... 23

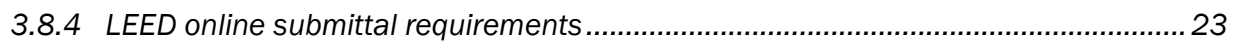

3.8.5 LEED and energy modeling .......................................................................... 24

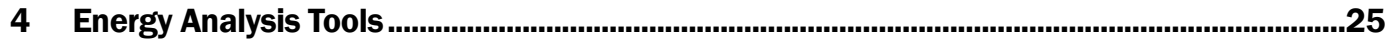

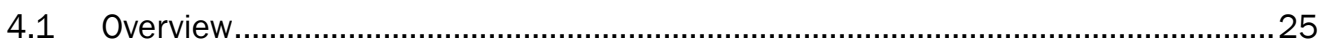

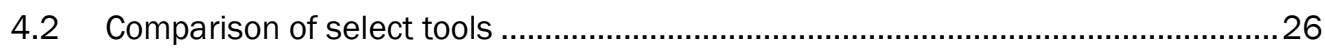




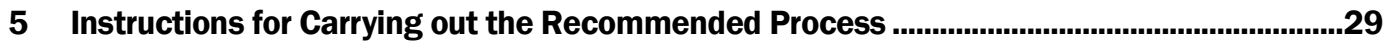

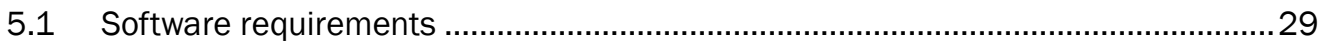

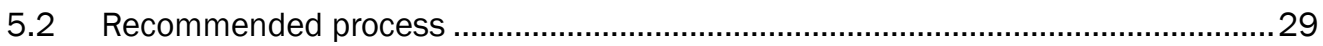

5.3 Instructions for carrying out the recommended process .........................................30

5.3.1 Step 1: Building the BIM Model ................................................................................. 31

5.3.2 Step 2: testing and fine-tuning the energy model.................................................... 38

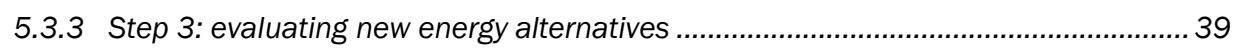

5.3.4 Further development of design alternatives ............................................................ 40

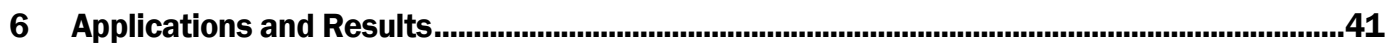

6.1 Case Study 1: Community Emergency Service Station; Fort Bragg, NC Complete BIM model provided in Autodesk Revit....................................................42

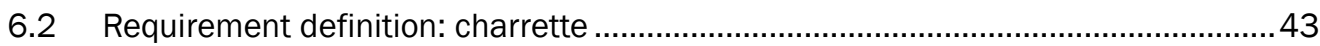

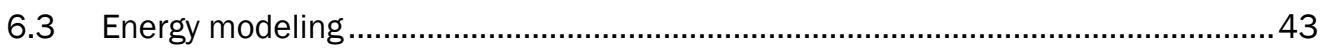

6.3.1 Concept design: macro-level energy analysis ........................................................ 44

6.3.2 Detailed design: micro-level energy analysis ........................................................46



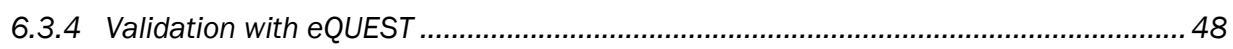

6.3.5 Community Emergency Services Station project update...........................................49

6.4 Case Study 2: Energy modeling of Fort Lewis (WA) Chapel - 2D-CAD Model in GraphiSoft ArchiCAD ........................................................................... 49

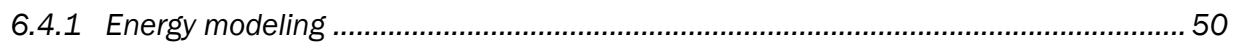

6.5 Case Study 3: Energy modeling of a Standard Design Child Development Center - 2D-CAD Model in Bentley Autodesk ........................................................53

6.6 Case Study 4: BIM Energy Analysis test at four Engineer Districts and one Army installation ............................................................................................... 58

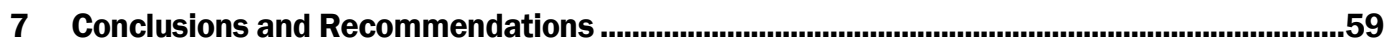

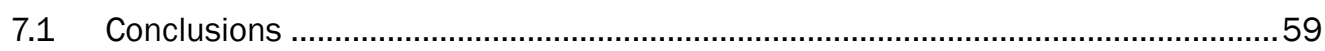

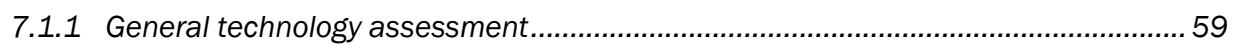

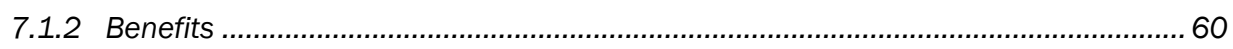

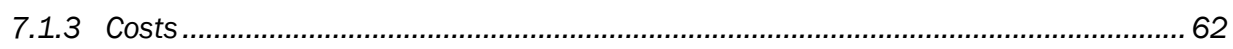

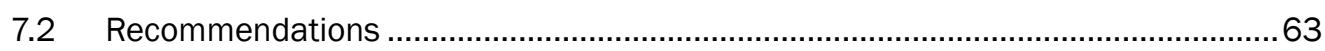

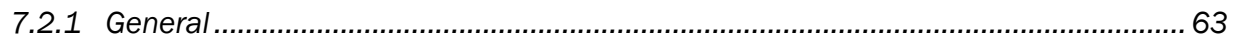

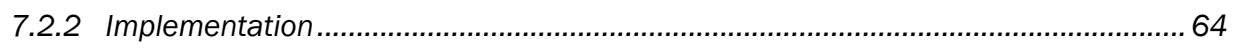

7.2.3 Future projects using integrated design with BIM and energy analysis ..................... 65

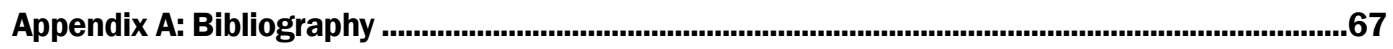

Appendix B: Descriptions of Widely Used Building Energy Analysis Software ...........................70

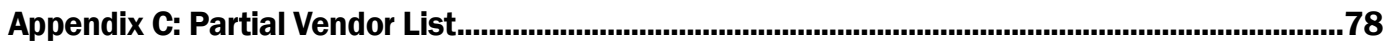




\section{List of Figures and Tables}

\section{Figures}

Figure 1. Data exchange of BIM models using IFC (Industry Foundation Class)................................. 8

Figure 2. Traditional energy analysis in the design process...............................................................11

Figure 3. Level of influence on costs as compared to time (Paulson 1976).....................................12

Figure 4. 3D-CAD/BIM model................................................................................................................13

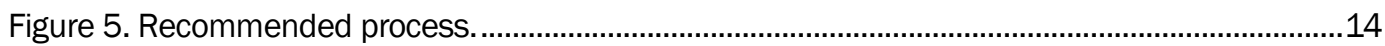

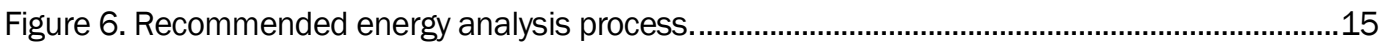

Figure 7. Framework for early design energy analysis...................................................................30

Figure 8. Overall scope of 3D-CAD/BIM energy analysis.....................................................................31

Figure 9. 3D-CAD/BIM model...................................................................................................32

Figure 10. 3D CAD/BIM modeling process for energy analysis.........................................................33

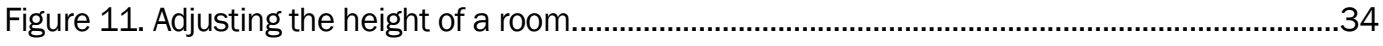

Figure 12. Steps to export gbXML file and import gbXML file into Green Building Studio ${ }^{\circledR}$..............35

Figure 13. A Green Building Studio ${ }^{\circledR}$ energy analysis report............................................................36

Figure 14. Energy analysis results screen from Green Building Studio ${ }^{\circledR}$...........................................36

Figure 15. Example of design alternatives. ..............................................................................39

Figure 16. Example comparison showing results of different energy runs......................................39

Figure 17. Further development of design alternatives in Green Building Studio ${ }^{\circledR}$ :

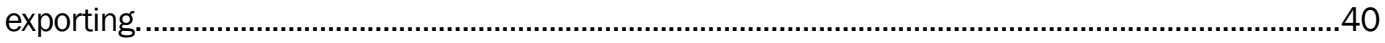

Figure 18. BIM model of CESS facility. .....................................................................................

Figure 19. Energy modeling for building configuration and orientation. ..........................................44

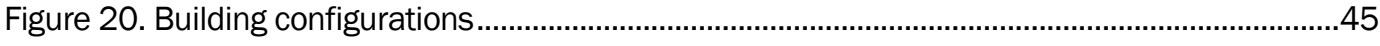

Figure 21. Comparison of estimated annual energy costs of three building configurations..............45

Figure 22. Different orientations of the CESS building at Fort Bragg. ...............................................46

Figure 23. Comparison of estimated annual energy cost for different building orientations.............46

Figure 24. Energy modeling for building elements and design details...............................................4

Figure 25. Annual energy cost comparison of different building component options. .......................48

Figure 26. Comparison of Green Building Studio ${ }^{\circledR}$ and eQUEST results for baseline and proposed design 49

Figure 27. Fort Lewis, WA Chapel building, (a) floor plan and (b) 3D image. ....................................50

Figure 28. Comparison of different energy estimates. ..................................................................51

Figure 29. Oak Grove, KY Child Development Center (CDC), (a) building plan (b) 3D image............54

Figure 30. Comparison of different energy estimates. 


\section{Tables}

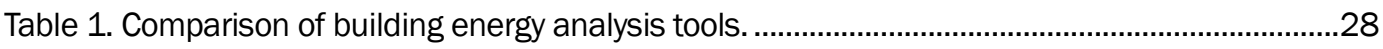

Table 2. List of case studies using CAD/BIM and Green Building Studio ${ }^{\circledR}$.........................................41 


\section{Preface}

This study was conducted for the Office of the Assistant Chief of Staff for Installation Management (ACSIM) under the Installation Technology Transfer Program, Project FY09-46, "Early Design Energy Analysis Using BIM." The technical monitor was Mr. Philip Columbus, DAIM-ODF. Requirement Lead/ Proponents for the project were: IMCOM (Mr. Paul Volkman), ACSIM (Mr. Vincent Kam, Mr. J ohn Scharl and Mr. Don Juhasz), Fort Bragg, NC (Mr. Glen Prillaman and Ms. J ennifer McKenzie), HQUSACE (Ms. J oanne Qualey and Mr. Harry Goradia), Huntsville Division (Mr. Richard Grulich), Fort Worth District (Mr. Jack Osborne), and the ERDC CAD/ BIM Technology Center (Ms. Beth Brucker).

The work was managed and executed by the Engineering Processes Branch (CF-N) of the Facility Division (CF), US Army Engineer Research and Development Center - Construction Engineering Research Laboratory (ERDC-CERL). The ERDC-CERL Project Manager was Annette L. Stumpf. At the time of publication, Donald K. Hicks was Chief, CEERD-CF-N, L. Michael Golish was Chief, CEERD-CF; and Martin J . Savoie, CEERD-CVZT, was Technical Director for Installations. The Deputy Director of ERDC-CERL was Dr. Kirankumar Topudurti and the Director was Dr. Ilker Adiguzel.

Appreciation is owed to Mr. Dale Herron (CEERD-CFE); Mr. Richard Schneider (CEERD-CFN); and Mr. J ack Osborne (CESWF) for their ideas to enhance this project; the entire ESTCP (Environmental Security Technology Certification Program) Research Team lead by Mr. Michael Franka and Ms. Manette Messenger (US Army IMCOM Southeast); Ms. Kim Fowler (Pacific Northwest National Laboratory); the Bragg Community Emergency Services Station project delivery team lead by Mr. Raymond Barbeau (Master Planner, Fort Bragg Directorate of Public Works), Ms. Stephanie Hall (Senior Project Manager, Fort Bragg Team, CESAS-PMMB), and Mr. J ohn Rose (Architect, Fort Bragg Directorate of Public Works) all for allowing us to experiment with BIM and energy modeling during the Bragg CESS project 35\% charrette; Mr. Thomas Napier (ERDCCERL) for sharing the Chapel Renovation Project at Fort Lewis with us; and to Mr. Richard Grulich, Mr. Chris Shepherd, and Mr. J ohn (Benny) Pitsinger (CEHNC) for sharing insight and the Center of Standardization models for both Fire Stations and Child Development Centers. During the 
second year of the project, we were lucky to have four USACE districts and one installation test the BIM Energy Modeling process. Thanks to Seattle District (J eanette Fiess, Steve Hutsell, Van Woods, Mark Ortner, Emma Chen, J ennifer Ramirez, Eli Chiriac, J ustin J ameson, Nathan Gregory, Renn Breshears, J ennifer Ramirez, and Lindsey Matetich); Fort Worth District (Greg Scheurich); Baltimore District (Trevor Williamson, Alan Eidsmore, and Mitchell Burns); Louisville District (Brandon Martin, and Teresa Hibbs); and Fort Bragg (Thomas Blue, J ohn Rose, William Middleton, Aaron Brown, J ohn Frinak, Kirk Rutkofske and Lee D. Hon Nelson). The authors also express appreciation to Autodesk, Inc., San Rafael, CA; and Bentley Systems, Inc., Exton, PA, for their assistance.

The Commander and Executive Director of ERDC is COL Kevin J. Wilson, and the Director is Dr. J effery P. Holland. 


\section{Unit Conversion Factors}

\begin{tabular}{|l|l|l|}
\hline Multiply & By & To Obtain \\
\hline feet & 0.3048 & meters \\
\hline inches & 0.0254 & meters \\
\hline square feet & 0.09290304 & square meters \\
\hline yards & 0.9144 & meters \\
\hline
\end{tabular}




\section{Introduction}

\subsection{Background}

The A/ E/ C (Architecture/ Engineering/ Construction) industry is interested in designing energy efficient, sustainable buildings, as evidenced by the increasing use of the US Green Building Council (USGBC) LEED ${ }^{\circledR}$ (Leadership in Energy and Environmental Design) green building rating system. This research utilized Building Information Modeling (BIM) for energy analysis during the conceptual design phase. Most building energy analyses are conducted later in the design by energy analysts. This report describes a process of exploring different energy saving alternatives in early design using 3D-CAD (computer aided design)/ BIM technology. The recommended framework allows project teams to utilize BIM models in energy simulations and compare results quickly. In order to test the feasibility of the proposed approach, a prototype energy modeling process was developed and tested on a new construction project, the Community Emergency Service Station at Fort Bragg, North Carolina with a team led by the US Army Corps of Engineers. The energy modeling process was applied to explore different building envelope and equipment scenarios to enable energy conscious decisions early in the design process when they make the biggest impact on building life-cycle costs.

Traditionally, most building energy analyses have been conducted late in design, by energy analyst specialists who are usually mechanical engineers. At this stage, the focus is to design a mechanical system that will support space conditioning requirements for the final building form. The ability to model different building configurations early in the design process to identify energy saving alternatives does not typically occur. This is due to the difficulty and expense of modeling the building and energy systems. Project resources are limited so effort to analyze building energy use is expended in the late stages of design using the current suite of energy modeling tools. Today's 3D-CAD/ BIM (Building Information Model) models provide the user with an opportunity to explore different energy saving alternatives in early design while avoiding the time-consuming process of re-entering all the building geometry, enclosure, and HVAC information necessary for a complete energy analysis. This method enables project teams to make energy conscious decisions early in design when they impact building life-cycle costs the most. The BIM energy analysis approach also supports cost effective decision-making during construction 
and creates a set of data files that will remain with the project through design, construction, and its operating life. This method can also be used to compare energy-saving alternatives for retrofit projects such as how many inches of rigid insulation should be put on the roof during re-roofing. The product of this research is a framework for the use of BIM models to conduct energy simulations in early building design. The results from this framework were compared with those from a commonly used energy modeling tool, eQUEST.

Both the Army Energy Strategy for Installations and the Army Strategy for the Environment support expanded use of renewable energy technologies and improved energy efficiency for new and existing buildings. The Energy Policy Act of 2005 mandates that new construction achieve a 30\% improvement in energy efficiency over the base case per ASHRAE 90.1. All Military Construction (MILCON) projects are mandated to be LEED Silver certifiable using the US Green Building Council's (USGBC) LEED rating tool. The Energy Independence and Security Act (EISA) of 2007 also requires project teams to take the energy conservation opportunities in design seriously - all federal facilities are supposed to be fossil fuel free by 2030 .

\subsection{Objectives}

The environmental impact of buildings in the United States is farreaching. Commercial and residential buildings consume nearly $40 \%$ of total energy, $70 \%$ of electricity, $40 \%$ of raw materials, and $12 \%$ of our fresh water supplies. Although sustainable design (def. the practice of designing, constructing, and operating buildings in a manner that minimizes their environmental impact) is becoming increasingly popular, evaluating design options for their sustainability is complex, time consuming, and often completed late in the design, making it difficult to incorporate many green building options. Current methods also do not support easy generation of the documentation needed to qualify for $\mathrm{LEED}^{\circledR}$ ratings.

The objective of this project was to develop and test a process which takes advantage of BIM models and energy analysis tools to consider design alternatives and energy tradeoffs early in design. This project considered use of a web-based energy analysis tool called Green Building Studio ${ }^{\circledR}$ for early design energy analysis using Building Information Modeling (BIM). The purpose was to develop a methodology, test the methodology, and document the lessons learned and recommendations for broader application of the method across the Army. 
Implementation of this methodology could greatly simplify the energy analysis process and help project teams effectively evaluate project decisions early in the design process for both new and retrofitted buildings. It also enables the project teams to take advantage of simple BIM models and avoid the time-consuming process of re-entering all the building geometry, enclosure and HVAC information necessary for a complete energy analysis. Currently, energy analysis is typically done by specialists, late in the process, when there is much less time to compare alternatives. This technology has already been used by the private sector but there were no known applications in the Army before this project. If this test is successful, the project team should be able to provide guidance for the Army adoption of Early Design Energy Analysis using BIM, and improve the energy efficiency of all our future buildings and retrofits.

\subsection{Approach}

The importance of incorporating energy modeling early in concept design cannot be overstated. Key decisions - made by architects, engineers and designers - have profound impacts on the building's energy performance for the life of the building. Federal mandates make energy and fossil fuel conservation a priority in all new designs and retrofits, with increasingly stringent energy reduction targets culminating in the requirement for all federal facilities to be fossil fuel free by 2030 .

During the past 2 years, there has been a dramatic improvement in the capability to conduct energy modeling early in design using data exported from preliminary designs modeled using BIM (Building Information Modeling) tools. The data exchange standard that enables this transfer of information is called "gbXML" (green building eXtensible Markup Language). Software vendors have been implementing the latest version of the gbXML data exchange in ways that make it easy for project delivery teams to create simple 3-D models of the design alternatives and then export essential information needed to conduct energy analyses. This allows energy modeling of design alternatives without recreating the building geometry, window placement, etc. for input into the energy analysis tool. Even Google Sketchup has a Plugin that allows users to export a gbXML file, although that tool wouldn't allow users to re-import the file after changes are made to it.

There are several software tools that are available to create BIM models. Centers of Standardization (COS) were required until 2011 to use Bentley BIM software on standard designs. Autodesk Revit and Graphisoft Archi- 
$\mathrm{CAD}$ also have frequently used on non-COS projects. All of these software programs are capable of exporting gbXML data which can be analyzed by an energy analysis tool.

The energy analysis tools approved for use on Army projects in the Military Transformation Request for Proposal (MT RFP) are Carrier HAP, Trane TRACETM 700, DOE-2, or EnergyPlus. Carrier HAP and Trane TRACETM 700 operate on their own, while DOE-2 and EnergyPlus are engines that are typically integrated into a more user friendly interface. Autodesk Green Building Studio ${ }^{\circledR}$ runs the DOE- 2 energy analysis engine, while Bentley AECOsim Energy Simulator runs the EnergyPlus engine.

When ERDC-CERL evaluated energy analysis tools at the beginning of this effort, one of these tools stood out for consideration: Green Building Studio $^{\circledR}$. Since that time, other promising energy analysis tools that work with gbXML files exported from BIM have emerged.

Green Building Studio ${ }^{\circledR}$ is a commercial off-the-shelf (COTS) web-based energy engineering analysis solution which integrates with today's 3DCAD/ BIM applications (https://www.greenbuildingstudio.com/). Autodesk Green Building Studio ${ }^{\circledR}$ is a web-based energy analysis service which uses a special gbXML file exported from 3-D BIM models created using tools such as AutoDesk REVIT, Bentley Architecture or Graphisoft ArchiCAD. Green Building Studio ${ }^{\circledR}$ was chosen for this ITTP evaluation because it runs the DOE-2 energy analysis engine (which has been approved for use on Army projects), it accepts gbXML files from the commonly used BIM design tools, and it is suitable for comparison of design alternatives early in design.

Three test projects were conducted using Green Building Studio ${ }^{\circledR}$ services. The first test of Green Building Studio ${ }^{\circledR}$ was conducted during the 4 day design charrette where the Architect/ Engineering firm used Revit BIM to create a 35\% design solution for a community emergency services center (CESS) at Fort Bragg, GA. A second test was conducted on a Revit BIM model of a retrofit project - known as the "move the chapel" project - at Fort Lewis, WA. Finally, the Bentley BIM model of an Army Standard Design (Child Development Center) was used by four districts and one Army installation to test the BIM Energy Analysis process developed during this project. 
The typical process is to export a gbXML file from the architect's BIM scheme, conduct energy studies using Green Building Studio ${ }^{\circledR}$ energy analysis (or other suitable tool) and then discuss the results with the project team. The BIM scheme can then be modified and resubmitted for further analysis until a complete design resulting in the 30\% energy savings above ASHRAE 90.1 is achieved.

This final report describes how the early energy analysis for the candidate projects was conducted and makes recommendations for use of the BIM energy analysis process during Army projects. A Technology Standards Group (TSG) summary report was written and submitted to the sponsor.

\subsection{Scope}

The Corps of Engineers has adopted BIM (Building Information Modeling) for use in their Standard Design and MILCON (Military Construction) projects. Three commonly used BIM tools are able to export gbXML for use with the Green Building Studio ${ }^{\circledR}$ web-based energy analysis tool: AutoCAD Revit, GraphiSoft ArchiCAD, and Bentley Architecture. All three BIM tools were tested as part of this project. Our team was able to successfully use BIM models exported from Revit and ArchiCAD during the first year of the project, but were unable to get the Bentley gbXML function to work successfully. This is important since the Corps of Engineers Standard Designs are mandated to use Bentley software.

During the follow-up ITTP project we successfully tested the newly released gbXML export functionality in Bentley Architecture v.8.i. with Green Building Studio ${ }^{\circledR}$. After the Bentley BIM Energy modeling procedure was developed, the ERDC-CERL project team worked with four District and one installation teams to test the energy analysis process using BIM that is described in this report. After the testing experience was completed, the final recommendations for adoption of this new technology (use of Green Building Studio ${ }^{\circledR}$ and BIM for energy analysis) were made to the ACSIM ITTP sponsor.

\subsection{Mode of technology transfer}

The TSG summary report will be used to provide guidance for implementing the use of early design energy analysis using BIM for project teams.

Two journal articles have been submitted for publication in American Society of Civil Engineers (ASCE) J ournals. Four papers were presented on 
this project at professional conferences (ASCE, ASHRAE, USACE Infrastructure and SAME Conferences). One video is available describing the integrated design charrette used for the Fort Bragg Community Emergency Services Station. It can be viewed at:

http://www.istc.illinois.edu/about/SustainabilitySeminar20081103.cfm or

http://www.istc.illinois.edu/about/SeminarPresentations/2008-11-03-Stumpf.pdf

Several opportunities for using this BIM Energy Modeling Process during FY10 USACE charrettes were identified and pursued. The ERDC CAD/ BIM Technology Center now offers BIM Energy Modeling software to USACE District personnel. District teams that participated in this project, and others, are now using tools such as Green Building Studio ${ }^{\circledR}$ and Ecotect during preliminary design charrettes to create more energy efficient and sustainable buildings. 


\section{BIM and the Design Process}

Building Information Modeling is a system of planning, constructing, and operating a facility throughout its life. A BIM model is "a digital representation of the physical and functional characteristics" (Smith 2007). BIM allows for collaboration and the use of shared information throughout a facilities life cycle. Digital representation allows stakeholders to simulate and analyze potential impacts before beginning physical construction.

BIM technology allows the reuse of information throughout a structures life cycle. Estimated cost savings of 4-6\% can be realized in the construction process alone (Brucker 2008), although General Motors reports 25 percent savings using BIM over conventional design-build approaches (Smith 2007). BIM technology can be used for modeling, drafting, visualizing, animating, simulating, analyzing and plotting (Spangler 2006). Development of code compliance checking should be complete in the United States soon (Smith 2007).

The US Army Corps of Engineers (USACE) has prepared for the MLCON Transformation process by instituting Building Information Modeling (BIM) as a new approach to its design process. In FY08, BIM will be required for all military construction projects. This new directive has led to many questions in the engineering community concerning the relevance of BIM to Civil Works projects of this nature within USACE. Answers to these questions will become evident as BIM matures within USACE. (Huell 2008). https://cadbim.usace.army.mil/MyFiles/EdwardHuellBIM_FINAL.pdf

The Corps of Engineers is requiring BIM deliverables for its MILCON Transformation standard facility types. There are over 40 standard facility types including barracks, dining facilities, and headquarters buildings. The Corps has developed a system called the Request for Proposal (RFP) wizard to automate the development of the contract language. (Corps of Engineers CAD/BIM Technology Center 2008). https://cadbim.usace.army.mil/default.aspx?p=s\&t=12\&i=27

In October 2006, HQUSACE released the document "Building Information Modeling (BIM) - A Road Map for Implementation to Support MILCON Transformation and Civil Works Projects within the US Army Corps of Engineers (ERDC TR-06-10)." This document, developed by par- 
ticipants from the CAD/ BIM Technology Center; Construction Engineering Research Laboratory (CERL); and Louisville District, details the US Army Corps of Engineers plan for the implementation of BIM technology. The document presents a timeline for that implementation and presents an implementation strategy for the Corps COS and Districts to follow. (ERDC 2006) https://cadbim.usace.army.mil/Myfiles/1/ERDC_TR-06-10.pdf

BIM also supports sustainable design in several unique ways (Autodesk 2005). One useful book, Green BIM - Successful Sustainable Design with Building Information Modeling (Krygiel and Nies 2008) discusses many ways that an integrated design team can effectively use BIM to create environmentally friendly design using a streamlined process.

\subsection{Building information modeling}

A building information model is a digital representation of the physical and functional characteristics of a facility (Smith 2007), as illustrated in Figure 1. As such it serves as a shared knowledge resource for information about a facility forming a reliable basis for decisions during its life-cycle from inception onward. A basic premise of the model is collaboration by different stakeholders at different phases of the life cycle of a facility to insert, extract, update or modify information in the modeling process.

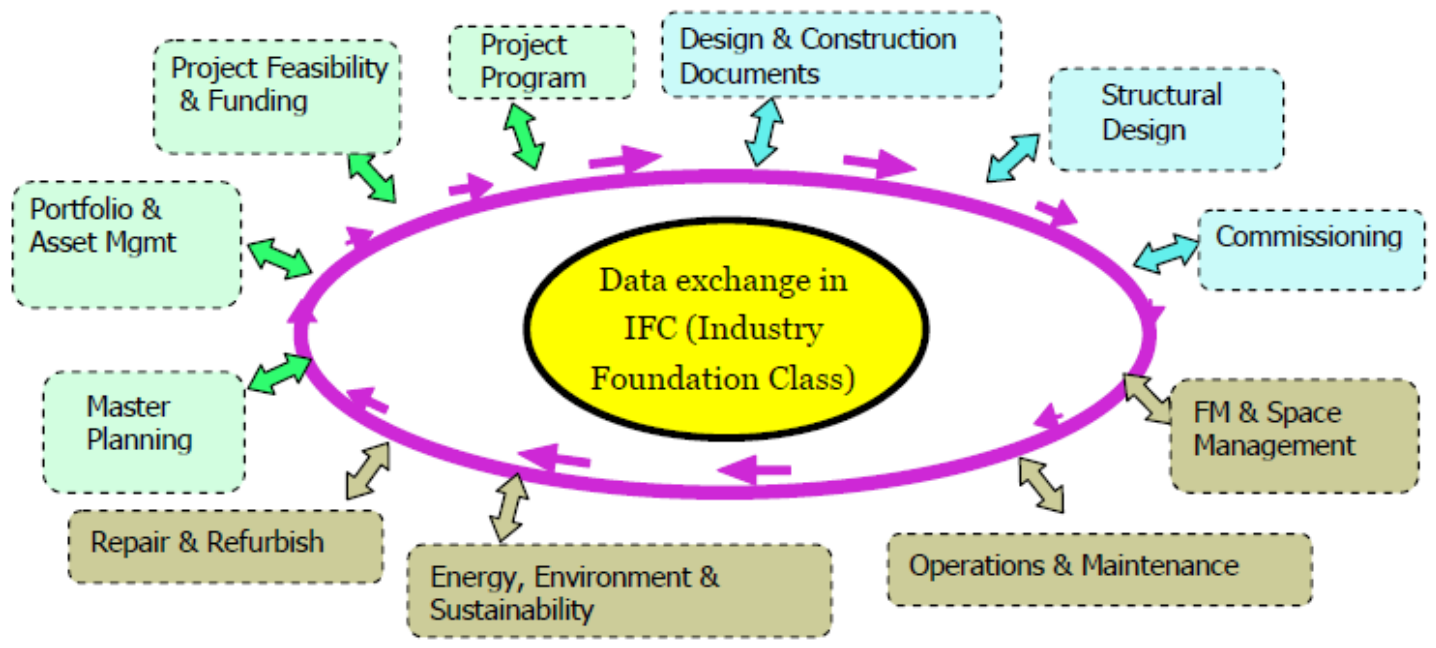

Figure 1. Data exchange of BIM models using IFC (Industry Foundation Class).

Figure 1 shows typical data exchange scenarios. Different BIM tools have their own proprietary data structures for representing a building and other design information. Some explicitly store properties and relations, while others compute them on demand. They internally use different geometric representations. The Industry Foundation Classes (IFC) data model is a 
neutral and open specification that is not controlled by a single vendor or group of vendors. It is an object oriented file format with a data model developed by the International Alliance for Interoperability (IAI) to facilitate interoperability in the building industry, and is a commonly used format for Building Information Modeling (BIM) (IAI 2007) ${ }^{1}$.

\subsection{Sustainable design}

An emerging trend in the $\mathrm{A} / \mathrm{E} / \mathrm{C}$ industry today is creating sustainable, high performance buildings. The industry standard $\mathrm{LEED}^{\circledR}{ }^{\circledR}$, assigns ratings of platinum, gold, silver or bronze in recognition of total credits earned by the project. The industry standard for energy efficiency, ASHRAE 90.1, is incorporated into LEED through Energy \& Atmosphere (EA) Prerequisite 2 - Minimum Energy Performance; EA Credit 1- Optimize Energy Performance; and EA Credit 2 - On-Site Renewable Energy. The US Army policy requires all new buildings to be certifiable at the LEED silver rating. Fort Bragg established the goal of LEED platinum by 2020 for all facilities.

Project teams who are using LEED online must enter data into the LEED Submittal Templates to prove they were able to earn the credits. LEED Energy and Atmosphere (EA) credit 1 Optimize Energy Performance requires the project team to submit data contained in the output of building energy modeling software programs. The data submitted for EA Credit 1 shows the reduction in annual energy cost the design building has achieved over the base building using the ASHRAE 90.1 standard. There are three compliance paths that project delivery teams (PDTs) can use:

- Option 1: Whole Building Energy Simulation (using Appendix G of ASHRAE Standard 90.1) (for projects using LEED for New Construction, Schools, \& Core and Shell).

- Option 2: Prescriptive Compliance Path: Use ASHRAE Advanced Energy Design Guide (for projects using LEED for New Construction \& Core and Shell).

- Option 3: Prescriptive Compliance Path: Advanced Buildings TM Core Performance Guide ${ }^{\mathrm{TM}}$ (for projects using LEED for New Construction, Schools, \&Core and Shell).

For the past 50 years, a wide variety of building energy simulation (BES) analysis tools have been developed, enhanced, and applied throughout the

1 http://en.wikipedia.org/wiki/Industry_Foundation_Classes. 
building energy community. Examples of these tools are BLAST, EnergyPlus, eQUEST, TRACETM 700, DOE2, and Ecotect ${ }^{\mathrm{TM}}$. These tools are complex, text-based applications which require a great deal of time to learn (Crawley et al. 2005). Many building designers consider energy analysis a time-consuming process and leave it to mechanical or electrical engineers late in the design process. Several research papers describe energy analysis as a holistic evaluation (Abaza 2002 and Magent et al. 2005)

Very little attention has been given to the significance of early design energy analysis. Dahl et al. (2005) showed that decisions made early in a project have a strong affect on the life-cycle costs of a building. As Paulson (1976) noted in Figure 1, building designs (conceptual and detailed designs) affect about 60-70 percent of the life-cycle costs of the construction and operation of a building.

A recent innovation in building design and construction, Building Information Modeling (BIM) has received tremendous interest for its impact on sustainable development and provides the opportunity to develop energy analysis software programs for the industry. It is also worth noting that several researchers proposed to combine Lean and BIM technologies to improve process modeling process in sustainable development (Riley et al 2005). While the converging approach would enable virtual simulation in collaborative environments, and thus is expected to change the $\mathrm{A} / \mathrm{E} / \mathrm{C}$ industry in terms of delivery and management of the built environment, it is found that the approach emphasizes the whole process in design-buildoperate-maintenance (DBOM) (Lapinski et al. 2005, and Magent et al. 2005). Little research has been conducted on the use of BIM for energy analysis in the early design stages. Early design energy analysis provides an opportunity to make cost-effective decisions early in the building life cycle, and to meet federally mandated energy conservation targets. (The Energy Policy Act of 2005 mandates that all new federal facilities must be at least 30\% more energy efficient than the base case of ASHRAE 90.1 2004). Healthy buildings can pay for themselves since building construction, operation and energy costs typically amount to small portion (about 10\%) of a business's costs while $90 \%$ goes towards salaries (USGBC 2008).

\subsection{Typical process}

Figure 2 diagrams the flow of the traditional energy analysis process in design activities that the Corps of Engineers follows for most facilities. This approach is defined in a Corps of Engineers regulation (Technical Manual 5-8000-2) and follows a common process to facility design for commercial 
construction. The process in Figure 1 shows major review milestones at the completion of 10, 35, 60 (for Air Force work), and 95 percent. The process also shows the review processes such as Biddability, Constructability, and Operability (BCO). First-cost and life-cycle-costs are used to compare and select the most cost effective fuel source and major building mechanical system. As depicted in Figure 2, most building energy analyses have been conducted later in design (during Design Development), by energy analyst specialists who are usually mechanical engineers. At this stage, the focus is to design a mechanical system that will support space conditioning requirements for the final building form. The ability to model different building configurations early in the design process to identify energy saving alternatives does not typically occur. This is due to the difficulty and expense of modeling the building and energy systems. Project resources are limited so effort to analyze building energy use is expended in the late stages of design using the current suite of energy modeling tools.

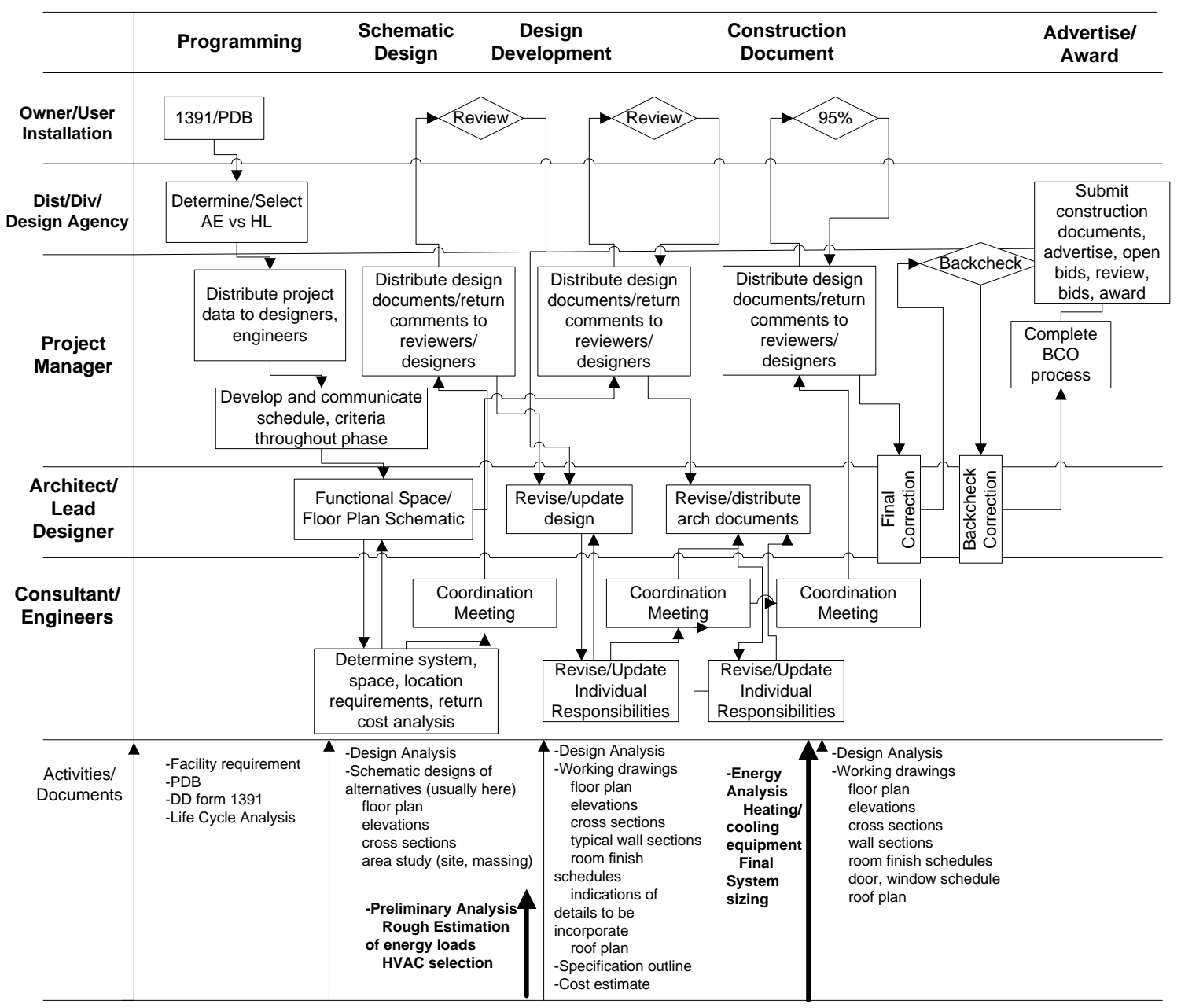

Figure 2. Traditional energy analysis in the design process. 


\subsection{Recommended process}

Figure 3 diagrams a cost benefit curve showing that design decisions made earlier in design affect the construction cost less than changes made later during the design/ construction process. This project intends to help project teams make energy related design decisions earlier in the design/ construction process. Project teams who are able to optimize the design aspects of building shape, orientation, configuration, envelope, and daylighting can design a building that requires less energy and smaller mechanical systems. For some projects, it might be possible to meet the EPACT 30\% better than ASHRAE goal with smart building configuration and envelope design, then to exceed the goal with smaller but more efficient mechanical systems within the project budget.

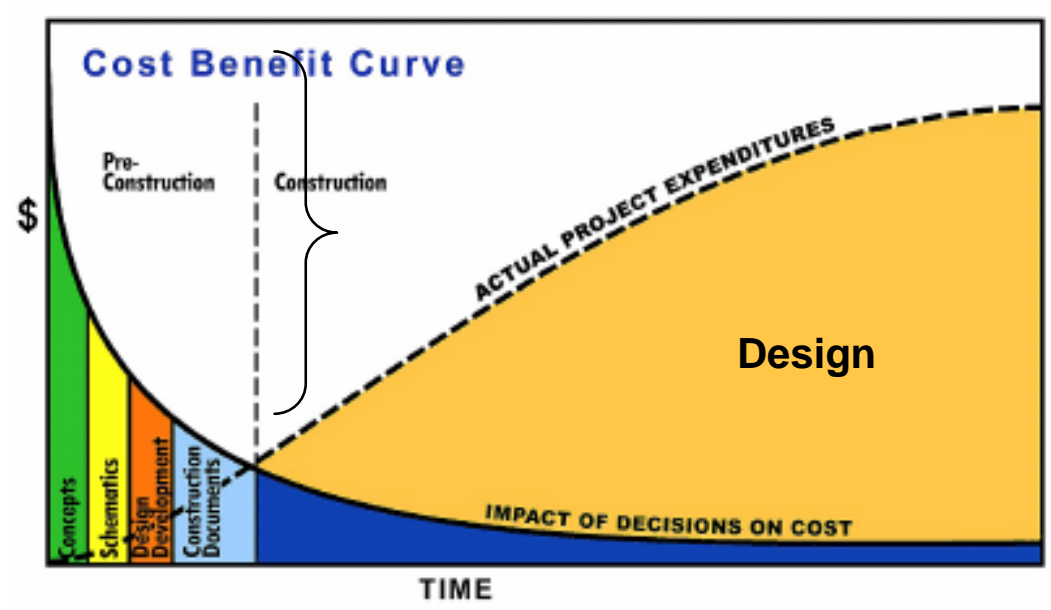

Figure 3. Level of influence on costs as compared to time (Paulson 1976).

The goal of this research was to use the building geometry and details contained in a BIM model to quickly build an energy analysis model to compare energy-related tradeoffs early in design. More than just the lines and arcs associated with traditional computer-assisted drawing (CAD) tools, BIM includes associated benefits of visualization, built-in intelligence and simulation, intelligent objects of a structure, such as spatial data (3D), unstructured data (text), and structured data (databases, spreadsheets), as shown in Figure 4. With the addition of building geometry data in a BIM model, the volume can be calculated and energy estimates made based on building envelope characteristics (doors and windows) and building orientation.

While there are several different BIM-based energy modeling software programs available, Green Building Studio ${ }^{\circledR}$ works with gbXML that was 
specifically developed to exchange energy-related information. That is, gbXML output from BIM programs can be imported into Green Building Studio ${ }^{\circledR}$. Green Building Studio ${ }^{\circledR}$ automatically checks for the correctness of the BIM model by warning the user of issues with the model before it is exported to the gbXML format. Therefore, Green Building Studio ${ }^{\circledR}$ was selected for energy modeling for the entire process which was subsequently validated with a separate energy modeling program.

Green Building Studio ${ }^{\circledR}$ (Autodesk 2008) is a web-based service that works with a gbXML file exported from various BIM applications including ArchiCAD, Revit and Bentley Architecture v.8.i and uses the building information to perform an energy evaluation with established tools such as DOE-2, eQUEST, and EnergyPlus. It allows various changes in design alternatives to the building design such as orientation, glazing, roof and wall construction, lighting, and HVAC to be quickly analyzed to determine which options are the most energy-efficient.

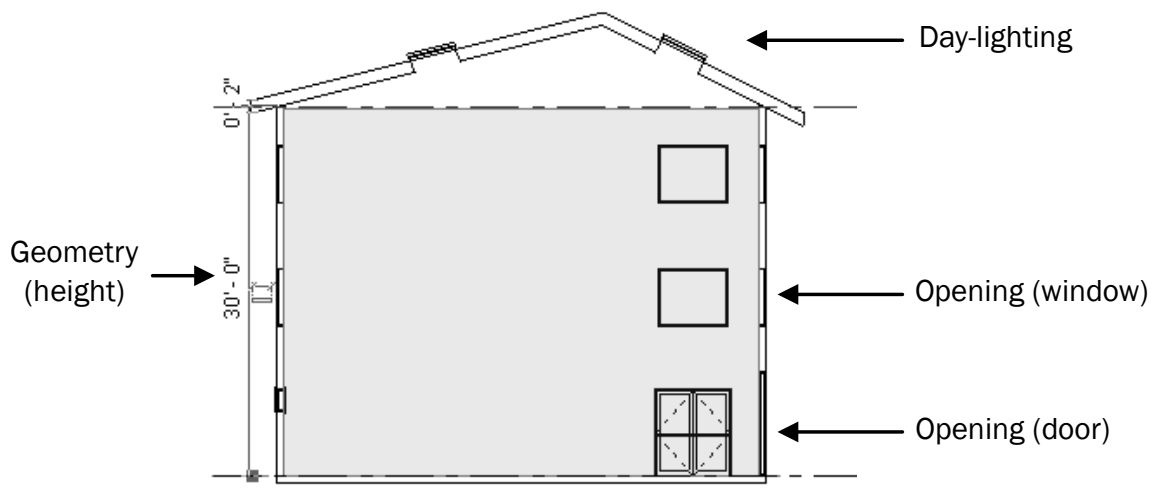

Figure 4. 3D-CAD/BIM model.

While we were exploring different BIM energy modeling software programs, we realized that there is a limitation in the BIM software. That is, BIM software does not have the capability to check for model integrity, correctness, or completeness. With the notion of garbage in and garbage out (GIGO), an incomplete BIM model will result in inaccurate energy analyses. In our experience, attractive renderings created by the BIM modeler during the Community Emergency Services Station charrette clearly showed the design intent to the customer, but the spaces were not consistently represented so the gbXML file could be read immediately by Green Building Studio ${ }^{\circledR}$. The error checking routine helped us iteratively refine the BIM model so it would accurately represent the building geometry. Similarly, inaccurate representation of building geometry within traditional energy analysis programs will result in inaccurate energy analysis. 
In order to conduct an energy analysis in the early design phase, we developed a recommended process of how an energy analysis model may be developed from a 3D CAD or BIM model and used to explore different energy use alternatives. A sequence of two different steps in the energy modeling process is outlined in Figure 5 and Figure 6.

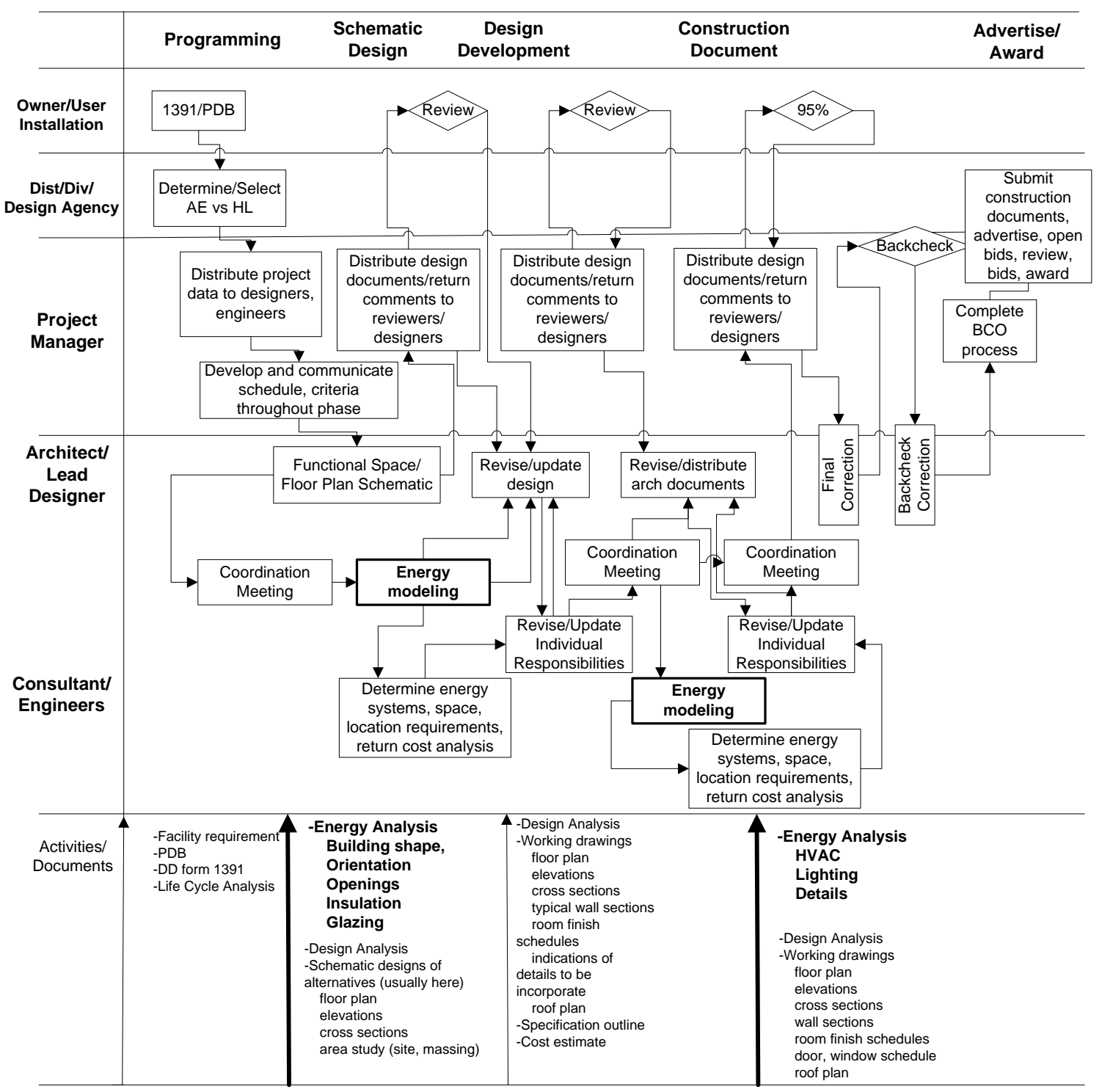

Figure 5. Recommended process.

The first step is to identify the project requirements during a coordination (or charrette) meeting. This may present challenges as many projects have constrained budgets, schedules, and resources. It is essential that all building stakeholders-including owners, designers, engineers and contractors-have a clear understanding of problem definition and participate in identifying a set of design alternatives early in the project planning 
process. The second step is energy modeling in schematic design. The third step is detailed energy modeling during detailed design. Energy modeling in concept design is mainly for building envelope shape and orientation, and size, shape, and material of wall penetrations while that in detailed design is for building mechanical systems and lighting.

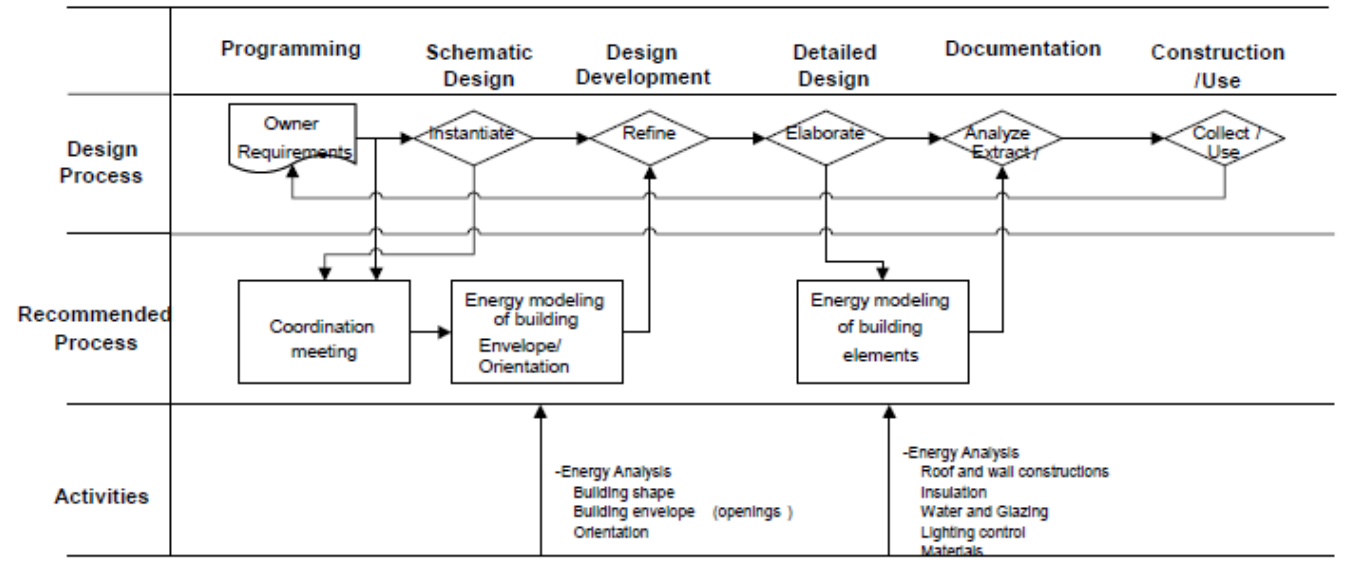

Figure 6. Recommended energy analysis process.

\subsection{CAD/BIM tools that work with Green Building Studio ${ }^{\circledR}$ and export gbXML files)}

The National BIM Standard was released 18 December 2007 by the National Institute of Building Sciences and is available through the NIBS Facility Information Council website

(http://www.facilityinformationcouncil.org/bim/publications.php). This website also contains links to project fact sheets, marketing/ communications, online resources (including software and service companies), and publications.

\subsubsection{Bentley Architecture}

Bentley Systems offers a wide range of related products for architecture, engineering and construction. Their architectural BIM tool, Bentley Architecture, introduced in 2004, is an evolutionary descendent of Triforma. Integrated with Bentley Architecture are: Bentley Structural, Bentley Building Mechanical Systems, Bentley Building Electrical Systems, Bentley Facilities, Bentley PowerCivil (for site planning), and Bentley Generative Components. These are file-based systems, meaning that all actions are immediately written to a file and result in lower loads on memory. Third parties have developed many different applications on the file system, some incompatible with others within the same platform. Thus, a user may have to convert model formats from one Bentley application to another. 
Interfaces with external applications include: Primavera and other scheduling systems and STAAD and RAM for structural analyses. Its interfaces include DGN, DQG, DXF, PDF, STEP, IGES, STL, gbXML and IFC. Bentley also provides a multi-project and multi-user model repository called Bentley ProjectWise.

\subsubsection{Revit}

Revit is the best known and current market leader for the use of BIM in architectural and mechanical-electrical-plumbing designs. It was introduced by Autodesk in 2002 after the company acquired the program from a start-up. Revit is a completely separate platform from AutoCAD, with a different code base and file structure. Revit is a family of integrated products that currently includes Revit Architecture, Revit MEP (Mechanical Electrical and Plumbing) and Revit Structure. It includes: gbXML interface for energy simulation and load analysis, a conceptual design tool, and other systems that export DXF file. Viewing interfaces include: DGN, DWG, DWF, DXF, IFC, SAT, SKP, AVI, ODBC, gbXML, BMP, J PG, TGA, and TIF. Revit relies on 2D sections as a way of detailing most types of assemblies. We found Revit MEP most useful because it allows the user to designate thermal zones which can then be exported in the gbXML file.

\subsubsection{ArchiCAD}

ArchiCAD is the oldest continuously marketed BIM architectural design tool available today. GraphiSoft began marketing ArchiCAD in early 80s. It is the only object-oriented architectural CAD system running on the Apple Macintosh. Headquartered at Budapest, GraphiSoft was recently acquired by Memetshek, a German CAD company popular in Europe with strong civil engineering applications. Today, ArchiCAD continues to serve the Mac platform in addition to Windows and has recently released a Mac OS $\mathrm{X}$ (UNIX) version. GraphiSoft recently introduced a number of construction-oriented applications on the ArchiCAD platform. ArchiCAD supports a range of direct interfaces, with Maxon for curved surface modeling and animation, ArchiFM for facility management and Google SketchUp. It has interfaces with a suite of interfaces for energy and sustainability (gbXML, Ecotect ${ }^{\mathrm{TM}}$, Energy+, ARCHiPHISIK and RIUSKA). Custom parametric objects are primarily defined using the GDL (Geometric Description Language) scripting language, which relies on CSG-type constructions and a Basic-like syntax. It contains extensive object libraries for users and also has an ODBC interface. 


\section{Energy Use in Buildings}

\subsection{Typical end uses}

Commercial and residential buildings consume nearly $40 \%$ of the total energy used in the US average energy intensity for office buildings is 79.8 $\mathrm{kBtu}$ per square foot and the average cost is $\$ 1.65$ per square foot. This breaks out to be $66 \%$ electrical and $34 \%$ natural gas and other fuels. When separated by end use, space conditioning accounts for $48 \%$ of all energy consumption, lighting $17 \%$, and office equipment $20 \%$. The remaining energy is used for water heating, cooking, and refrigeration and other miscellaneous uses (Franconi and Huang 1996).

\subsection{ASHRAE 90.1}

The American Society of Heating, Refrigerating and Air Conditioning Engineers, Inc. (ASHRAE) creates a number of standards for building engineers and generally applies to commercial, institutional and large residential buildings. For energy efficiency, ASHRAE developed standard 90.1, which initially was pegged to the Model Energy Code (MEC) ( 1989) but has now shifted to the International Energy Conservation Code (IECC). This standard basically equates to the IECC. In other words, better than code energy efficiency standards require increased efficiency over ASHRAE 90.1-2004-for example, 20 percent better for the Energy Star multifamily pilot program mentioned previously. There have been revisions to 90.1 in 2001,2004, 2007, and 2010 to keep up with changes in the IECC. In 2007 USGBC adopted ASHRAE Standard 90.1-2004 as a prerequisite to obtain LEED-NC 2.2 Certification. LEED 2009 has transitioned to ASHRAE Standard 90.1-2007.

\subsection{Army requirements}

The Army requirements for building energy use are derived from several key Federal policy instruments. Key Federal laws and statutes that govern building energy use include The Energy Policy Act of 2005 (EPAct 2005), Energy Independence and Security Act of 2007 (EISA), and Executive Order 13423, Strengthening Federal Environmental, Energy, and Transportation Management.

EPAct 2005 requires "the building, including the building envelope, HVAC, ventilation and exhaust systems, service water heating, power, and 
lighting systems shall be designed to achieve an energy consumption that is at least $30 \%$ below the consumption of a baseline building meeting the minimum requirements of ANSI/ ASHRAE/ IESNA Standard 90.1-2004" (Standard requirement in the MILCON Transformation RFP).

The Army Energy Strategy for Installations and Army Energy and Water Campaign Plan for Installations form the foundation for energy management and capture requirements of higher directives. The Strategy, signed by the Army Chief of Staff on 8 J uly 2005, sets forth Army energy goals for 25 years. The Campaign Plan defines intermediate actions, approaches, initiatives, and funding over the 25 years to support attainment of longrange goals.

The Strategy defines general direction for the Army in five major initiatives:

1. Eliminate energy waste in existing facilities.

2. Increase energy efficiency in new construction and renovations.

3. Reduce dependence on fossil fuels.

4. Conserve water resources.

5. Improve energy security.

The Campaign Plan was implemented in late 2005 and is being used in the POM development process. Generally it establishes the desired "end state" for goals and provides resource requirements and an investment plan.

Additional Army guidance includes AR 420-1, Army Facilities Management; Army Energy Conservation; Army Sustainable Design and Development; and the Army Strategy for the Environment.

New requirements have been published to increase building air tightness.

\subsection{Building construction (MCA) requirements and standards}

The USACE Army LEED Implementation Guide (HQUSACE, J an 15 2008) defines how project teams will use the LEED rating tool and perform integrated design. See the description below to understand the requirements for the Army's use of LEED and integrated design teams (https://eko.usace.army.mil/_kd/go.cfm?destination=Showltem\&ltem_ID=47308). 


\subsubsection{Requirements}

a. MINIMUM REQUIREMENT - NEW CONSTRUCTION. Starting with the FY08 program, all vertical construction projects with climatecontrolled facilities will achieve the SILVER level of LEED-NC. This requirement applies worldwide to all construction on permanent Army installations, Army Reserve, Army Readiness Centers and Armed Forces Reserve Centers, regardless of funding source and including BRAC. For tenant projects on Army property, USACE project Master Planner and Project Manager (PM) will make the tenant organization aware of this requirement and advise them to coordinate directly with the installation DPW if this requirement cannot be met. Projects prior to the FY 08 program will continue to use SPiRiT and achieve the minimum GOLD rating level. Such projects may be scored using LEED if the LEED SILVER rating level can be achieved within the programmed amount.

b. MINIMUM REQUIREMENT - RENOVATION AND REPAIR. Renovation and repair projects are defined as major renovation and shall meet the same requirement as new construction when they:

(1) Exceed the garrison commander authority AND

(2) Have a repair to replacement ratio equal to or greater than 25 percent. Note: Both UFC 3-701-07, DoD Facilities Pricing Guide, and DA Pamphlet 420-11, Project Definition and Work Classification, provide guidance for computing the facility replacement value.

Renovation and repair projects that do not meet the above definition for major renovation will be scored using LEED-NC and incorporate sustainable design features to the maximum extent possible, but will be exempt from the minimum score that applies to new construction.

\section{c. NEW CONSTRUCTION MINIMUM LEED-NC SCORE EXEMPTIONS:}

(1) HORIZONTAL CONSTRUCTION. Horizontal construction projects, such as ranges, roads and airfields, will be scored using LEED-NC and incorporate sustainable design features to the maximum extent possible, but will be exempt from the minimum score that applies to new construction. Climate-controlled buildings included in horizontal construction projects are not included in this exemption and shall achieve the minimum LEEDNC rating. 
(2) BUILDINGS THAT ARE NOT CLIMATE-CONTROLLED. If the build-

ing has no climate controlled area, the building will be scored using LEED$\mathrm{NC}$ and incorporate sustainable design features to the maximum extent possible, but it is exempt from the minimum score that applies to new construction. Climate controlled area is area that is mechanically heated and/ or mechanically cooled for human comfort.

(3) ARMY FAMILY HOUSING. SPiRiT will be used to rate all Army Family Housing new construction projects and homes built under the Residential Communities Initiative. These projects will achieve SPiRiT GOLD level.

\section{(4) OVERSEAS CONTINGENCY CONSTRUCTION AND CONUS INTERIM FACILITIES.}

This requirement applies to permanent facility construction only. Excluded are overseas contingency construction and CONUS interim facilities. An interim facility requirement is a short-term (normally 3 years or less) urgent requirement for facilities due to transitory peak military missions, deployments, military contingency operations, disaster relief requirements, or pending approval and construction of real property facilities via normal military construction programs.

d. FAILURE TO MEET REQUIREMENTS If, after budget lock, a project cannot meet LEED requirements within funds available, the PDT shall submit a change request per the procedures in Army Regulation (AR) 4201, Army Facilities Management (chapter 4). This will be done as soon as the failure is known, but no later than the next prescribed reporting point (paragraph 7). If, at project completion, the required level is not achieved, the PM will prepare a lessons learned report and forward it to the Regional Integration Team (RIT) Program Manager and the E\&C cost engineering POC with an explanation as to why this level was not achieved.

\subsubsection{Integrated design and project delivery team members}

An integrated design approach will be used and the PDT composition will reflect this approach. For a description of integrated design see ERDC/ CERL TR-04-19, SPiRiT Scoring through Self-Assessment Charrettes. All PDTs will include a LEED Accredited Professional (LEED AP) for both the design and construction phases. A LEED AP contributes to the PDT by ensuring correct interpretation of LEED credit requirements by the PDT, providing guidance and assistance to PDT members in developing suitable and complete documentation, tracking overall LEED accom- 
plishments, and monitoring individual actions of PDT members responsible for each specific LEED credit.

\subsection{Energy modeling}

Energy modeling must be accomplished by project delivery teams in order to show compliance with the EPACT 2005 and ASHRAE 90.1 energy conservation goals, to obtain necessary data to fill in the LEED templates for the energy optimization credits, and to fulfill the design energy analysis requirements described in the contracts for design or design/ build projects. There are specific energy modeling requirements embedded in the RFP (Request for Proposal) Wizard which is used to develop RFPs for the typical Army MILCON (Military Construction) projects.

Section 3.4 of the standard RFP (Compliance with the Energy Policy Act of 2005 (EPACT 2005) describes the detailed energy modeling requirements for Army projects, and prescriptive technology solutions for specific climate zones if an alternative compliance path is selected.

(See the RFP Wizard at http://mrsi.usace.army.mil/rfp/SitePages/Home.aspx and a sample CTYPE RFP containing Section 3.4 at http://mrsi.usace.army.mil/rfp/Shared\%20Documents/Forms/Examples.aspx.)

\subsection{Procurement process}

Most Army projects are awarded using Design/ Build contracts to save time and money. Much focused effort has been made to improve the facility delivery process resulting in "MILCON Transformation". Through the MILCON Transformation program, the US Army Corps of Engineers is improving construction time and costs. In order to meet construction deadlines and costs, the Corps is changing existing design philosophies and methods and adopting technologies such as BIM.

MILCON Transformation depends on standardized facilities but also changes the Request for Proposal (RFP) process as we transition from prescriptive requirements to more performance-based criteria. The criteria will help ensure that new Army MILCON projects meet the mandates of the Energy Policy Act of 2005, including the requirements to be 30 percent more efficient than the American Society of Heating, Refrigeration and Air-conditioning Engineers (ASHRAE) standard and use of Energy Star equipment, and requires the Army to achieve 2 percent energy use reduction each year from 2006 thru 2015 (totaling 20 percent reduction) based 
on the 2003 baseline. This RFP process will capitalize on industry strengths and best practices, encouraging non-traditional builders to compete. It provides repeat business incentives for good performance with the awareness that the repetitive nature of work then reduces the learning curve, providing for lower cost, faster delivery and improved quality (LTG Robert Wilson, Oct. 2006; http://www.hq.usace.army.mil/cepa/pubs/oct06/story1b.htm).

\subsection{Prescriptive versus modeling}

ASHRAE 90.1 has several compliance paths. A project team can choose either to follow prescriptive requirements for building envelope and systems or the team can do detailed energy modeling following all the ASHRAE 90.1 modeling rules. These rules are complicated but ASHRAE has published a 317 page manual showing energy modelers how to do the detailed energy modeling. No wonder many project teams would prefer to choose the compliance path.

The MILCON Standard RFP text section 3.4 COMPLIANCE WITH THE ENERGY POLICY ACT OF 2005 (EPACT 2005) offers teams the following choices:

1. Compliance Path - meet the Target Energy Consumption Budget and prove it by detailed energy modeling, or

2. Prescriptive Path - follow the Use of Technology Solution Set that is specified for the specific facility type in a certain climate zone.

When the "compliance path" is selected, the facility design shall include a uniquely developed technology solution set which can be shown by the design analysis (using facility energy simulation software) not to exceed the target energy consumption budget stated in 3.3.2 above and meet all the criteria in the DOE interim final rule: "Energy Conservation Standards for New Federal Commercial and Multi-Family High-Rise Residential Buildings and New Federal Low-Rise Residential Buildings".

For example RFP text see

https://ff.cecer.army.mil/rfp_wizard/docs/refs/CTYPEmodelSAMPLE.pdf

\subsection{LEED $^{\circledR}$ ratings and energy conservation}

A national standard for sustainable design was established by the US Green Building Council (USGBC), a group of leaders from the North American building industry that was formed in 1993. The USGBC is the 
guiding force behind the voluntary Leadership in Energy and Environmental Design (LEED) Green Building Rating System. LEED is widely accepted as the national standard for sustainable design and has been adopted by all federal agencies, including the Army.

\subsubsection{Army construction and LEED}

$\mathrm{LEED}^{\circledR}$ has been adopted by the US Army as the standard for new building construction. Beginning in FY08, all new Army buildings are required to be certifiable at the LEED-NC 2.2 silver level. The Energy Independence and Security Act of 2007 requires 5\% of Army buildings to be registered and certified. Recent Army policy mandated LEED Certification for appropriate projects.

\subsubsection{LEED credits}

LEED-NC 2.2 provides credits for optimizing energy performance. These options include Option 1: Performance Rating Method, ASHRAE 90.1Appendix G or equivalent (up to 10 points possible); Option 2: ASHRAE Advanced Energy Design Guide for Small Office Buildings 2004 (4 points); and, Option 3: Advanced Buildings Benchmark Version 1.1, Basic Criteria $\&$ Prescriptive Measures (1 point).

The USACE Army LEED Implementation Guide gives project teams guidance on how to successfully use LEED for their projects (see https://eko.usace.army.mil/_kd/go.cfm?destination=Showltem\&ltem_ID=47308 ).

\subsubsection{Design/build submittal requirements}

Additional guidance is kept current on the "LEED in the Model RFP and MILCON Transformation" page of the RFP Wizard website https://ff.cecer.army.mil/rff_wizard/leed.html.Specifically, the LEED 2.2 Documentation Requirements and Submittals Checklist link indicates what project data must be captured and submitted for each LEED credit earned for the project. The LEED Project Credit Guidance contains suggestions on how to earn each LEED credit, and also discusses problematic credits.

\subsubsection{LEED online submittal requirements}

Project teams must document each LEED credit that is earned. LEED OnLine allows a Project Administrator to assign responsibility for specific credits to different team members. LEED templates are online Adobe PDF 
files that must be filled out to prove that the LEED credit requirements were complied with.

A recent Engineering Construction Bulletin (Sustainable Design and Development (SDD) Registration and Certification) issued 25 Sept 2008, requires each Army project to be "Registered" with the USGBC

(http://www.wbdg.org/ccb/ARMYCOE/COEECB/ecb_2008_27.pdf). This will enable project teams to use LEED-Online and LEED Letter Templates to document and track project progress towards achieving Army SDD Goals.

\subsubsection{LEED and energy modeling}

The LEED Letter Template for the Energy Optimization credit must be filled out with data from the energy analysis to document energy savings beyond the ASHRAE 90.1 baseline building. 


\section{Energy Analysis Tools}

\subsection{Overview}

There are currently about a dozen qualified energy analysis software tools for calculating commercial building energy and power cost savings under EPAct 2004. These include Green Building Studio ${ }^{\circledR}$, EnergyPlus ${ }^{\circledR}$, Trane TRACE $^{T M}$ 700, Carrier HAP, and several versions of DOE-2. A complete list of qualified software can be found on the US Department of Energy website, and is updated as more packages are certified (http://www1.eere.energy.gov/buildings/qualified_software.html). US Army Military Transformation construction projects require another set of energy analysis tools. The Military Transformation Request for Proposal (MT RFP) includes the requirement to use Carrier HAP, Trane TRACETM 700, DOE-2, or EnergyPlus (US Army 2008).

Qualified software for calculating commercial building tax deductions satisfies requirements of the Internal Revenue Service. A list of the software as well as the IRS requirements document for each version of the software can be found on the Department of Energy, Energy Efficiency and Renewable Energy (DOE-EERE) website

(http://www1.eere.energy.gov/buildings/qualified_software.html). An exhaustive list of energy modeling software is also reviewed by DOE. The reviews cover aspects such as input, output, platform, intended audience, strengths, and weaknesses (http://www.eere.energy.gov/buildings/tools_directory/).

When this project was begun in 2008, very few of the energy analysis tools were able to import building information from BIM models using the gbXML data exchange standard. Green Building Studio ${ }^{\circledR}$ was identified as a unique energy analysis tool that could both accept a gbXML file from the BIM software used by USACE, and run an Army-approved energy analysis engine. Green Building Studio ${ }^{\circledR}$ is also relatively easy to learn and use, and is suitable for decisions made early in design.

The following energy analysis and design tools were briefly evaluated as part of this ITTP project: Carrier HAP, DesignBuilder, DProfiler, Eco-

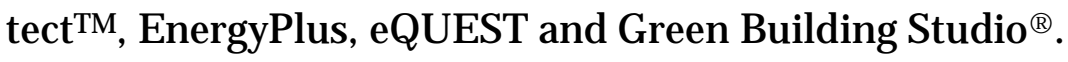

As of September 2009, there has been considerable progress in the AEC software industry, and gbXML has become a de facto industry standard 
schema. gbXML Consortium Member companies have been adding import and export capabilities to the major BIM, engineering modeling and energy analysis tools. The use of gbXML streamlines the transfer of building design information to and from engineering models, eliminating the need for plan take-offs. It is likely that energy analysis tools besides Green Building Studio ${ }^{\circledR}$ would be suitable for Army projects, but identifying them is outside the scope of this current project. For current information on the BIM and energy analysis tools that import/ export gbXML files, please view the gbXML consortium website at http://www.gbxml.org/.

Energy analysis vendors have also tailoring their software to make it easier and quicker for teams to create energy analysis calculations that meet the ASHRAE Standard 90.1 requirements and the LEED EA Credit 1 on-line submittal templates.

The process for successfully creating good BIM models and exporting gbXML files, then importing the gbXML files into an energy analysis tool and conducting energy analysis runs is implemented differently by each software vendor. Some vendors are aiming towards the detailed energy analysis that is typically done when the building design is almost complete, and others are aiming at helping designers make better decisions early in design.

Brief descriptions of the most widely used building energy analysis software tools are provided in Appendix B.

\subsection{Comparison of select tools}

For this project energy analysis software programs were tested for early design energy analysis based on a common set of criteria. The tools that were tested are Green Building Studio ${ }^{\circledR}$, EnergyPlus, Trane TRACETM 700, eQUEST, ROCAD, and DProfiler. Criteria for evaluation was the following:

1. CAD model: To calculate energy cost, a building footprint, envelope, and dimensions need to be configured. It can be an exhausting job if the energy modeler must create a new building model from scratch. In the proposed approach, the original building CAD model will be utilized since electronic $\mathrm{CAD}$ models are commonly available in building design and construction.

2. Design analysis in early stage: Historically, building designers and engineers had a difficult time predicting how effective energy efficient design alternatives were until too late in the planning and construction 
process to make changes. The goal of this project was to evaluate energy saving options early in the design process to enable informed decision-making about building components during the energy modeling process.

3. Industry Foundation Class (IFC) Compliant, in support of standard data exchange: This project is intended to be applied to Army installation military construction projects that may be designed with several industry standard $\mathrm{CAD}$ packages. Compatibility of energy analysis tools with the industry data exchange standard, such as IFC (Industry Foundation Class), is necessary to exchange building design information between $\mathrm{CAD}$ and energy modeling software.

4. Energy standard for buildings: Different energy standard and requirements available in the industry. However, energy requirements recognized as industry standard such as ASHRAE/ DOE are highly desired.

5. Required outputs:

a. Annual energy consumption

b. Peak electrical demand

c. Life cycle energy consumption

d. On-site energy generation from photovoltaic and wind systems

e. Water use analysis

f. Carbon emissions

Six different software programs were tested. While all the software is expected to deliver energy analysis during design, Green Building Studio is the only software currently to be applied in early design stage and to standard data exchange. Thus, it was found that Green Building Studio meets all the criteria established for this evaluation, as shown in Table 1. 
Table 1. Comparison of building energy analysis tools.

\begin{tabular}{|c|c|c|c|c|c|}
\hline & 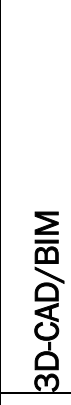 & 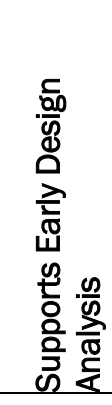 & 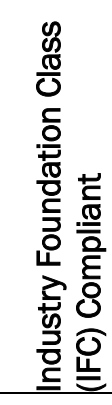 & 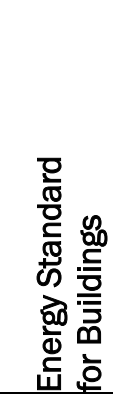 &  \\
\hline $\begin{array}{l}\text { Green Building } \\
\text { Studio }\end{array}$ & $x$ & $x$ & $x$ & $x$ & $X$ \\
\hline Energy Plus & & & & $x$ & $x$ \\
\hline TRACE ${ }^{\text {TM }} 700$ & & & & $x$ & $x$ \\
\hline eQUEST & & & & $x$ & $x$ \\
\hline Ecotect $^{\mathrm{TM}}$ & $x$ & $x$ & $x$ & & $x$ \\
\hline VE-Ware & $x$ & $x$ & & & $x$ \\
\hline DesignBuilder & & & & & $x$ \\
\hline Carrier HAP & $x$ & $x$ & & & $x$ \\
\hline DProfiler & $x$ & $x$ & & $x$ & $x$ \\
\hline
\end{tabular}

We found an interesting effort made by Beck Technology (DProfiler) that combines a cost estimation tool with energy analysis for more efficient decision making during the design process. In that regard, we realize that our overall approach may be improved by adding existing cost estimation software such as Timberline to the "Early Design Energy Analysis using BIM" project. 


\section{Instructions for Carrying out the Recommended Process}

\subsection{Software requirements}

Certain software is required in order to follow the recommended process for building energy analysis in early design. For this energy modeling process in early design phase, we recommend that Green Building Studio ${ }^{\circledR}$ be used. Green Building Studio ${ }^{\circledR}$ is a web-based service where files are uploaded, shared, and analyzed using engineering software programs. Since it is a web-based service, the entire calculations reside on the server computer. Before the user runs Green Building Studio ${ }^{\circledR}$ web service, he/ she has to download a small Green Building Studio ${ }^{\circledR}$ client. Then each time an analysis is run, the user needs to launch Green Building Studio ${ }^{\circledR}$ from an Internet browser and submit the saved file (gbXML format) for energy analysis. (Note: the process we developed uses Green Building Studio ${ }^{\circledR}$, which offered unique capabilities at the time. However, other tools with similar capabilities may now be available.)

\subsection{Recommended process}

In order to conduct an energy analysis in the early design phase, we developed a framework of how an energy analysis model may be developed from a 3D CAD or BIM model and used to explore different energy use alternatives. In this section, a sequence of three different steps in the energy modeling process is outlined, as shown in Figure 1 (page 8).

Most major BIM software programs (Autodesk Revit, Bentley Architecture v.8.i, and ArchiCAD) take almost the same approach by exporting their model data to a gbXML file. The difference we found is very minor between the different BIM applications (Revit requires the use of Room Tags in the BIM model, while ArchiCAD uses its Zone Tool.). Therefore, instead of describing different processes for all BIM applications, we will describe the process that works for Revit in this section, based on the assumption that the other applications would be similar to the instructions described here.

The first step is to identify the project requirements. This may present challenges as projects typically have constrained budgets, schedules, and resources. It is essential that all building stakeholders--including owners, 
occupants, designers, engineers and contractors--have a clear understanding of problem definition and participate in identifying a set of design alternatives early in the project planning process.

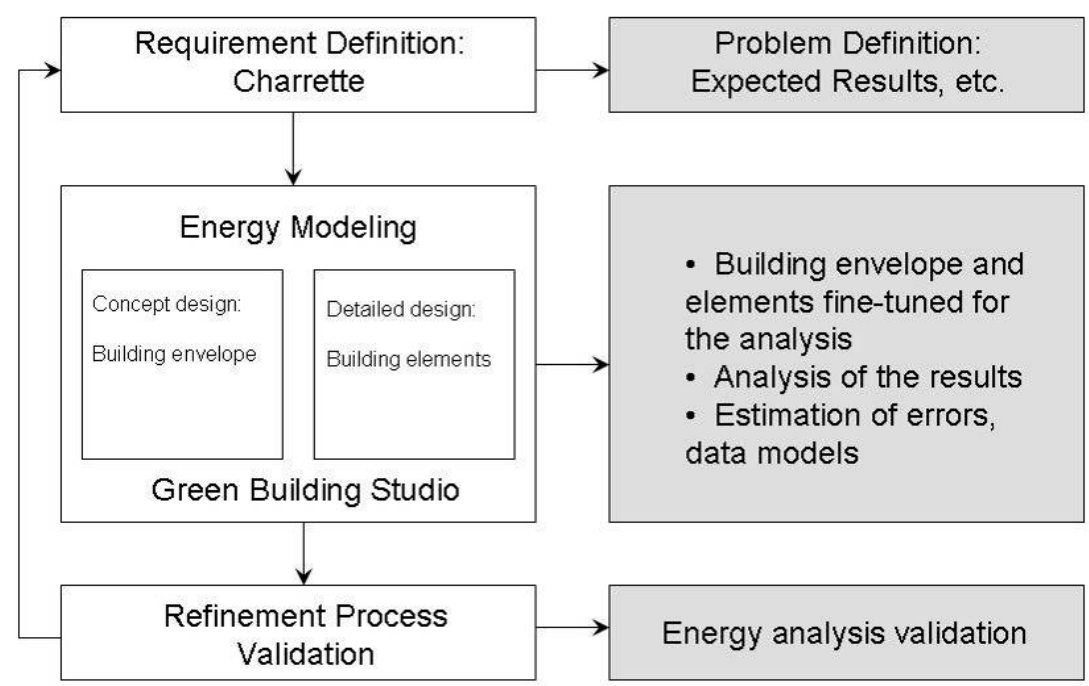

Figure 7. Framework for early design energy analysis.

The second step, energy modeling, is divided in two phases, concept design and detailed design. Energy modeling in concept design is mainly for building envelope shape and orientation, while that in detailed design is for building elements such as size, shape, and material of wall penetrations.

The third step, refinement process, supports the essential need to validate results of the early design energy analysis using an independent energy modeling software program. Crawley et al. (2005) stated that many users rely on a single energy simulation tool when they might be more productive having a suite of tools from which to choose. In this research, the validation was conducted by comparing the results from the Green Building Studio $^{\circledR}$ analysis with results from an eQUEST analysis.

\subsection{Instructions for carrying out the recommended process}

This section provides instructions on how to carry out energy analysis during the conceptual design phase to explore different energy saving alternatives in early design. The instructions involves building 3D-CAD/ BIM models, implementing/ exploring the energy model using Green Building Studio ${ }^{\circledR}$, proposing new energy alternative strategies, and validating the suggested energy strategies. Figure 8 shows the scope of this instruction. 


\begin{tabular}{|c|c|c|c|c|c|c|}
\hline (1) & \multicolumn{5}{|c|}{ BUILDING 3D-CAD/ BIM MODEL } & \\
\hline \multirow{2}{*}{\begin{tabular}{|l} 
BUILD A \\
ROOM/ZONE \\
OBJECT \\
\end{tabular}} & \multirow{3}{*}{5} & \multirow{2}{*}{$\begin{array}{l}\text { CHECK } \\
\text { HEIGHT OF } \\
\text { ROOM } \\
\text { OBJECT } \\
\end{array}$} & \multirow{3}{*}{4} & \multirow{2}{*}{$\begin{array}{l}\text { EXPORT } \\
\text { GBXML } \\
\text { TO GBS }\end{array}$} & \multirow{3}{*}{$\square$} & $\begin{array}{l}\text { ENERGY } \\
\text { ANALYSIS }\end{array}$ \\
\hline & & & & & & \multirow{2}{*}{$\begin{array}{l}\text { Visualize a model } \\
\text { in } 3 \mathrm{D} \text { (VRML). } \\
\text { Analyze the } \\
\text { result (energy } \\
\text { estimation of } \\
\text { base model }\end{array}$} \\
\hline $\begin{array}{l}\text { procedures of } \\
\text { locating } \\
\text { room/zone } \\
\text { object(s) }\end{array}$ & & $\begin{array}{l}\text { Complete } \\
\text { CAD/BIM for } \\
\text { energy modeling }\end{array}$ & & $\begin{array}{l}\text { Feed an } \\
\text { energy } \\
\text { model to } \\
\text { GBS }\end{array}$ & & \\
\hline
\end{tabular}

\section{(2) TESTING AND FINE TUNING THE ENERGY MODEL}

1. Explore design alternatives (rotation, lighting, HVAC, roof, walls, etc.).

2. Simulate the energy performance.

3. Test and calibrate the simulation results.

4. Compare the analysis results to decided on the impact of building envelope (building footprint, glazing/skylight, floor plan and shading) and tech equipment (heat gains, insulation, transparency, HVAC, etc).

Energy analysis includes measuring whole building energy, photovoltaic potential, wind potential, water use details.

Derive energy efficient alternatives among different options.

(3) EVALUATING NEW ENERGY ALTERNATIVES

1. Validate the results with engineers, or energy experts.

2. Recommend design alternatives by integrating energy estimates, PV analysis, water used, etc., to conserve energy.

3. Recommend design strategies to reduce energy consumption.

Figure 8. Overall scope of 3D-CAD/BIM energy analysis.

The proposed building simulation model is composed of three major components. The first component is building a 3D-CAD/BIM model that creates the building geometry for the building base design. Second, the energy model is tested an explored to find better and more efficient building design alternatives. Finally, a building design minimizing energy use is determined and the results are validated.

\subsubsection{Step 1: Building the BIM Model}

The goal of the process is to use the building geometry and details contained in a BIM model to quickly build an energy analysis model to com- 
pare energy-related tradeoffs early in design. More than just the lines and arcs associated with traditional computer-assisted drawing (CAD) tools, BIM includes associated benefits of visualization, built-in intelligence and simulation, intelligent objects of a structure, such as spatial data (3D), unstructured data (text), and structured data (databases, spreadsheets), as shown in Figure 9. With the addition of building geometry data in a BIM model, the volume can be calculated and energy estimates made based on building envelope characteristics (doors and windows), thermal zones, and building orientation.

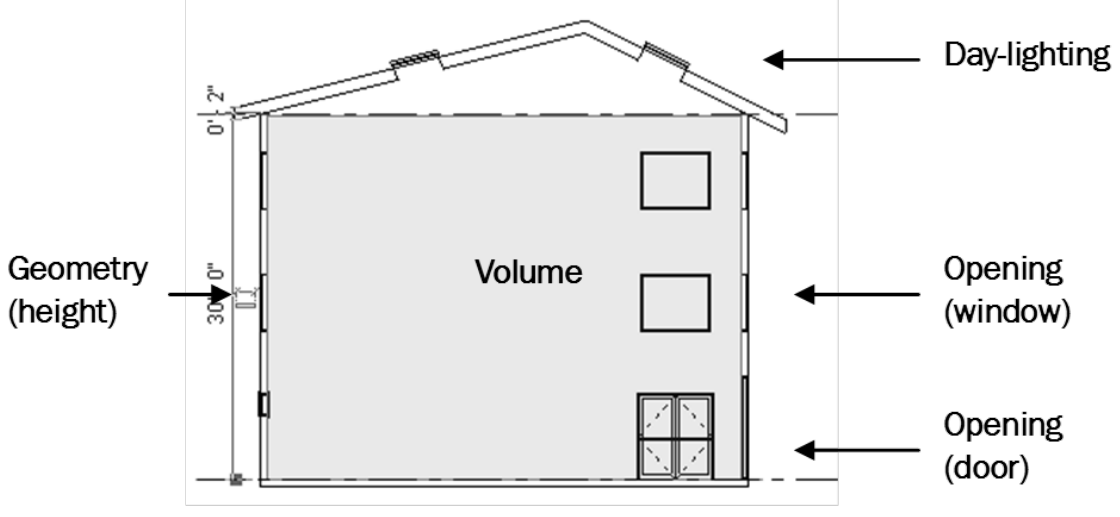

Figure 9. 3D-CAD/BIM model.

While there are several different BIM-based energy modeling software programs available, Green Building Studio ${ }^{\circledR}$ works with gbXML which was specifically developed to exchange energy-related information. That is, gbXML output from BIM programs can be imported into Green Building Studio ${ }^{\circledR}$. Green Building Studio ${ }^{\circledR}$ automatically checks for the correctness of the BIM model by warning the user of issues with the model before it is exported to the gbXML format. Therefore, the Green Building Studio ${ }^{\circledR}$ was selected for energy modeling for the entire process which was subsequently validated with a separate energy modeling program. Green Building Studio ${ }^{\circledR}$ (Autodesk 2008) is a web-based service that works with a gbXML file exported from various BIM applications including ArchiCAD, Revit and Bentley Architecture (v.8.i) and uses the building information to perform an energy evaluation with established tools such as DOE-2, eQUEST, and EnergyPlus. It allows various changes in design alternatives to the building design such as orientation, glazing, roof and wall construction, lighting, and HVAC to be quickly analyzed to determine which options are the most energy-efficient.

Figure 10 shows the CAD/BIM modeling process which consists of four different steps with two different software products. 


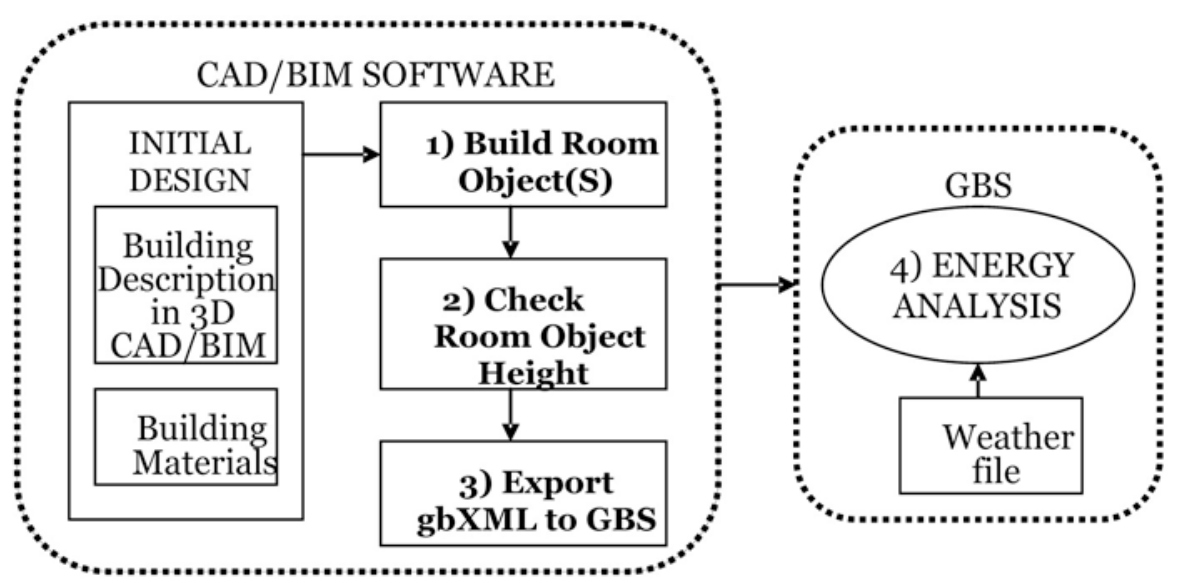

Figure 10. 3D CAD/BIM modeling process for energy analysis.

$\mathrm{CAD} / \mathrm{BIM}$ software is used to build room objects, check room object height, and export gbXML to Green Building Studio ${ }^{\circledR}$. Lastly energy analysis will be conducted using Green Building Studio ${ }^{\circledR}$.

\subsubsection{Room object in BIM (Revit)}

The BIM model must have Room objects defined for all rooms or group of rooms that you want to be exported to gbXML and analyzed by the Green Building Studio web service. You cannot simply add the Room object without checking to ensure it is positioned properly in the model.

\subsubsection{Checking Room Object Height (Revit)}

The best way to view a Room object's height is viewing it in section. First you have to ensure the Visibility of the Room Object's Interior fill is selected. You can access the Visibility/ Graphic Overrides dialog box using the View/Visibility/Graphics menu. Once you have enabled the Interior Fill for Rooms to be visible, you will see the Room object in section view (Figure 11). If your room object is not touching the entire roof or ceiling in the room, then not all of that roof or ceiling will be exported to the gbXML file. 


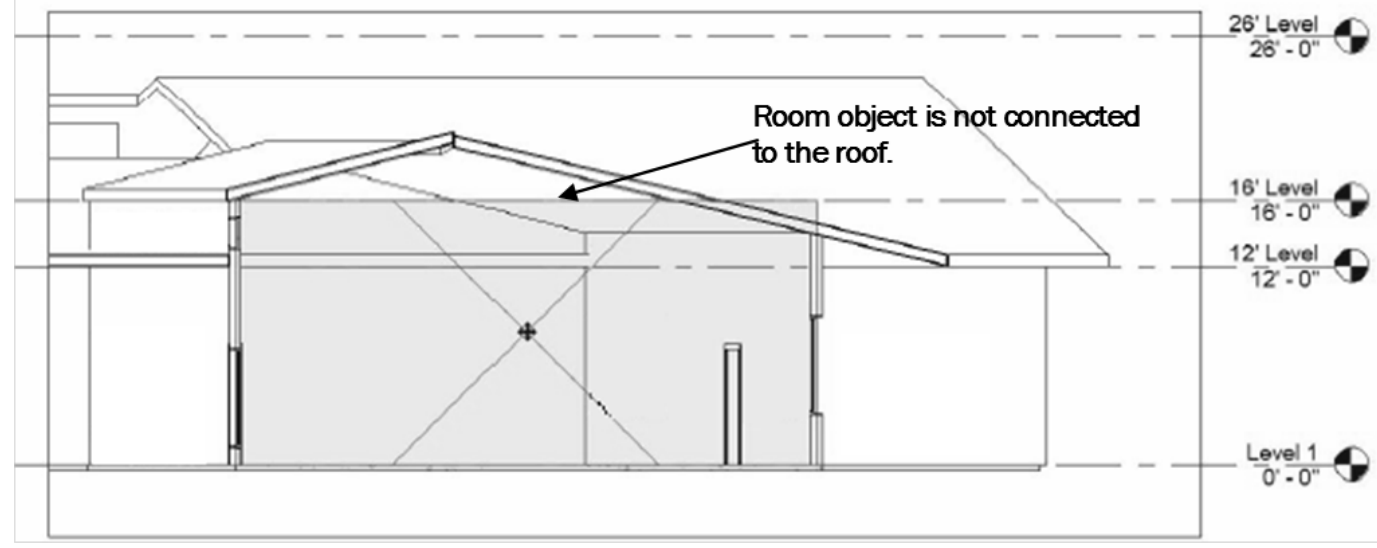

Figure 11. Adjusting the height of a room.

Only the surfaces in contact with the room object will be exported to gbXML. The way to fix these types of issues is to go back to the plan view as you can not select a room object in section. Select the Room object by right-clicking the $\mathrm{X}$ over the Room object when it appears and selecting the Properties menu item. In properties window for the Room change the Upper Limit to the level the roof or ceiling is on and add in a Limit Offset that will increase the Room object height to enclose the entire roof. Then go back to the section view to confirm the roof or ceiling is now fully enclosed in the Room object as below. A building usually consists of more than one room that has different heating and cooling load. Thus, it is often necessary to place multiple room objects to consider different settings of room temperature or ventilation in a single building. In Revit MEP and ArchiCAD, users can place multiple room objects in the same building for optimal energy modeling and calculations.

\subsubsection{Exporting gbXML from BIM modeling software}

The Green Building XML (gbXML) can be used to facilitate the transfer of building information stored in CAD building information models, enabling integrated interoperability between building design models and a wide variety of engineering analysis tools and models available today. Today, gbXML has the industry support of Autodesk, Graphisoft, and Bentley.

Also, XML, extensible markup language, is a type of computer language that allows software programs to communicate information with little to no human interaction. This approach allows building designers to focus on what they want to do most that uses intelligent technologies to meet their client's needs at the lowest cost possible. In short, gbXML allows intelli- 
gent solutions for the design, certification, operation, maintenance, and recycling of buildings.

Figure 12 shows the procedure to export gbXML from BIM software.

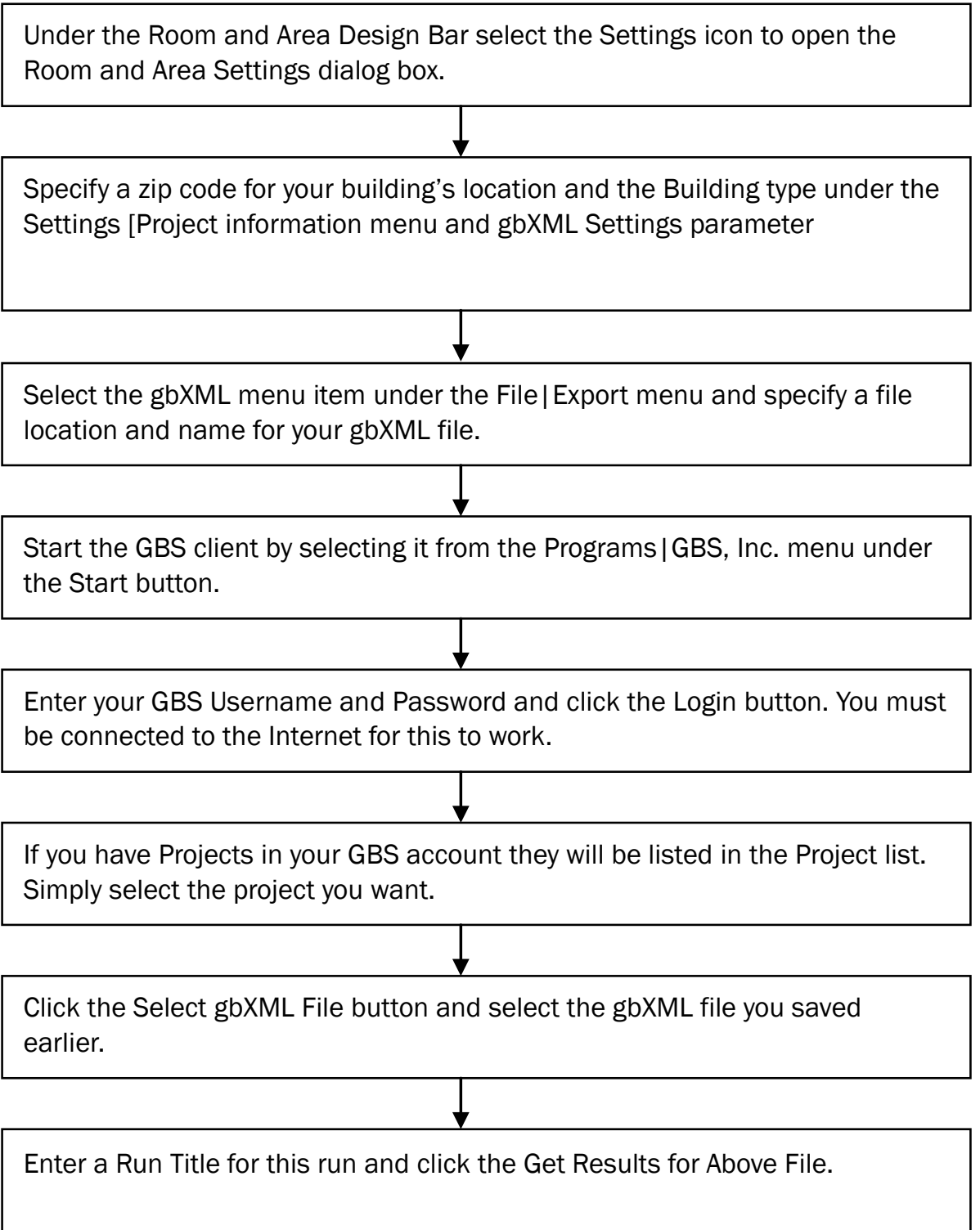

Figure 12. Steps to export gbXML file and import gbXML file into Green Building Studio ${ }^{\circledR}$.

If everything with your model is correct a browser window will open similar to the one below presenting you with the status of your Green Building Studio ${ }^{\circledR}$ energy analysis.

Once your run is complete you will see a screen similar to the one shown in Figure 13. 


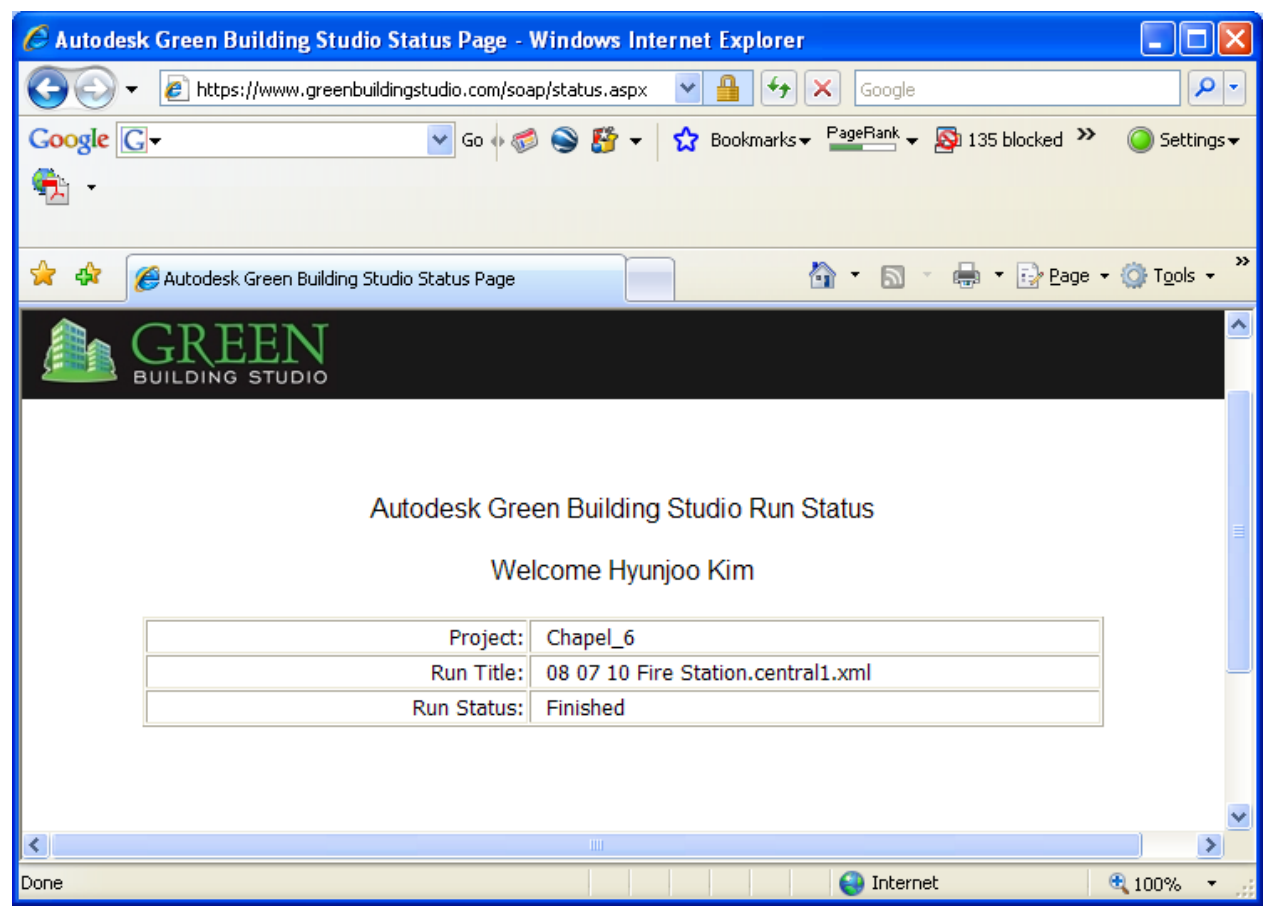

Figure 13. A Green Building Studio ${ }^{\circledR}$ energy analysis report.

\subsubsection{Energy analysis}

The Green Building Studio ${ }^{\circledR}$ energy results pages provide summarized information on building energy and resource use performance and costs that can be used at the early conceptual design stage (Figure 14).

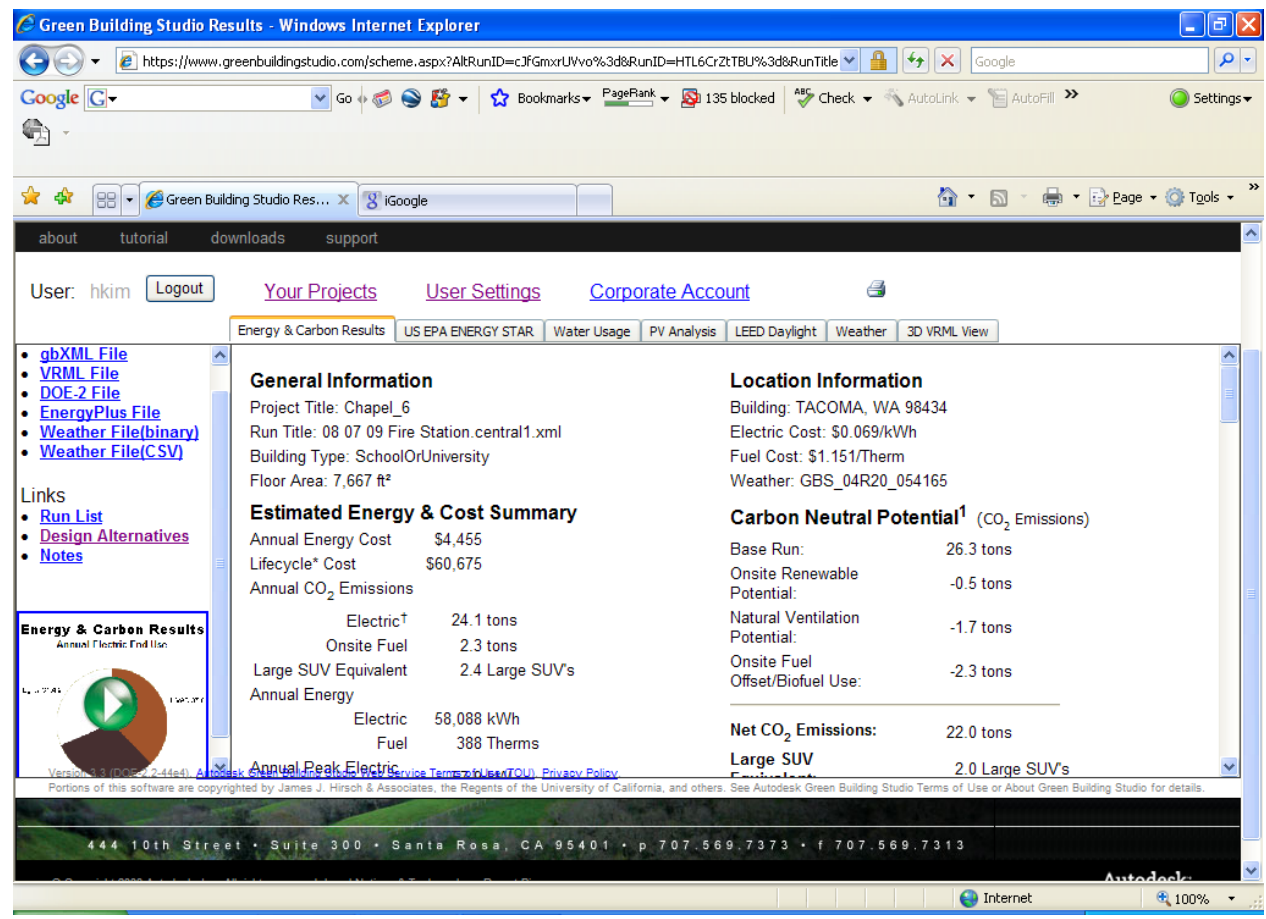

Figure 14. Energy analysis results screen from Green Building Studio ${ }^{\circledR}$. 
Detailed results from the screen are described as follows:

- General Information: The General Building information section at the top of the page describes the project scenario, building type, geographic location, and gross floor area.

- Estimated Energy \& Cost Summary: Most building energy cost comparisons and early compliance decisions can be made using annualized energy cost and consumption information. Costs are estimated using local utilities rates. The following information is provided: annual energy cost, lifecycle energy costs, annual energy consumption (electric and gas), peak electric energy demand ( $\mathrm{kW}$ ), lifecycle energy consumption (electric and gas), CO2 Emissions are based on the onsite fuel use and the fuel sources for the electricity in the region, and an equivalency using a SUV (15k miles/yr) is given to provide a more relevant understanding of the building's $\mathrm{CO} 2$ emissions.

- Energy- End-Use Charts: Further breakdowns of energy use for major electric and gas end uses like lighting, HVAC, and space heating are provided in graphical format. Numbers associated with each category can be seen by clicking on the pie charts with your mouse.

- Electric Power Plant Sources: The US Environmental Protection Agency has historical records for all the fuel and emissions of all power plants in the United States. The Fossil fuel portion is given and this is a good proxy on how much electricity use needs to be reduced by the building to achieve a carbon neutral electricity use.

- Water Usage and Cost: A summary is given of the estimated water use in the building based on indoor water factors (number of people in the building, percent of time occupied) and outdoor water factors (irrigated area, timed sprinkler, pool or other equipment).

- Photovoltaic Potential: Green Building Studio ${ }^{\circledR}$ automatically analyzes every exterior surface of the building for its potential for generating electricity using photovoltaic. The result of this analysis is summarized in this section. Annual Energy is given in kilowatt-hours (kWh). This annual sum takes into account temperature, solar radiance levels, and shading information throughout the year. If 60 percent of the surface is shaded by other parts of the building, then the remaining 40 percent is used for photo-voltaic calculations. PV also considers lifecycle cost based on the number of panels and shows how long it takes to pay back the installation cost in years.

- LEED Daylighting Score: The LEED glazing score is the percentage of floor area that has a glaze factor greater than 0.2 . This value should be 
over $75 \%$ to fully benefit from daylighting controls throughout the building.

- Wind Energy Potential: The amount of electricity that can be annually generated from one $15 \mathrm{ft}$ diameter wind turbine of conventional design.

- Natural Ventilation Potential: Summarizes the amount of mechanical cooling the current building design requires and estimates the amount of hours the current design could use the outdoor air to naturally ventilation the building. The energy savings associated with not running the mechanical cooling system and associated fans during these periods is also summarized. Further, the net hours of mechanical cooling is also provided to determine if mechanical cooling is really warranted for this building.

- Building Summary: Detailed statistics and information on building constructions are also provided. This information allows the building designer to get an early assessment of code compliance and rough estimates of equipment sizing requirements for heating, cooling, and water heating, as well as window, wall, and floor area breakdowns.

\subsubsection{Step 2: testing and fine-tuning the energy model}

Once a general building configuration and orientation were selected, the next step was to develop a detailed energy analysis incorporating design and system details. In this section, a detailed energy modeling process was developed as shown in Figure 8. This analysis considers a number of options for building elements in four categories: general, lighting, roof, and walls. The Green Building Studio ${ }^{\circledR}$ design alternative feature assists the user in determining the variations to a run that will improve the run's energy efficiency. Clicking on either the results page design alternative link or the run list page link will take the user to the design alternative page as seen below. The top portion of the table as standard links to the run list, the results page for the base run associated with these design alternatives.

Begin making the modifications you would like to consider by selecting a tab and choosing the drop down list value you would like to be applied for the Design Alternative (Figure 15). Once all the design alternatives are run, you can review their results either on the Design Alternatives web page or the Run list page. Figure 22 shows an example comparing energy estimates based on different building elements between "baseline" and proposed design models to find which options had the greatest impact on annual energy costs. 


\begin{tabular}{|c|c|c|c|c|c|}
\hline Project: Chapel_6 & $\underline{\text { Run List }}$ & \multicolumn{3}{|c|}{ Base Run: 080709 Fire Station.central1.xml, Energy Cost: $\$ 4,455$} & Project settings \\
\hline General & Lighting & Roof & Northern Walls & Southern Walls & Western Walls \\
\hline $\begin{array}{l}\text { Rotation } \\
\text { fVAC } \\
\text { vo Change }\end{array}$ & $\begin{array}{l}\text { Lighting Efficiency } \\
\text { No change } \\
\text { Lighting Control } \\
\text { No change }\end{array}$ & \begin{tabular}{|l} 
Construction \\
No Change \\
Glazing Type \\
No Change \\
Glass Amount \\
No change
\end{tabular} & \begin{tabular}{|l} 
Construction \\
No Change \\
Glazing Type \\
No Change \\
Glass Amount \\
No change
\end{tabular} & \begin{tabular}{|l} 
Construction \\
No Change \\
Glazing Type \\
No Change \\
Glass Amount \\
No change
\end{tabular} & \begin{tabular}{|l} 
Construction \\
No Change \\
Glazing Type \\
No Change \\
Glass Amount \\
No change
\end{tabular} \\
\hline \multirow[t]{2}{*}{ 1. Select Changes } & \multicolumn{2}{|c|}{5 Below. 2. Enter Alternative Name: } & \multicolumn{2}{|c|}{ 3. Add Alternative } & 4. Run Added Alternatives \\
\hline & \multicolumn{2}{|c|}{ Reset Dropdown Selections Below } & \multicolumn{2}{|c|}{ Save Added \& Unrun Alternatives } & Cancel \& Don't Save Added Alte \\
\hline General & Lighting & Roof & Northern Walls & Southern & Western Walls \\
\hline
\end{tabular}

Figure 15. Example of design alternatives.

The baseline design model measures the annual energy cost for a building design intended for use as a baseline for rating above the standard design, as defined in ASHRAE 90.1, Informative Appendix G. When each design alternative was chosen in Figure 15, the annual energy cost was calculated in Green Building Studio. Figure 16 shows an example of ten different sets of annual energy costs run in Green Building Studio and compared baseline cost with proposed design costs. According to the result in Figure 16, option 9 can be considered to be the most efficient energy saving among all alternatives.

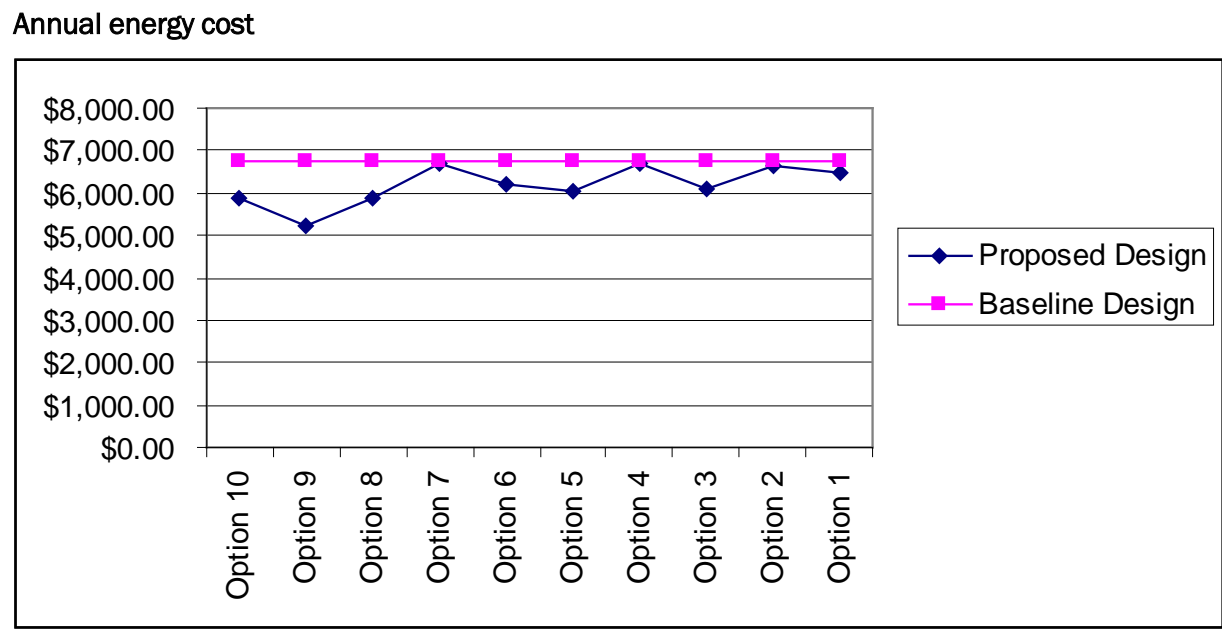

Figure 16. Example comparison showing results of different energy runs.

\subsubsection{Step 3: evaluating new energy alternatives}

There is the essential need to validate results from energy analysis models because the inability to adequately evaluate energy analysis models may become the limiting factor in our ability to utilize 3D CAD/ BIM technologies for energy analysis. In this section, a walkthrough with an expert for conceptual validation involves a small group of qualified individuals or experts, who carefully review and revisit the logic and assumptions of the energy model. 
After the results are evaluated through the process in Figure 10, design changes and alternatives are proposed and recommended so that building designers may incorporate them in the design process.

\subsubsection{Further development of design alternatives}

Green Building Studio provides the user with several file export and download capabilities that link the user with others in the design team performing detailed engineering analysis, equipment sizing and design, or building product sales functions (Figure 17).

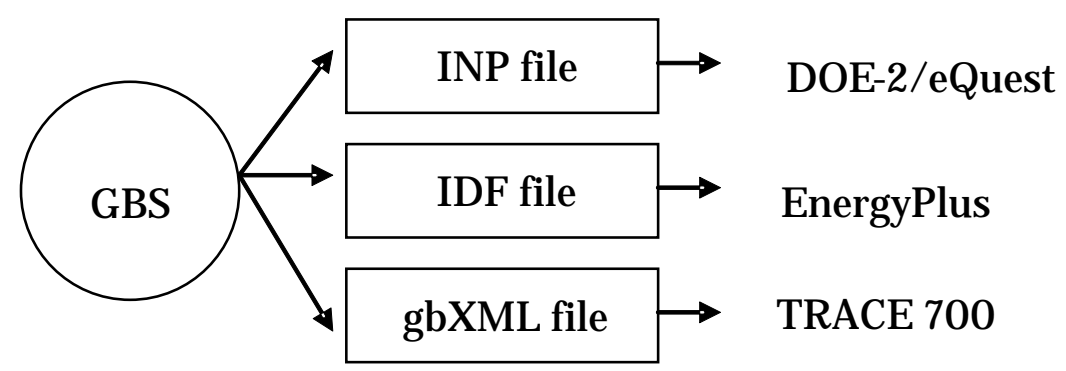

Figure 17. Further development of design alternatives in Green Building Studio ${ }^{\circledR}$ : exporting.

The user simply clicks on the option with the mouse to activate. Each capability is described below.

- DOE-2 file: This link exports the geometrically accurate DOE-2.2 input file that was generated by Green Building Studio ${ }^{\circledR}$ for the energy simulation. It can be used downstream as the starting point for more detailed engineering analysis. This file can be directly imported into the free eQUEST DOE-2 application at www.doe2.com. Please note that the eQUEST 2D view will not work with these files nor will the eQUEST wizards.

- EnergyPlus file: This link exports the geometrically accurate EnergyPlus file for that was generated by Green Building Studio ${ }^{\circledR}$. It can be used as a starting point for more detailed engineering analyses.

- gbXML file: This link is to the fully populated gbXML file that contains all the building information necessary for an advanced energy simulation as well as the results from the Green Building Studio ${ }^{\circledR}$ simulation. The building information also includes the 3D-CAD building information model and the local assumptions and building code information brought in through Green Building Studio ${ }^{\circledR}$. This file can be used with design tools like Trane's TRACETM 700 application. 


\section{Applications and Results}

The preceding chapters have addressed the required steps for the energy modeling and analysis process. Any lengthy process of energy analysis would be incomplete without real applications providing descriptions of the results. This section explores the analysis of results from several case studies. The case studies have been generalized to include all the situations where the proposed instructions can be utilized in analyzing energy models as shown in Table 2.

Table 2. List of case studies using CAD/BIM and Green Building Studio ${ }^{\circledR}$.

\begin{tabular}{|l|l|l|}
\hline CAD/BIM modeling software & \multicolumn{1}{|c|}{ 3D-CAD/BIM Model } & \multicolumn{1}{|c|}{ 2D-CAD Model } \\
\hline Autodesk Revit & $\begin{array}{l}\text { Community Emergency Service } \\
\text { Station (CESS) facility (Fort Bragg, } \\
\text { North Carolina) }\end{array}$ & NA \\
\hline GraphiSoft ArchiCAD & NA & $\begin{array}{l}\text { Chapel Building (Fort } \\
\text { Lewis, Washington) }\end{array}$ \\
\hline Bentley Architecture v.8.i & $\begin{array}{l}\text { CDC-Child Development Center } \\
\text { (Fort Stewart, Georgia) }\end{array}$ & NA \\
\hline
\end{tabular}

Table 2 shows the list of different projects conducted as case studies for energy analysis. Even though the terms "interoperability" and BIM are certainly popular topics within the AEC industry at the moment, we discovered that the industry is not fully ready for the new technology (3D$\mathrm{CAD} / \mathrm{BIM}$ ) which resulted in 2D CAD models in several projects. Thus, there needs to make a distinction between projects; one with BIM models and the other without BIM models as shown in Table 1 . As for the project with a BIM model, the 3D CAD/ BIM model was re-used from an architect's design model and imported to Green Building Studio ${ }^{\circledR}$ for energy analysis. For the project without BIM model(s), we showed how a BIM model can be built quickly and used it for energy analysis. Based on our experiences, the whole process of creating 3D-BIM models was incredibly fast compared to traditional energy modeling process since only a simple BIM model was necessary with the exterior shell description (walls, doors, windows, and roof) and zones defined inside of a building. The following shows each case study in Table 2. 


\subsection{Case Study 1: Community Emergency Service Station; Fort Bragg, NC - Complete BIM model provided in Autodesk Revit}

The project described in this paper is a new Community Emergency Service Station (CESS) facility at Fort Bragg, North Carolina (Figure 18). This building will provide firefighting, ambulance, and police support services for a residential neighborhood on this military installation in Fayetteville, NC. The station consists of offices, training rooms, physical training, day room, kitchen, dormitory area, apparatus room, decontamination room, storage area/rooms, latrines, communication and electrical closets, and a mechanical room. The size of the proposed new facility is approximately 8,300 square feet. The apparatus room was sized for fire trucks, military police cars, and ambulances. Space for hose drying, lockers and a work bench were also required in the apparatus room.

This LEED Platinum building was the result of 3 different projects:

1. MILCON project PN 65830 to build a Community Emergency Service Station (CESS) in the new residential neighborhood on the north side of Fort Bragg. (Design/ Bid/ Build).

2. ESTCP (Environmental Security Technology Certification Program) Research Project SI-0724: Design, Monitoring, \&Validation of a High Performance Building.

3. ITTP (Installation Technology Transfer Program) Research Project: Early Design Energy Analysis Using BIM (Building Information Modeling).

The Environmental Security Technology Certification Program (ESTCP) is a Department of Defense (DoD) program that promotes innovative, costeffective environmental technologies through demonstration and validation at DoD sites. The technical objectives of the 4 year ESTCP project Design, Monitoring \& Validation of a High Performance Building are:

- Validate whether whole-building design achieves higher building performance.

- Assist Architect of Record with design, modeling, and LEED to meet high performance objectives.

- Monitor performance of a new building (CESS designed using the whole-building approach) versus an existing building (FY02 Fire Station designed using the traditional serial design approach) for a year

- Compare performance results and costs. 


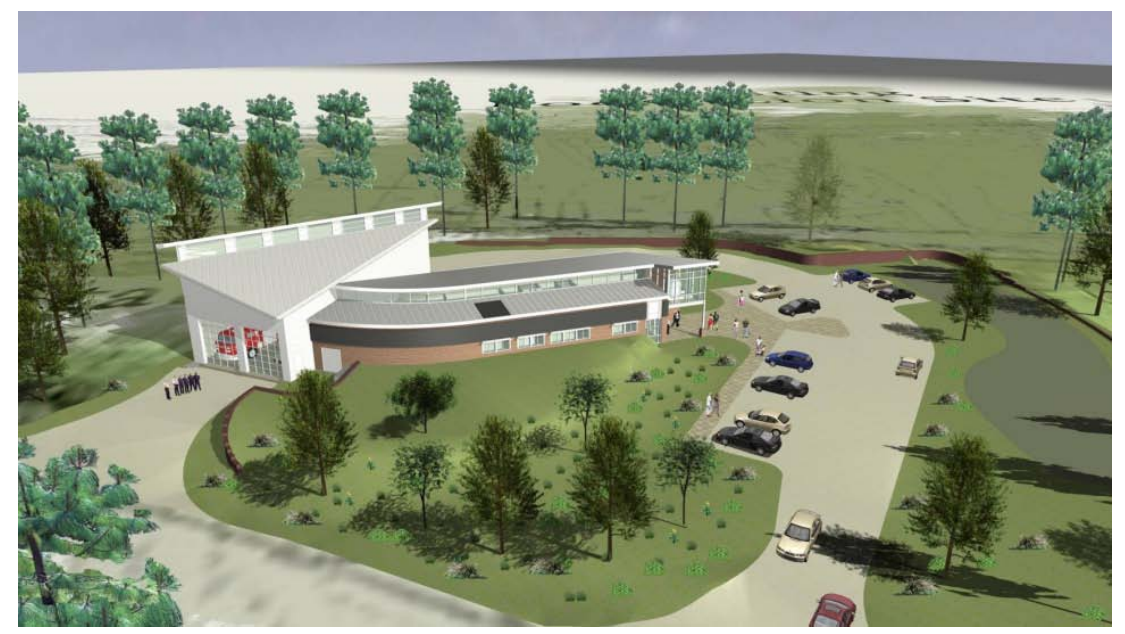

Figure 18. BIM model of CESS facility.

\subsection{Requirement definition: charrette}

Identification of requirements for the CESS facility was accomplished using the charrette process. A charrette is held at the beginning of a project where a group of designers, engineers, and contractors may draft solutions to design problems. For our case study, the four day charrette took place in the early stage of design and also included stakeholders outside of the design/ build team. Each participant presented his/ her work to the full group. The charrette served as a way of quickly generating solutions while understanding and integrating the interests of different groups of people. The outcome of the charrette was a 35\% complete integrated building design with a target rating of LEED-NC 2.2 Platinum.

Energy modeling in the case study presented several challenges. First, it was essential to provide energy analysis results to the participants during the 4 day charrette so we could identify energy-saving improvements while the design was being modified. In addition, energy modeling usually involves the time-consuming process of re-entering all the building data for an energy analysis. In order to meet the time demands of energy modeling "live" during the charrette, we convinced the A/E that it was essential to bring a BIM modeler to try out various building design alternatives. Our team could then use the BIM models to quickly explore energy impacts using the Green Building Studio ${ }^{\mathrm{TM}}$ tool.

\subsection{Energy modeling}

The first step in the early energy modeling process requires the use of energy modeling software to generate annual energy consumption and cost data for a set of building design alternatives. Annual energy use will 
vary depending on building configuration and design details. The energy modeling process is grouped into two sub-processes: the macro-level energy analysis focuses on comparing building size, shape, and orientation; and, the micro-level energy analysis considers building details such as wall penetrations and building system details.

\subsubsection{Concept design: macro-level energy analysis}

The first step of energy modeling is to develop an energy model at the macro level. It includes exploring different building shapes and orientations that are usually considered in conceptual design process (Figure 19).



Figure 19. Energy modeling for building configuration and orientation.

In order to meet the requirements of the CESS at Fort Bragg as determined in the charrette process, two different spaces were required, a main office and an apparatus room.

Before the charrette, three distinct building configurations were suggested by the architects in Fort Bragg: (1) the use of two separate buildings (an office building and an apparatus building), (2) a single two-story building, and (3) a single one-story building. Based on the suggestions, computer renderings of these configurations are built in 3D CAD/BIM, as shown in Figure 20. ERDC-CERL modeled these buildings and brought the results to the charrette for discussion. We also tried to model a fourth option-an underground structure-but were unsuccessful in getting any meaningful energy analysis results. Note that the high bay space is heated but not cooled. 


\begin{tabular}{|c|c|c|c|}
\hline & Model 1 & Model 2 & Model 3 \\
\hline Type & Two separate buildings & Two-story building & One-story building \\
\hline Plan & $=$ & $\begin{array}{l}= \\
=\end{array}$ & 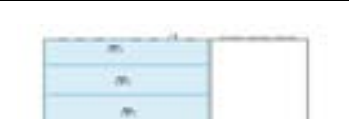 \\
\hline & & 0000000 & \\
\hline 3D- CAD & 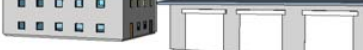 & $\because \begin{array}{c}0 \\
0\end{array}$ & 01000 angan \\
\hline
\end{tabular}

Figure 20. Building configurations

Figure 21 shows the comparison of estimated annual energy costs of the three building configurations. The dominant energy load for this building is summer cooling, due to its location in Fayetteville, NC. The single onestory building is expected to have the lowest annual energy costs. Ground source heat pumps were considered an optimum source for cooling based on interviews with mechanical engineers who had researched the cost and effectiveness of various options. Therefore, the one-story building configuration for office and apparatus spaces as shown in Model 3 in was chosen to be the most energy efficient building envelope.

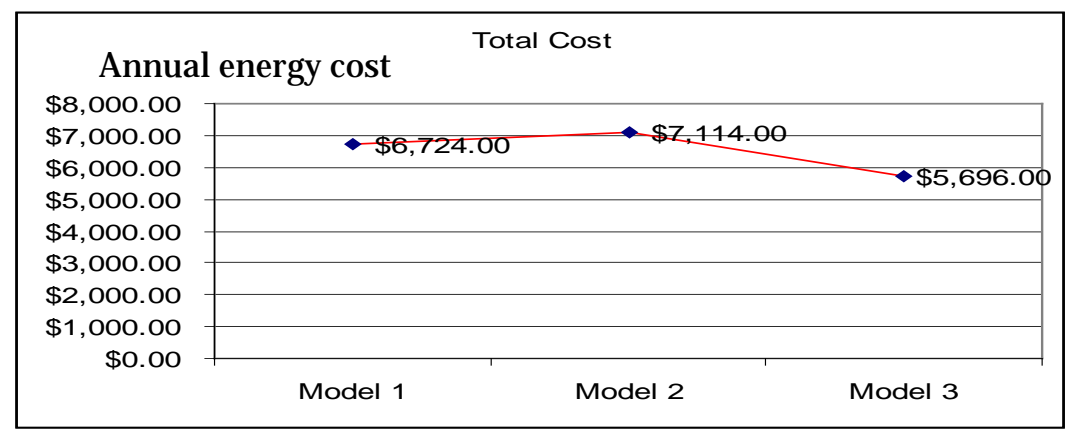

Figure 21. Comparison of estimated annual energy costs of three building configurations.

Different building orientations were considered at the conceptual design stage (Figure 22). Typically, a building will be oriented to minimize energy requirements. For example, in many cases, facing the long axis of a building to the south minimizes energy required to heat and cool it because solar gain can easily be controlled by horizontal shading. 


\begin{tabular}{|l|c|c|}
\hline & Model 4 & Model 5 \\
\hline Rotation & 15 degree deviation & Notation \\
\hline Plan &
\end{tabular}

Figure 22. Different orientations of the CESS building at Fort Bragg.

During the charrette, the designers wanted to rotate the orientation of the apparatus room by 15 degrees from the rest of the building to allow easy entrance of emergency vehicles onto the access street. While analyzing the differences in energy load for each orientation, it was found that the 120 degrees generated the highest energy cost, as shown in Figure 23 The designer's request for a 15-degree rotation resulted in only \$76 increased annual energy cost. Therefore, the concept design was modified because we discovered that a true south orientation is not an absolute requirement. During a recent interview, the lead architect who designed the CESS building said this project was the first time they ever had access to energy modeling during the charrette, and they were excited to have immediate feedback implications of changing the building orientation. Repositioning the building to minimize cut and fill on a sloped site while allowing good vehicle access to the high bay resulted in reduced construction cost without greatly impacting the energy consumption.

Annual energy cost

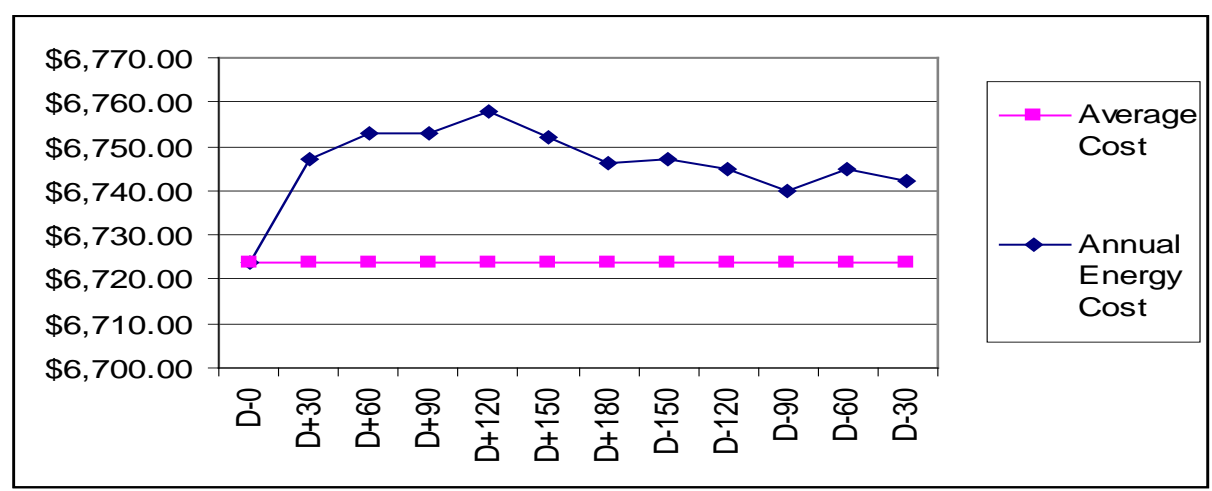

Figure 23. Comparison of estimated annual energy cost for different building orientations.

\subsubsection{Detailed design: micro-level energy analysis}

Once a general building configuration and orientation were selected, the next step in the process was to develop a detailed energy analysis incorporating design and system details. In this section, a micro-level energy 
modeling process was developed as shown in Figure 24. This analysis considers a number of options for building elements such as HVAC, roof, walls, windows, mechanical systems, and lighting. Six different categories of building elements were modeled in BIM software. For this study, Revit MEP was used. The gbXML file was exported to Green Building Studio ${ }^{\circledR}$. Each potential system component was considered for its impact on overall annual energy costs. Building energy cost comparisons were made using consistent local annualized energy rates and schedule information, for example, expected occupancy of the building. Comparison of annual energy costs for each design alternative was conducted for the six categories (10 different options for HVAC, 17 in glazing, 20 in roof, $15 \mathrm{in}$. walls, 4 in. lighting, and $3 \mathrm{in}$. lighting control) of building elements that were considered using Green Building Studio ${ }^{\circledR}$.



Figure 24. Energy modeling for building elements and design details.

The comparison in Figure 25 shows how different building elements affected the energy estimations. Compared to the baseline building performance, HVAC options had the greatest impact on annual energy costs, with estimated \$1,507 saving using a 17 Seasonal energy efficiency ratio (SEER)/ 0.85 Annual Fuel Utilization Efficiency (AFUE) Split/ Pkgd heat pump. On the other hand, lighting controls had the least impact on energy costs: \$11-17/ year. Based on the results of Figure 31, the following design alternatives were recommended:

- HVAC: 17 SEER/ 0.85 AFUE Split/ Pkgd Heat Pump<5.5 ton

- Lighting efficiency: LPD $40 \%$ less than base run

- Lighting control: Occupancy sensors 
- Roof: Cool Roof - R38 continuous ins. over roof deck

- Wall construction: Insulated Concrete Form (ICF) Wall, 14" thick form

- Glazing: Clear Wall Panel (U-0.10, SHCG 0.06, Tvs 0.04).

\section{Annual energy cost}

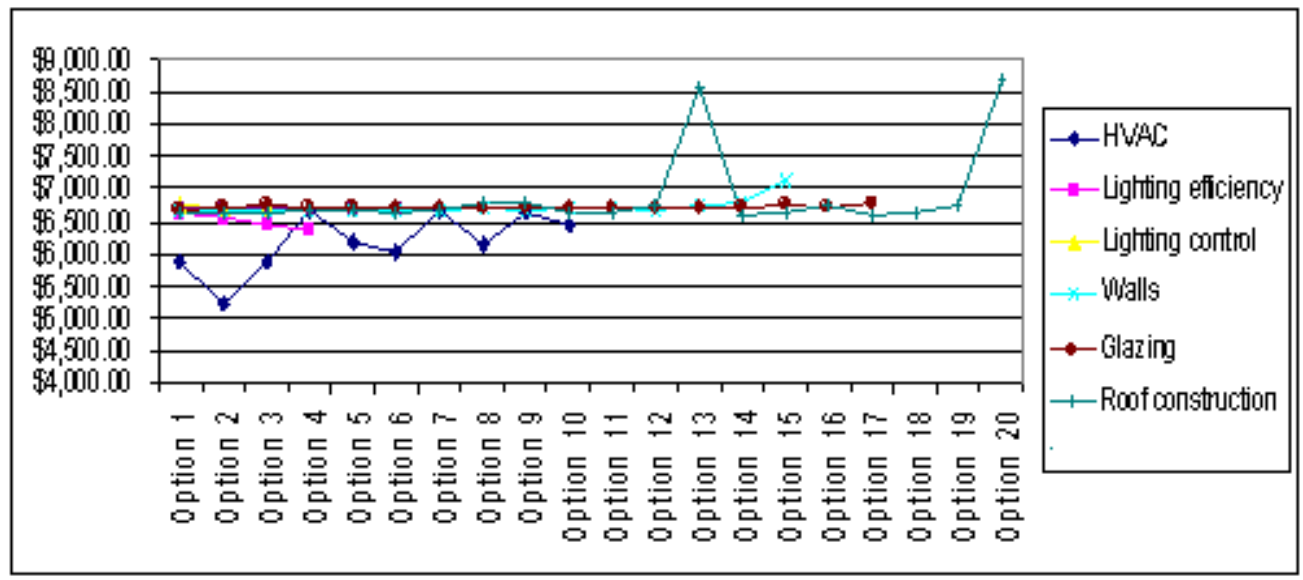

Figure 25. Annual energy cost comparison of different building component options.

\subsubsection{Refinement process}

There is an essential need to validate results from early building energy modeling because the inability to adequately evaluate energy analysis may become the limiting factor in our ability to utilize energy modeling technologies. Energy engineers input data into most of the existing energy analysis tools using electronic 2D DWG drawings and manual data input describing the building, envelope, and mechanical system and occupancy parameters to estimate energy consumption. Each energy analysis tool generates different results based on different assumptions and input data. Validation for the CESS building was conducted by comparing the results from BIM based energy modeling with building energy analysis completed by an expert energy analyst using eQUEST, an energy modeling software that is an industry staple.

\subsubsection{Validation with eQUEST}

A comparison was made in Figure 26 between the baseline model and proposed design model generated by Green Building Studio ${ }^{\circledR}$ and eQUEST, where ten different zones (corridor, office, dorm, PT, mechanical, high bay, reception, kitchen and open space) were modeled. The baseline model represents the annual energy cost for a building design as defined in ASHRAE 90.1-2004, Informative Appendix G. Comparison of the two models revealed that the difference is in a range of approximately $9 \%$ 
( $6 \%$ between baselines; $15.5 \%$ between proposed). Also the differences between baseline model and proposed model were in 35-40\% at the confidence level of 80-85\%, which shows that BIM based energy modeling was successful. Looking closer at the Green Building Studio ${ }^{\circledR}$ and eQUEST models, which were done by two different people, we found variations that accounted for much of the variation in thermal loads. However, there is a need for further work in developing ways in which to perform the validation in detail for different energy models.

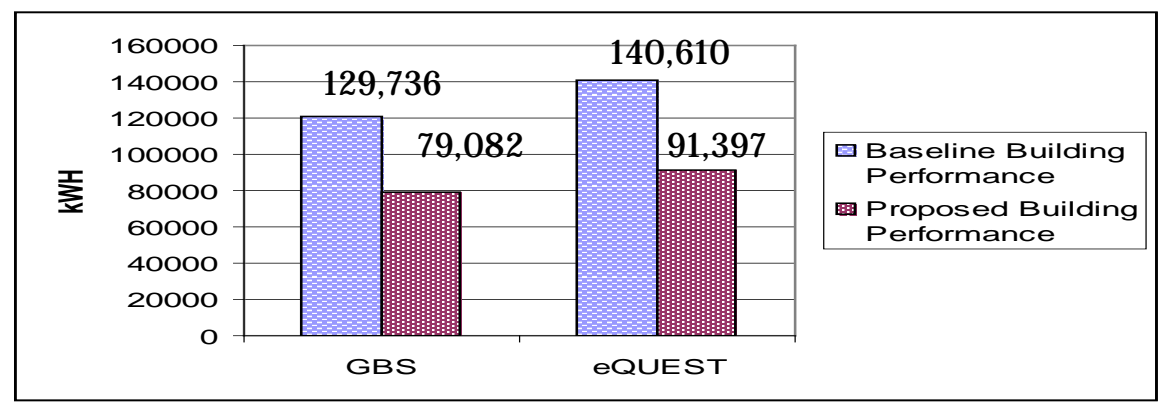

Figure 26. Comparison of Green Building Studio ${ }^{\circledR}$ and eQUEST results for baseline and proposed design.

\subsubsection{Community Emergency Services Station project update}

Design drawings and specifications were completed for the CESS, and a construction contract was awarded late summer 2009. The current LEEDNC 2.2 rating is LEED Platinum. The CESS project has been registered with the USGBC and will be certified with the USGBC upon construction completion. The ESTCP project team is continuing to monitor progress of this project, and to ensure that the LEED On-Line submittals are being documented throughout the project. Although the PA (program amount or construction budget) of this project was not increased, labor for several LEED credits is being accomplished by members of the ESTCP project team. During FY10 and FY11, lessons learned during this ESTCP project will be shared with USACE, and all three military services.

\subsection{Case Study 2: Energy modeling of Fort Lewis (WA) Chapel - 2D- CAD Model in GraphiSoft ArchiCAD}

This project was to demonstrate a process to economically recover materials from obsolete buildings and capitalize on their value instead of disposing of them in a landfill. This work was performed at Fort Lewis, a large Washington Army National Guard installation in west-central California. A 600 WWII-era wooden building was relocated to be used as a classroom building which consists of one main lecture room, mechanical 
room, and restrooms. The size of the proposed new facility is approximately 4,000 $\mathrm{ft}^{2}$ ( $80^{\prime} \mathrm{X}$ 50') with 120 daily users. Since the building is located in the state of Washington, the design of cooling load was not required. Regarding the energy modeling process, ArchiCAD uses its Zone Tool to designate space(s) for energy simulation in a BIM model while Revit requires the use of Room Tags in the BIM model. However, the rest of the process is almost the same between two programs (Revit and ArchiCAD) where a gbXML file is generated to extract the data required for analysis.

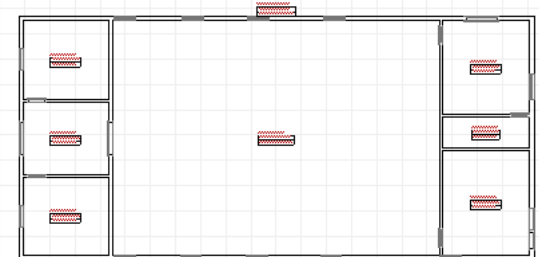

a.

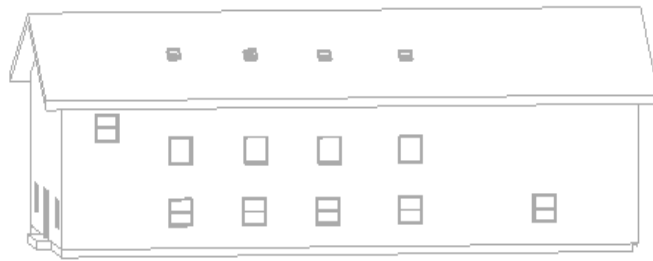

b.

Figure 27. Fort Lewis, WA Chapel building, (a) floor plan and (b) 3D image.

\subsubsection{Energy modeling}

The comparison in Figure 28 shows that different building elements result affected the energy estimations. Compared to the baseline building performance, HVAC options had the greatest impact on annual energy costs, with estimated \$2,710 saving using a 17 SEER/ 0.85 AFUE Split/ Pkgd heat pump. On the other hand, orientation had the least impact on energy costs: \$-11/year. Based on the results of Figure 34, the following design alternatives were recommended:

- HVAC: 17 SEER/ 0.85 AFUE Split/ Pkgd heat pump <5.5 ton

- Lighting efficiency: LPD 40\% less than base run

- Lighting control: Occupancy sensors

- Roof: Wood Frame Roof with Super High Insulation or Metal Frame Roof with Super High Insulation

- Wall construction: Wood Frame Wall with Super High Insulation

- Glazing: Clear Wall Panel (U-0.10, SHCG 0.06, Tvs 0.04). 
Annual energy cost

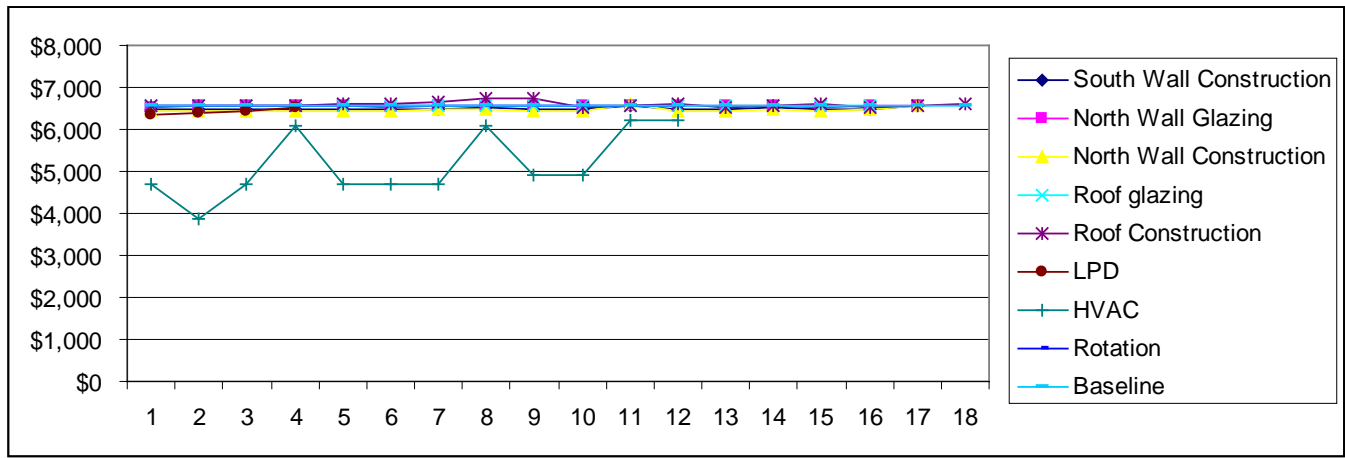

Figure 28. Comparison of different energy estimates.

Rotation: The building was rotated at every 15 degrees for 24 times and measured the differences. Basically, the energy cost for each rotation was not significantly different (0 to -\$11).

- The best option is to face south.

- The worst option is turning the building 90 degrees clockwise (-\$11).

HVAC: Twelve different types of HVAC equipment were tested and measured.

- The range of annual energy costs for HVAC is between $\$ 2,710$ and $\$ 336$.

- The best option is with 17 SEER/ 0.85 AFUE Split/ Pkgd heat pump $<5.5$ ton.

- More efficient HVAC equipment may be available for additional saving.

- In overall, heat pumps are more efficient than Pipe Fan Coil Systems.

- Variance

o The greatest variance is found with heat pump systems.

o The least variance is with Pipe Fan Coil Systems.

LPD (Light Power Density): Tested were four different LPD such as $10,20,30$, and 40 percent. The most optimal result was to choose 40 percent of LPD.

- The range of savings is within $\$ 232$ and 59 .

- Average Lighting Power Density: $1.55 \mathrm{~W} / \mathrm{ft}^{2}$.

Roof Construction: Roof construction was considered with 17 different options. The result confirmed our belief that cool roof was not a desirable 
option, due to the fact that the sun heat is not significant in the northwestern region of the country.

- Range of roof construction is between \$47 and \$-143.

- The best option is with either Wood Frame Roof with Super High Insulation or Metal Frame Roof with Super High Insulation (\$47).

- The worst is from Cool Roof - R15 continuous ins. over roof deck (\$143).

- Increasing R values with Cool Roof was not a good alternative.

- No difference is found between wood frame roof and metal frame roof.

- Wood or metal frame is better than Continuous Deck Roof, Cool Roof R15 continuous ins. over roof deck, or Structural Insulation.

- Increasing R value in Cool Roof continuous ins. over roof deck is good until R 30.

- Variance

o The greatest variance is with Cool Roof - R15 continuous insulation over roof deck.

o The least variance is found with Structural Insulated Panel (SIP) Roof.

Roof Glazing: Different options of roof glazing showed very little impact on estimated energy results with the range of the saving is between $\$ 7$ and \$-1.

- The best option is from Insulated Clear Low-e Cold Climate.

- The worst choice is from Insulated Reflective (\$-1).

- Green or bronze is a little superior to blue or grey. (about \$5)

- Insulated low-e is better than reflective or clear.

- Monolithic Clear Low-e is a good choice in roof glazing. But it is quite a different story with wall windows.

- Clear was highest while Reflective was lowest in performance.

Wall Construction: When choosing types of wall construction, types of insulation and construction materials were important factors to consider.

- The best is to choose Wood Frame Wall with Super High Insulation (\$148).

- The worst is to choose Massive Wall (or metal frame) with Code Compliant Insulation (\$-18).

- The best alternatives are either Structural Insulation or Insulated Concrete Form (ICF). 
- Unlike the roof, there is a difference between wood frame and metal frame.

- Variance

o high with Massive Wall

o low with Structural Ins. Panel (SIP) Wall or Insulated Concrete Form (ICF) Wall.

North Wall Glazing: 17 different wall glazing materials were considered.

- The range of energy cost was between $\$ 34$ and $\$ 8$.

- The best option is to choose Clear Wall Panel (U-0.10, SHGC 0.06, Tvis 0.04 ).

- The worst option is Clear Wall Panel (U-0.53, SHGC 0.36, Tvis 0.25).

- Variance

o High with Clear Wall Panels.

o Low with Insulated Low-e glazing.

\subsection{Case Study 3: Energy modeling of a Standard Design Child Development Center - 2D-CAD Model in Bentley Autodesk}

Bentley is also following the other CAD vendors (Autodesk and GraphiSoft) and pursuing a similar goal of utilizing CAD/BIM models for energy analysis. With the release Bentley Architecture V8i beta, it now can now create gbXML files for direct export and analysis in products such as Green Building Studio (now part of Autodesk). However, we tested a 2009 beta version, and several technical issues had to be to be resolved before a full implementation could be made.

The ERDC CERL project team was able to develop BIM models using Bentley Architecture v.8.i and export gbXML files successfully to Green Building Studio to consider energy efficient design alternatives. But the Corps of Engineers has not implemented v.8.i Corps-wide yet so several steps have to be taken before this process is implemented fully. First, Bentley needs to release the full Bentley Architecture v.8.i version with all the updated features. This was supposed to happen in the fall of 2009. Next, the Corps of Engineers must develop a "workspace" for Bentley Architecture v.8.i that sets up all the layers and fonts and other project standard information. Third, a USACE test project must be accomplished to work out any workspace problems. Once these steps are taken, any Corps project could apply this BIM energy process using Bentley Architecture v.8.i and Green Buildings Studio. 
Huntsville Division, the Center of Standardization for CDCs, sent CERL three different standard designs for CDCs, drawn using Bentley Architecture (see Figure 29). Also included on the DVD was energy modeling results for a CDC located at Fort Stewart, GA (Figure 30). Once the Bentley Architecture v.8.i gbXML file has been exported, energy analysis can be done using Green Building Studio and the results can be compared with the energy analysis conducted by the Huntsville team.

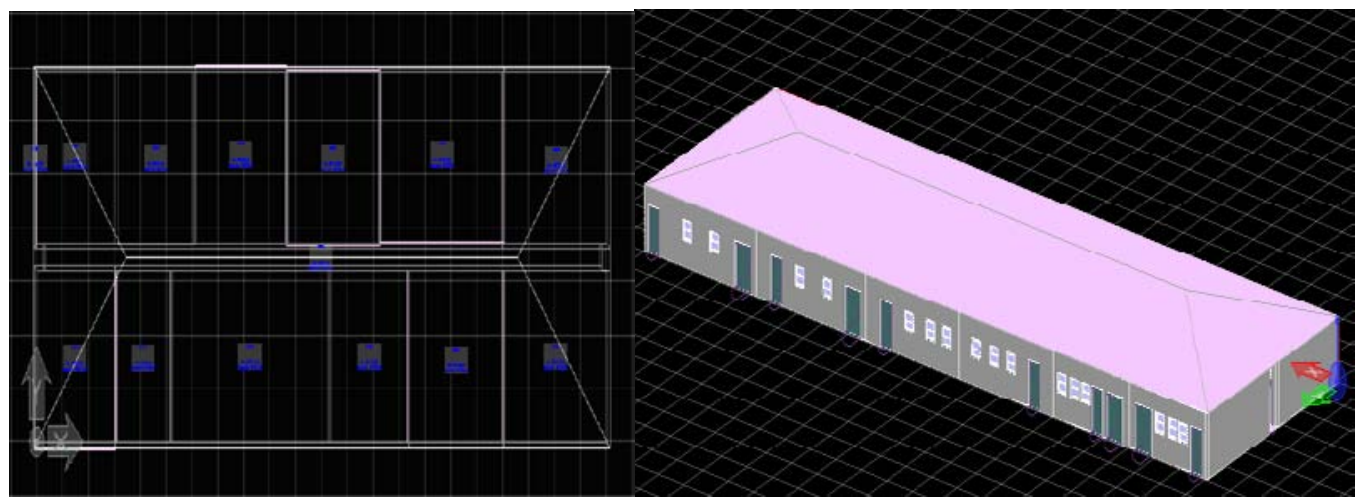

Figure 29. Oak Grove, KY Child Development Center (CDC), (a) building plan (b) 3D image.

Annual Energy Cost



Figure 30. Comparison of different energy estimates.

The comparison in Figure 30 shows that different building elements affected the energy estimates. Compared to the baseline building performance, HVAC options had the greatest impact on annual energy costs, with an estimated \$5,070 saving using a 17 SEER/ 0.85 AFUE Split/ Pkgd. 
heat pump. On the other hand, rotation had the least impact on energy costs: $\$ 45 /$ year. Based on the results of the energy analysis the following design alternatives were recommended:

- HVAC: 17 SEER/ 0.85 AFUE Split/ Pkgd heat pump <5.5 ton

- Lighting Efficiency: LPD 40\% less than base run

- Lighting control: Occupancy Sensors, Daylighting or Both

- Roof: Wood Frame Roof with Super High Insulation or Metal Frame Roof with Super High Insulation

- Wall Construction: Insulated Concrete Form (ICF) wall, 14" thick form

- Glazing: Clear Wall Panel (U-0.10, SHGC, 0.06, Tvs 0.04)

- South Wall Glazing: Insulated Clear Low-e Cold.

Rotation: The building was rotated every 15 degrees for 23 times and the differences were measured. Basically, each rotation was not significantly different (3-\$45).

- The best option is 0 degree rotation (facing south)

- The worst option is turning the building 90 degrees clockwise.

HVAC: Thirteen different types of HVAC equipment were tested and measured.

- The range of savings of HVAC systems is between $\$ 5,070$ and $\$ 291$.

- The best option is with 17 SEER/ 0/ 8-35 AFUE Split/ Pkgd heat pump $<5.5$ ton.

- More efficient HVAC equipment may be available for additional saving.

- In overall, heat pumps are more efficient than Pipe Fan Coil System.

- Variance

o The greatest variance is found with heat pumps

o The least variance is with Pipe Fan Coil System.

LPD (Light Power Density): Tested were four different LPD such as $10,20,30$, and 40 percent. The most optimal result was to choose 40 percent of LPD.

- The range of savings is within $\$ 1032$ and $\$ 349$.

- Average Lighting Power Density: $1.55 \mathrm{~W} / \mathrm{ft}^{2}$. 
Roof Construction: Roof construction was considered with 21 different options. The result showed that metal or wood frame roof without insulation and cool roof is not a desirable option.

- Range of roof construction savings is $\$ 1,941$ and $\$ 77$.

- The best option is either the Wood Frame Roof with Super High Insulation or Metal Frame Roof with Super High Insulation.

- The worst option is the Metal Frame Roof without Insulation and the Wood Frame Roof without Insulation. The Cool Roof also proved not to be a sustainable choice.

- No difference was found between the Metal Frame Roof nor the Wood Frame Roof.

- Metal Frame Roof or a Wood Frame Roof proved to more desirable than Deck Frame Roof or Cool Roof.

Wall Construction: Twenty-one types of wall construction were tested. Insulation and construction materials were important factors to consider.

- The best choice for all sides of the wall was the Insulated Concrete Form (ICF) Wall, 14" thick form.

- The worst choice is the Metal Frame Wall without Insulation.

- The Range of Savings for the North Wall is within \$424 and \$162.

- The Range of Savings for the South Wall is between $\$ 309$ and \$123.

- The Range of Savings for the East Wall is among \$149 and \$60.

- The Range of Savings for the West Wall is within \$143 and \$59.

- The best alternatives are Insulated Concrete Form (ICF) Wall, 10" thick form or Wood Frame with Super Insulation.

North Wall: Seventeen Glazing Types and Six Glass Amounts were tested. Different options showed very little impact on estimated energy results.

- The best option for Glazing Type is the Clear Wall Panel (u-0.10, SHGC 0.06, Tvis 0.04).

- The worst option is the Monolithic Clear Low-e.

- The Range of Savings for Glazing Type is within \$11 and \$1.

- The best option for Glass Amount is - $50 \%$.

- The worst option for Glass Amount is $+50 \%$.

- The Range of Savings for Glass Amount is within $\$ 10$ and \$3. 
South Wall: Seventeen Glazing Types and Six Glass Amounts were tested. Little variance in range of savings showed. For Glazing type the range of savings is within $\$ 17$ and $\$ 1$ and for Glass Amount it is within $\$ 2$ and $\$ 1$

- The best option for Glazing Type is Insulated Clear Low-e Cold.

- The best option for Glass Amount is $+50 \%$.

East Wall: Due to the fact that no windows are on the east wall all of the results for the east wall reported to be the same.

West Wall: Seventeen Glazing Types and Six Glass Amounts were tested. The results mirrored the North Wall. The results should little impact on the energy savings cost. The Range of Savings for the Glazing Type is within $\$ 5$ and $\$ 1$ and the Range of Savings for the Glass Amount is within $\$ 4$ and $\$ 1$.

- The best option for the Glazing Type is the Clear wall panel (u-0.10, SHGC 0.06, Tvis 0.04)

- The best option for the Glass Amount is - $50 \%$.

During this project, questions arose regarding the ASHRAE baseline de faults available when using Green Building Studio ${ }^{\circledR}$. "We are close to that, but we do not try to position Green Building Studio as a compliance tool. Our simulations are more focused on predicted performance for economic analysis whereas an ASHRAE baseline is focused on compliance and may have no basis to the actual energy costs of the building" (email from J ohn Kennedy 18 September 2008).

"How does the Autodesk Green Building Studio web service choose the material assemblies, schedules, etc. required for whole building energy analysis? Green Building Studio determines the appropriate defaults based on where your building is located, the building type, and the size of your building. The majority of construction, schedule and equipment defaults are ASHRAE 90.1 compliant. However, some locations have energy codes that supersede ASHRAE 90.1, and in these cases the baseline energy simulation will be compliant with those regional codes" (from Autodesk Website Q\&A page, regarding Omari Fuller email of 22 September 2008). 


\subsection{Case Study 4: BIM Energy Analysis test at four Engineer Districts and one Army installation}

ERDC-CERL worked with four districts and one installation to test the BIM Energy Analysis process that was developed during this ITTP project. Teams at Fort Bragg, Seattle District, Louisville District, Fort Worth District and Baltimore District were given the sample gbXML file for the Child Development Center, a Bentley Architecture v.8.i model of the CDC, plus instructions on how to create proper BIM files on their own, how to export the necessary gbXML file, and how to use Green Building Studio ${ }^{\mathrm{TM}}$. Reports of their experience are due to CERL within a couple of weeks, but the preliminary results are promising. Seattle District was able to test the process on a variety of projects and BIM models and they later developed methods that can be used in future projects. Seattle is very excited to be able to use this process to improve the energy efficiency of their designs. The other Districts invested less time and effort in this experiment, but they had some good results too. Fort Bragg was the most challenged. They had extreme difficulty getting permission to load necessary software applications on computers in order to test the BIM Energy Analysis process.

Training was identified as a necessary component to get this process adopted by more project delivery teams. There are some technical questions that must be answered also. For instance, Seattle District did energy models of buildings with and without windows and did not see a significant difference in the energy used. We followed up with the Green Building Studio technical experts. 


\section{Conclusions and Recommendations}

\subsection{Conclusions}

\subsubsection{General technology assessment}

The importance of incorporating energy modeling early in concept design cannot be overstated. Key decisions - made by architects, engineers and designers - have profound impacts on the building's energy performance for the life of the building. Federal mandates make energy and fossil fuel conservation a priority in all new designs and retrofits, with increasingly stringent energy reduction targets culminating in the requirement for all federal facilities to be fossil fuel free by 2030 .

During the past several years there has been a dramatic improvement in the capability to conduct energy modeling early in design using data exported from preliminary designs modeled using BIM (Building Information Modeling) tools. The data exchange standard that enables this transfer of information is gbXML (Green Building Extensible Markup Language). Software vendors have been implementing the latest version of the gbXML data exchange in ways that make it easy for project delivery teams to create simple 3-D models of the design alternatives and then export essential information needed to conduct energy analyses. This allows energy modeling of design alternatives without recreating the building geometry, window placement, etc. for input into the energy analysis tool. Even Google SketchUp has a plug-in that allows users to export a gbXML file, although that tool wouldn't allow users to re-import the file after changes are made to it.

There are several software tools that are available to create BIM models. Centers of Standardization (COS) were mandated to use Bentley BIM software on standard designs until 2011. Autodesk Revit and Graphisoft ArchiCAD are frequently used on non-COS projects. All of these programs are capable of exporting gbXML data which can be analyzed by an energy analysis tool.

The energy analysis tools approved for use on Army projects in the Military Transformation Request for Proposal (MT RFP) are Carrier HAP, Trane Trace 700, DOE-2, or EnergyPlus. Carrier HAP and Trane Trace 700 operate on their own, while DOE- 2 and EnergyPlus are engines that 
are typically integrated into a more user friendly interface. Autodesk Green Building Studio runs the DOE-2 energy analysis engine, while Bentley AECOsim Energy Simulator runs the EnergyPlus engine.

When ERDC-CERL evaluated energy analysis tools at the beginning of this effort (2008 and 2009), one of these tools stood out for consideration: Green Building Studio. Since that time, other promising energy analysis tools that work with gbXML files exported from BIM have emerged. Autodesk Green Building Studio is a web-based energy analysis service which uses a special gbXML file exported from 3-D BIM tools such as AutoDesk REVIT, Bentley Architecture or Graphisoft ArchiCAD. Green Building Studio was chosen for this ITTP evaluation because it runs the DOE-2 energy analysis engine (which has been approved for use on Army projects), it accepts gbXML files from the commonly used BIM design tools, and it is suitable for comparison of design alternatives early in design.

\subsubsection{Benefits}

The use of BIM and energy analysis tools early in design would help the Army build and renovate buildings that are more energy efficient.

The benefits of using Green Building Studio as a decision tool early in design include the ability to automatically capture the 3-D building and roof configuration, window placement, thermal zones, and orientation on the site - and to get quick results when comparing different alternatives. Massing and fenestration design alternatives are helpful tools to determine the most energy efficient building. The representation of building geometry and details in typical energy analysis software can take up to two weeks, depending on the complexity of the building. It takes less than a minute to export a gbXML file from a correctly built BIM model. In general the main exterior walls, windows, roofs, floors and interior partitions separating the building's thermal zones are all that is needed in the BIM model for energy analysis. More detail tends to add time and complexity to the model without improving simulation accuracy.

Most current BIM tools require the user to create a model with completely closed volumes and spaces before exporting the gbXML file. If there are problems with the BIM model, Green Building Studio will generate errors instead of analyzing energy use. But the error messages can be used to sequentially "fix" all the problems in the BIM model to prepare a good gbXML file. 
Once the gbXML file is successfully exported from the BIM tool to the Green Building Studio web-service, energy analysis can begin. It is really simple to represent the "base" ASHRAE building and to try many different design alternatives to save energy. For convenience, Green Building Studio has set ASHRAE defaults for the chosen location and building type. The analysis results are reasonably accurate for comparing design alternatives, building orientation, envelope and HVAC systems during early design. The design team could apply a whole building design process to optimize the building energy efficiency.

Other desirable features of Green Building Studio include capabilities to:

- model all the building exterior surfaces in 3-D with predicted solar access for application of Photovoltaic (PV) systems

- determine how many years it would take to pay back the initial costs of a variety of PV systems, taking into account local energy costs

- calculate whether the project earned the LEED Daylighting credit (and to move windows in the BIM model, re-export the gbXML file and try again until the credit is earned)

- estimate water demand by the building fixtures (typical, low-flow or waterless fixtures) and also for landscape uses

- estimate how much rain water can be collected off the roof for use by building fixtures or landscaping purposes

- work toward carbon-neutral design.

With the advent of MILCON Transformation, the responsibility for conducting energy modeling falls solely on the Design/ Build contractor or their consultants. The Army Corps of Engineers has limited if any influence on either the manner in which the energy modeling is conducted, or the resulting energy savings for the building as designed and built. Few if any buildings are designed using the integrated design approach where energy tradeoffs are considered early in design before the floor plan is set.

To help address this problem, and to recognize the expense and challenge of repeatedly modeling annual energy usage and performance for repetitive building types, ERDC-CERL partnered with NREL (National Renewable Energy Laboratory) to develop Design Guides similar to the ASHRAE Design Guides for the eight most commonly constructed MILCON facility types: TEMF (Tactical Equipment Maintenance Facility), Dining Facilities, Barracks (both Training and 1-plus-1), Child Development Centers, Battalion Headquarters, Company Operations, and Reserve Centers. These pre- 
scriptive requirements are being incorporated into the MILCON Transformation RFP. PDTs (Project Delivery Teams) designing those projects could choose to follow the prescriptive energy conservation requirements for the climate region or completing detailed building energy modeling following the ASHRAE rules.

But what about all the unique facility types which are built by the Army? Do we expect each PDT to follow the 317 page User's Manual which explains the ASHRAE 90.1 modeling requirements?

There is a better way. A tool such as Green Building Studio should be used during a planning or early design charrette to identify energy saving measures which meet or exceed the $30 \%$ energy saving requirement over the ASHRAE baseline. If the project is being awarded as a Design/ Build project, the RFP could require the energy saving measures for the project similar to the MILCON Transformation Design Guides. If design is continuing, the PDT could continue refining the BIM model and use more sophisticated energy analysis tools to complete emerging analysis for the project.

\subsubsection{Costs}

There is no cost to ACSIM if USACE or private sector A/ E firms use this technology during planning and design charrettes. USACE and private sector A/E teams will have appropriate BIM software and typical energy analysis software due to existing requirements. They would most likely be conducting the planning and design charrettes, which installation personnel can actively participate in.

Bentley BIM software is available through a USACE-wide and an Armywide purchase agreement. The Bentley v.8.i workspace has been developed and distributed throughout USACE soon. Bentley recently offered an energy analysis tool called AECOsim Energy Simulator that ties the Bentley BIM model to EnergyPlus and allows import/ export of various file formats. AECOsim should be included in the USACE purchase agreement soon.

Autodesk has completed a USACE-wide purchase agreement which allows design teams to access Revit, Green Building Studio and Ecotect.

For very simple design or retrofit exercises at Army installations, it might be appropriate to use Google SketchUp to create a simple 3-D model to 
export the gbXML file from. Google SketchUp is a very inexpensive tool. (Seattle District is in the process of testing SketchUp to create gbXML files). If SketchUp works, it might be more appropriate for Army installation personnel due to the lower cost and simplicity.

Prospective users can try Green Building Studio or AECOsim Energy Simulator for 1 month at no cost. Annual subscriptions are available with a qualifying Autodesk product or as a Standalone Web Service.

\subsection{Recommendations}

\subsubsection{General}

It is recommended that an energy analysis tool such as Green Building Studio or AECOsim Energy Simulator be used early in design to optimize the building configuration, orientation, fenestration and other features. Project delivery teams need to have this conversation early enough to be able to improve the floor plans and overall design. It is apparent that USACE or A/Es will have stronger capabilities than installation personnel to create BIM models during the planning or design charrettes, but installation personnel should be actively engaged in the integrated design process to optimize the building. This same process was applied during the 4 day Fort Bragg 35\% design charrette which resulted in a LEED NC 2.2 Platinum Community Emergency Services Station.

Project delivery teams (PDT) should learn how to take full advantage of the BIM software they are using for designs so they can export gbXML files to an appropriate energy analysis tool for analysis of design tradeoffs. PDTs will choose different energy analysis tools based on their past experience, the capabilities needed for the project, and the stage of design, but it is essential that an integrated design process be used to optimize the building early in design. This BIM energy analysis capability needs to be integrated into BIM and Sustainable Design training, planning and design charrettes, and into the BIM "pit" where standard designs are developed. This capability should be adopted by the USACE Centers of Standardization so the designs they produce take full advantage of passive design strategies to minimize building energy consumption.

Teams will need training and guidance to resolve these typical questions and implementation issues: 
- The team had a lot of interest in understanding the baseline behind GBS defaults, and other teams will have similar questions such as "what is the thickness of the walls in the different design alternatives?"

- Teams will need a Green Building Studio primer to help them, for example, avoid becoming preoccupied with details since GBS is a highlevel decision tool for working to about the $10 \%$ design stage.

Several key questions need to be resolved within USACE:

- How does the use of Green Building Studio (or other tools) fit into standard Corps delivery processes?

- What is the expectation for Green Building Studio use for adapt-build projects where $80 \%$ designs are delivered to Corps geographic districts for use?

o Can changes be made to the fenestration on adapt-build?

- Can changes be made to exterior façade to make the building more efficient?

Army and USACE projects using Bentley BIM software must use Bentley Architecture v.8.i or later to use the gbXML feature because gbXML does not work well in earlier versions.

\subsubsection{Implementation}

There are eight Centers of Standardization (COS) in USACE that address 42 building types (Temple 2006). Model Requests for Proposals (RFPs) are being created for seven standard building types by the Engineering $\mathrm{Re}$ search and Development Center, Construction Engineering Research Laboratory, with assistance from the Department of Energy's Pacific Northwest Laboratory (PNNL). Each RFP establishes target energy consumption budgets for each of 15 climate zones. In addition, prescriptive technology solutions are included for each building system and each climate zone. The covered building systems are roof, walls, slabs, doors, infiltration barriers, vertical glazing, skylights, interior lighting, HVAC, economizer, ventilation, ducts, and service water heating (ERDC-CERL 2007).

The following summarizes a proposed integrated design process using Green Building Studio (or AECOsim Energy Simulator):

1. Design Charrette: Use BIM and Green Building Studio to optimize building geometries and orientations. 
2. BIM Pit: Use Green Building Studio (with optimized building geometry) to evaluate building components and systems.

3. Design using components and systems selected.

4. Run Carrier HAP energy model (or other approved energy modeling software) when the design is nearly completed.

It is anticipated that Army installation personnel may have difficulties acquiring the software approval and training. We recommend improved coordination between USACE technical experts with the Army Certificate of Networthiness $(\mathrm{CoN})$ reviewer so IMCOM and installation personnel can document for local information technology personnel that these design and engineering analysis software tools are used commonly by Army Engineer Districts and private sector A/E firms. Because it currently takes about 6 months to receive an initial response on a CoN submittal, closer coordination between USACE and the Army CoN reviewer could decrease response time significantly.

Finally, it is recommended that new software tools such as Bentley AECOsim Energy Simulator and Autodesk Ecotect be considered as tools to design high performance buildings. AECOsim Energy Simulator is a robust energy analysis tool using the EnergyPlus engine, which could be used with the Bentley Architecture v.8.i BIM models. Ecotect is a promising tool which is tightly integrated with Autodesk Revit BIM models. We did not evaluate the full capabilities of either AECOsim Energy Simulator or Ecotect, but think they may be more suitable for design analysis, rather than early design (which could be completed using Green Building Studio).

\subsubsection{Future projects using integrated design with BIM and energy analysis}

Based on this ITTP effort, the Army Reserve Support Team at Louisville District has proposed selecting a FY10 project which will use Bentley Architecture v.8.i, gbXML, and AECOsim Energy Simulator to design and construct a building that is $50 \%$ to $65 \%$ more energy efficient than the ASHRAE baseline.

As a continuation of the ESTCP project researching how to design a high performance building using the whole building design process, ERDC CERL and other ESTCP team members will participate in planning or design charrettes for several USACE Standard designs. We will apply the lessons learned during the ESTCP and ITTP Early Design Energy Analysis Using BIM projects to help the COS design high performance, energy effi- 
cient buildings. This will include energy modeling during the charrette using the process proposed in this research effort.

Seattle District is incorporating energy analysis using BIM models into their projects. A Seattle District team member who participated in this research project, has since developed a process for using Autodesk Revit, Green Building Studio, Ecotect and daylight modeling tools early in design to improve the energy efficiency and sustainability of their designs. Other districts are also experimenting with these tools during their design processes.

The 2030 USACE Integration Project team used BIM Energy Modeling and other advanced analysis tools while working on a project to make Fort Leonard Wood net-zero energy, water, and waste. Their design entry was submitted to the most prestigious international design competition of the $21^{\text {st }}$ Century, the Holcim Award for Sustainable Construction. The team of creative people was selected from a USACE wide competition, and they are bringing lessons learned during this special project back to their Districts. The winning entries will be announced in October 2011. Early design energy analysis using BIM is encouraged by leaders in HQUSACE and ACSIM, and is being adopted by District and $\mathrm{A} / \mathrm{E}$ design teams to create better buildings. 


\section{Appendix A: Bibliography}

\section{Cited references}

Abaza, H. (2008), "An interactive design advisor for energy efficient building”, J ournal of Green Building.

Autodesk (2008), "Building Information Modeling for Sustainable Design", http:// images.autodesk.com/adsk/ files/bim_for_sustainable_design_jun05.pdf.

Building Information Modeling (BIM): A Road Map for Implementation to Support MILCON Transformation and Civil Works Projects within the US Army Corps of Engineers. ERDCTR-06-10. Champaign: ERDC. October 2006.

Crawley, D., Hand, J ., Kummert, M. and Griffith, B. (2005), “Contrasting the capabilities of building energy performance simulation programs", J oint Report, Version 1.0.

Dahl, P., Horman, M., Pohlman, T. and Pulaski, M (2005), "Evaluating design-buildoperate-maintenance delivery as a tool for sustainability", Construction Research Congress.

ERDC-CERL. 2007. Draft TEMP EPAct addition to MT RFP 011000. 15 Sep 2007.

Franconi, E. and Huang, Y.J . "Shell, System, and Plant Contributions to the Space Conditioning Energy Use of Commercial Buildings." In Proceedings of the ACEEE 1996 Summer Study on Energy Efficiency in Buildings, August 25 - 31, 1996, Washington, DC, American Council for an Energy-Efficient Economy, 1996. Vol. 4. LBNL-38970.

Huell, Edward (2008), "Building Information Modeling: Collaboration, Integration, and Interoperability". https://cadbim.usace.army.mil/MyFiles/EdwardHuellBIM_FINAL.pdf

Krygiel, Eddy, and Nies, Bradley (2008) “Green BIM - Successful Sustainable Design with Building Information Modeling”, Wiley Publishing Inc.

Lapinski, A., Horman, M., and Riley, D. (2005), “Delivering sustainability: lean principles for green projects", Construction Research Congress

Magent, C., Riley, D., and Horman, M. (2005), “High performance building design process model", Construction Research Congress

Mora, R., Rivard, H., and Bedard, C. (2005), "From architectural sketch to feasible structural system solution", Computing in Civil Engineering

Paulson, B. (1976), "Designing to reduce construction costs", J ournal of the Construction Division, 102 (C04): 588

Riley, D., Sanvido, V., Horman, M., McLaughlin, M., and Kerr. D. (2005), “Lean and green: the role of design-build mechanical competencies in the design and construction of green building", Construction Research Congress, ASCE. 
Smith, Deke, AIA. 2007. An Introduction to Building Information Modeling (BIM). J ournal of Building Information Modeling. NBIS/ NIBS. Pp 12-14. Fall 2007.USGBC (2008). "The cost \& benefits of achieving green building", https:// www.usgbc.org/ ShowFile.aspx?DocumentID=2583

Temple, Merdith W.B., BG, USA. 2006. Memorandum: Realignment/Establishment of Centers of Standardization (COS), FY-06. Department of the Army, US Army Corps of Engineers. 6 March 2006.

US Army. MT RFP, Section 0133 16, Design After Award. 30 May 2008.

Wilson, Lt. Gen. Robert. USA. Oct 2006. MILCON Transformation: ACSIM Offers View of MILCON Transformation. Department of the Army, Engineer Update Oct 2006. . http://www.hq.usace.army.mil/cepa/pubs/oct06/story1b.htm

\section{Building Information Modeling (BIM)}

Autodesk Revit White Paper. Building Information Modeling for Sustainable Design. 2005.

Davis, Dianne. 2007. Lean, Green and Seen. J ournal of Building Information Modeling. NBIS/ NIBS. Pp 16-18. Fall 2007.

Holness, Gordon V.R., 2008. BIM: Gaining Momentum. ASHRAE J ournal. J une 2008.

Spangler, Stephen. 2006. What is BIM and why should I care about it? http:// www.axiomint.com/ mst/2006/ 200612-spangler-on-bim.htm.

Suermann, Patrick C. and Raja R.A. Issa. 2007. BIM Effects on Construction Key Performance Indicators (KPI) Survey. J ournal of Building Information Modeling. NBIS/ NIBS. Pp 26-27. Fall 2007.

\section{Energy policy}

Architecture 2030. 2008. Meeting the 2030 Challenge Through Building Codes. J une 20, 2008.

ASHRAE. 2004. Energy Standards for Buildings Except Low-Rise Residential Buildings, I-P Edition. Atlanta: ASHRAE. 2004.

ASHRAE. 2004. 90.1 User's Manual, ANSI/ASHRAE/ IESNA Standard 90.1 - 2004. Atlanta: ASHRAE. 2004.

Department of the Army. 2007. Army Energy and Water Campaign Plan for Installations. December 2007.

ERDC-CERL. 2007. Draft TEMP EPAct addition to MT RFP 011000. 15 Sep 2007.

US Congress. 2007. H.R. 6 Energy Independence and Security Act of 2007. 4 J an 2007.

The President. 2007. Executive Order 13423-Strengthening Federal Environmental, Energy, and Transportation Management. 26 J an 2007. 
Department of Energy 2007. 10 CFR Parts 433, 434, and 435-Energy Conservation Standards for New Federal Commercial and Multi-Family High-Rise Residential Buildings and New Federal Low-Rise Residential Buildings. Federal Register. Vol. 72, No. 245. 21 Dec 2007.

\section{LEED}

Federal Register, Executive Order 13423. 2007. Strengthening Federal Environmental, Energy, and Transportation Management.

Headquarters, US Army Corps of Engineers. 2008. USACE Army LEED Implementation Guide. J anuary 15, 2008.

\section{Energy modeling}

Crawley, D.B., et. al. 2005. Contrasting the Capabilities of Building Energy Performance Simulation Programs. US Department of Energy, University of Strathclyde, and University of Wisconsin. J uly 2005.

Hand, J.W., et. al. 2005. Improving the Data Available to Simulation Programs. University of Strathclyde, US Department of Energy, Victoria University of Wellington, and DHL Consulting. Ninth International IBPSA Conference: Montreal. August 15-18.

Novitski, B.J . 2008. Energy Modeling for Sustainability: Evolving software for modeling energy dynamics makes it easier for architects and engineers to design green buildings. McGraw-Hill Construction Continuing Education. April 2008.

US Army. MT RFP, Section 0133 16, Design After Award. 30 May 2008.

\section{General}

Army.mil. 2008. Fort Bragg earns White House Closing the Circle Award. http:// www.army.mil/-newsreleases/ 2008/ 06/ 23/ 10384-fort-bragg-earnswhite-house-closing-the-circle-award/.

Fry, Al. 2005. Water: Facts and Trends. Water and Sustainable Development Program. World Business Council for Sustainable Development.

Galloway, D.L., D.R. J ones, and S.E. Ingebritsen. 2000. Land Subsidence in the United States. USGS Fact Sheet-165-00. US Department of Interior, US Geological Survey. December 2000.

Konopacki, S.J . and H. Akbari. 1996. Estimates of Energy Consumption by Building Type and End Use at US Army Installations. LBL-38577, UC-000. Berkeley: Lawrence Berkeley Laboratory. August 1996. 36 pp.

Temple, Merdith W.B., BG, USA. 2006. Memorandum: Realignment/ Establishment of Centers of Standardization (COS), FY-06. Department of the Army, US Army Corps of Engineers. 6 March 2006.

USACE Policy on Applicability and Use of the Military Construction Transformation (MT) Model Request for Proposal RFP) (November 2006) 


\section{Appendix B: Descriptions of Widely Used Building Energy Analysis Software}

\section{Carrier Hourly Analysis Program}

A versatile system design tool and an energy simulation tool in one package, Carrier's Hourly Analysis Program (HAP) uses a Windows-based graphical user interface (http://www.carrier-commercial.com/software). HAP's design module uses a system-based approach to HVACload estimating. This approach tailors sizing procedures and results to the specific type of system being considered. Central air handling units (AHUs), packaged rooftop units, split systems, fan coils, water source heat pumps and Packaged Terminal Air Conditioner (PTACs) can be sized, as can constant air volume (CAV), variable air volume (VAV) and multiple-zone systems. Calculation rigor and integrity are provided by the ASHRAE Transfer Function Method for calculating building heat flow. HAP's energy analysis module performs an hour-by-hour simulation of building loads and equipment operation for all 8,760 hours in a year. HAP uses typical meteorological year (TMY) weather and the ASHRAE Transfer Function to calculate dynamic heat flow. Many types of air handling systems, packaged equipment and central plant equipment can be simulated. Carrier HAP is intended for use by practicing engineers involved in the design, specification and analysis of commercial HVAC systems/ equipment; instructional tool in colleges and universities; design/build contractors; HVAC contractors; facility engineers, energy service consultants and other professionals involved in the design and analysis of commercial building HVAC systems. It is useful for new design, retrofit and energy conservation work. General knowledge of HVAC engineering principles is required. Carrier HAP is available for purchase.

Carrier HAP accepts gbXML files but it isn't clear if the gbXML export feature has been added to the software yet.

\section{DesignBuilder}

DesignBuilder uses the EnergyPlus thermal simulation engine. It works in 3D, allowing building models to be assembled by positioning, stretching, and cutting 'blocks'. The program has data templates containing common building elements which allows early-stage modeling of building designs. 
Users with a wide range of HVAC types should export IDF files and work in the EnergyPlus IDF editor. It has a number of different ways of organizing the 3D model hierarchy, and also provides an OpenGL visualization option that allows the user to view the model with realistic materials and accurate shadow-casting. However, despite its innovations, DesignBuilder is limited in its ability to import CAD/ BIM files created in other applications - currently it is only possible to import 2D DWG/ DXF files. Consequently, a proposed building would need to be modeled virtually from scratch within the DesignBuilder application; for practices that have adopted a BIM workflow, this would mean that time that could otherwise have been invested in the building information model would have to be allocated to creating a standalone, building simulation model. Another counter-productive consequence would be that changes in the building simulation model would then have to be recreated in the building information model, again resulting in a duplication of information and resources. A free 30 day trial is available. Figure B1 shows an energy analysis in DesignBuilder.

Version 2 of DesignBuilder software does provide interoperability with BIM models through a gbXML import capability. The DesignBuilder gbXML import process includes sophisticated healing algorithms which allows problems with the CAD surfaces to be corrected.

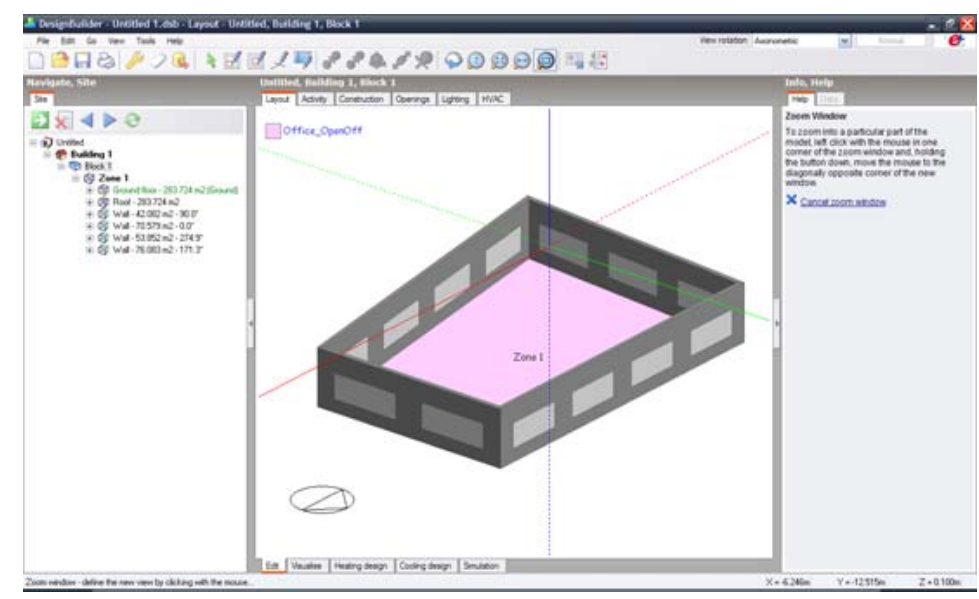

Figure B1. Energy analysis using DesignBuilder.

\section{DProfiler}

DProfiler is a "macro" BIM software targeted towards the planning and conceptual design phase to get an accurate cost estimate of a proposed design. It is integrated with the RSMeans cost database that is updated quarterly and includes modules that integrate with Timberline's estimating ap- 
plications and eQuest for energy analysis. DProfiler allows massing model capability and includes site design tools that automate parking layouts. There are multiple options for viewing and editing costs and DProfiler has IFC export capability. DProfiler is more suitable for "after-the-fact" design representation rather than conceptualization. The costing interface is useful for a contractor, however, the modeling aspect is useful for architects. DProfiler is sold by Beck Technology with a user license at $\$ 3400 /$ year.

It is unclear if DProfiler accepts gbXML files. The DProfiler website does not mention use of the gbXML data exchange standard, and the product is not listed on the gbXML consortium website.

\section{Ecotect ${ }^{\mathrm{TM}}$}

Ecotect ${ }^{\mathrm{TM}}$ is an environmental design tool which couples a 3D modeling interface with solar, thermal, lighting, acoustic and cost analysis functions (Figure B2). Ecotect ${ }^{\mathrm{TM}}$ supports the use of environmental design principles during conceptual stages of design. The software provides essential visual and analytical feedback from a simple sketch model, progressively guiding the design process as more detailed information becomes available. The model is scalable, handling simple shading models to full-scale cityscapes. Its export facilities allow final design validation by interfacing with Radiance, EnergyPlus and other focused analysis tools. Ecotect ${ }^{\mathrm{TM}}$ is intended for users with some CAD and environmental design experience but contains an extensive help file and tutorial. Ecotect ${ }^{\mathrm{TM}}$ is useful for testing design ideas at the conceptual stages, progressively guiding the user as more detailed design information becomes available. The user must be aware of required data inputs for different modeling analyses. Ecotect ${ }^{\mathrm{TM}}$ was developed by the Centre for Research in the Built Environment and has since been purchased by Autodesk and is being sold as Autodesk Ecotect ${ }^{\mathrm{TM}}$ 2009. A demo version can be downloaded at http://www.EcotectTM.com/.

Ecotect ${ }^{\mathrm{TM}}$ has the ability to import both gbXML and IFC file formats, but gbXML provides the ability to create 3D zone models for thermal and energy analysis. 


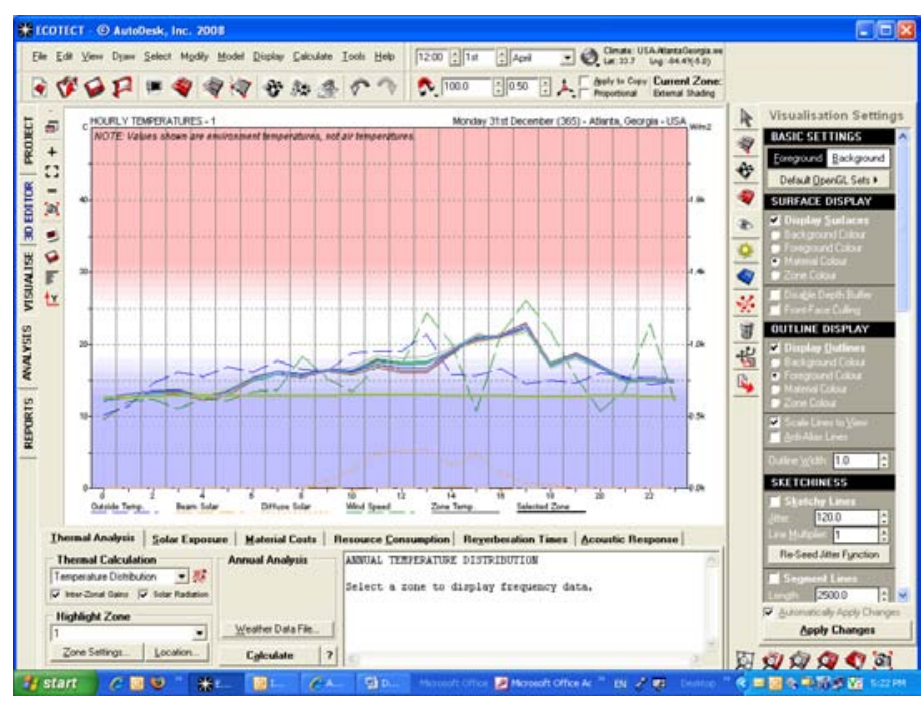

Figure B2. Energy analysis using Ecotect ${ }^{\mathrm{TM}}$.

\section{EnergyPlus}

EnergyPlus models heating, cooling, lighting, ventilating, and other energy flows as well as water in buildings (http://www.energyplus.gov). Originally based on features of BLAST and DOE-2.1E, EnergyPlus was developed by the US Department of Energy as an energy analysis and thermal load simulation program available by download for free. It includes additional capabilities such as time steps of less than an hour, modular systems and plant integrated with heat balance-based zone simulation, multizone air flow, thermal comfort, water use, natural ventilation, and photovoltaic systems. EnergyPlus is a stand-alone simulation program without a "user friendly" graphical user interface. EnergyPlus reads input and writes output as text files. (Figure B3.

A number of graphical interfaces have been written for EnergyPlus, and Department of Energy continues to fund the development of enhanced features (http://apps1.eere.energy.gov/buildings/energyplus/).

The EnergyPlus simulation engine has been embedded in commercially available energy analysis tools such as Hevacomp, which was purchased by Bentley. It was renamed AECOsim Energy Simulator and should be available soon to USACE through the Bentley software agreement. 


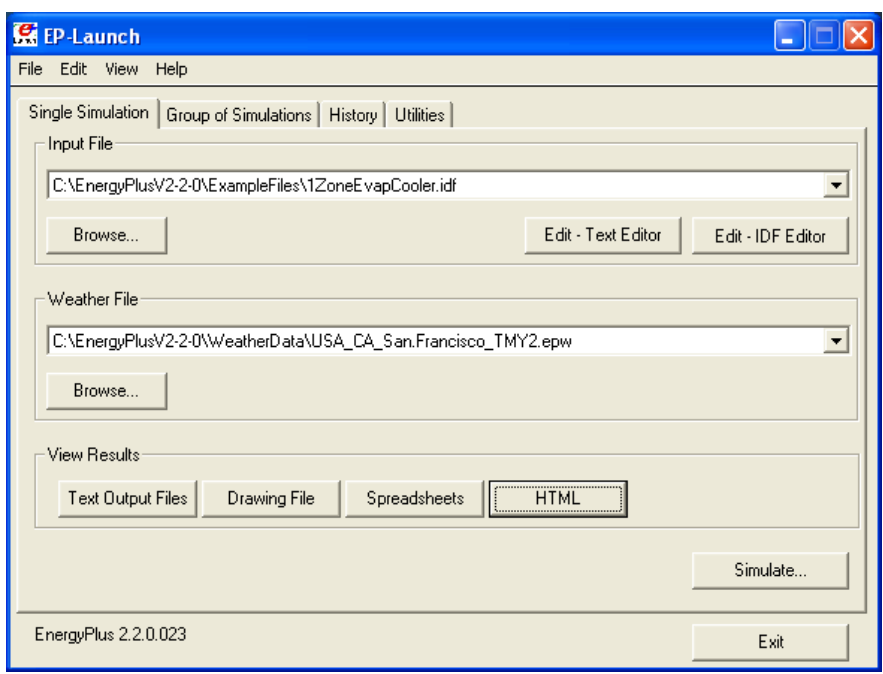

Figure B3. Graphical User Interface of EnergyPlus.

\section{eQUEST $^{\circledR}$}

eQUEST (http://www.doe2.com/equest/) is a freeware building energy analysis tool that utilizes the DOE-2 analytic engine (Figure B4). eQUEST incorporates wizard functions, called energy efficiency measures (EEM), that allow sophisticated simulation without extensive experience in building performance modeling. Analysis output is contained in a graphical results display module. eQUEST guides users through the creation of a detailed building model and allows users to perform parametric simulations of design alternatives.

It isn't apparent that eQUEST can import gbXML files, however Green Building Studio ${ }^{\circledR}$ can export eQUEST files that can be used for further analysis.



Figure B4. Energy Analysis using eQUEST. 


\section{Green Building Studio ${ }^{\circledR}$}

Green Building Studio ${ }^{\circledR}$ links architectural 3-D CAD building designs with energy analysis (http://www.greenbuildingstudio.com). Green Building Studio ${ }^{\circledR}$ enables architects to calculate the operational and energy implications of early design decisions (Figure B5). The Green Building Studio ${ }^{\circledR}$ web service automatically generates geometrically accurate, detailed input files for major energy simulation programs such as eQUEST and EnergyPlus. Green Building Studio ${ }^{\circledR}$ uses the DOE-2 version 3.3 (EPAct 2005 qualified) simulation engine to calculate energy performance. Key to the integrated interoperability exhibited is the Green Building XML schema (gbXML), an open XML schema of the International Alliance of Interope rability's aecXML Group. By using gbXML-enabled applications, Green Building Studio ${ }^{\circledR}$ users are able to eliminate redundant data entry and dramatically reduce the time and expense traditionally associated with whole-building energy simulation analyses. Their service offers whole building energy analysis, Energy STAR scoring, carbon emission reporting, water usage and costs evaluation, daylighting (qualification for the LEED daylighting credit), photovoltaic potential, natural ventilation potential, and wind energy potential analysis tools for architects and designers using $\mathrm{CAD}$ and BIM software from industry providers such as Autodesk, Archi$\mathrm{CAD}$ and Bentley. Green Building Studio ${ }^{\circledR}$ provides the ability to quickly and efficiently analyze building design proposals, providing building performance information to support sustainable design. This tool is free for a month, then users have to purchase a web-based license.

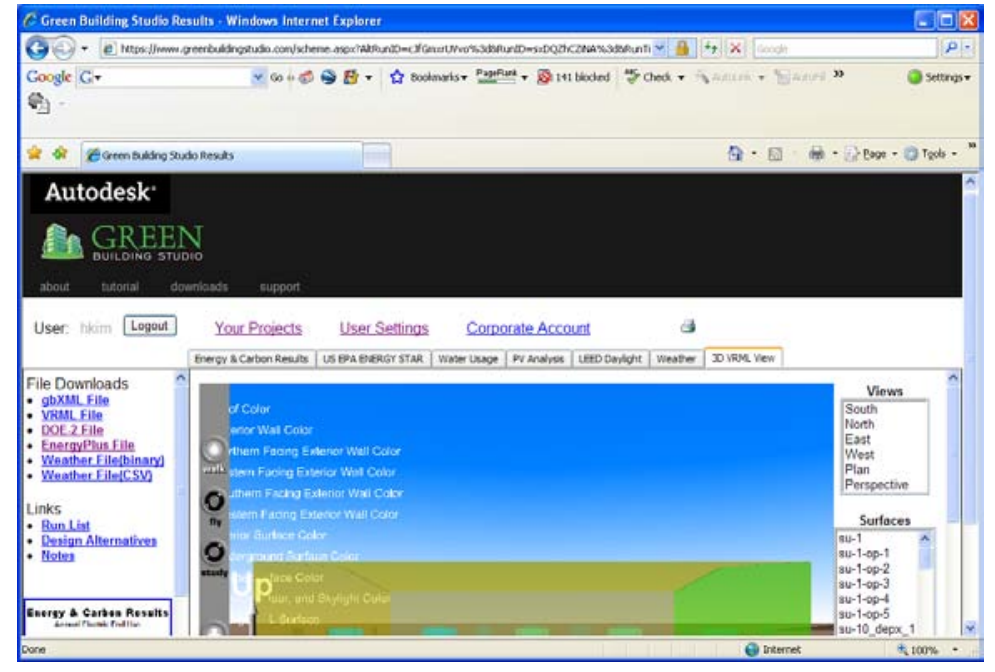

Figure B5. Energy analysis using Green Building Studio ${ }^{\circledR}$. 


\section{VE}

Integrated Environmental Solutions Ltd (IES) produces a suite of building simulation and assessment tools that are emerging BIM tools. VE-Ware, VE-Toolkits, VE/ Energy, VE/ Lighting \& Daylighting, and VE/ Solar are some of the software tools (http://www.iesve.com/Software/VE-Ware). While it is certainly not a substitute for the detailed energy analysis that can be conducted with the full product suite, VE-Ware can be used at the early design stages for comparing different design, layout and system options to find the most energy efficient solution. It works with the building geometry as input and uses international data on climatic conditions and the typical characteristics of different building, room and system types to provide feedback on the building's energy consumption and carbon dioxide emissions. One of the drawbacks is that currently works only with models exported from Revit or Google SketchUp ${ }^{\mathrm{TM}}$. IES plans to expand it to work with other BIM applications in the future version. The VE-Ware wholebuilding energy and carbon usage tool is available free, as is the IES plugins to Google SketchUp ${ }^{\mathrm{TM}}$.

\section{Trane TRACETM 700}

Trane Air Conditioning Economics, or TRACE is a design-and-analysis tool and used by HVAC professionals to optimize the design of a building's HVAC system based on energy utilization and life-cycle cost. TRACETM 700 is accepted for Army projects. (http://www.trane.com/commercial/software). TRACETM 700 brings the algorithms recommended by the American Society of Heating, Refrigerating, and Air-Conditioning Engineers (ASHRAE) to the Windows operating environment (Figure B6). TRACE ${ }^{\mathrm{TM}}$ 700 can be used to assess the energy and economic impacts of buildingrelated selections such as architectural features, comfort-system design, HVAC equipment selections, operating schedules, and financial options. TRACETM 700 compares up to four alternatives for a single project by modeling various air distribution and mechanical system/ control options and assesses the life-cycle cost and payback of each combination based on 8,760 hours of operation. TRACETM 700 is intended for use by engineers, architects, and contractors who design and analyze commercial HVAC systems/ equipment for new and existing buildings; energy consultants and utility companies; building technology researchers; state and federal agencies; and colleges and universities. General knowledge of HVAC engineering principles and building geometry are required. TRACETM 700 is sold and training is recommended. 
TRACETM 700 now imports/ exports gbXML files which can be used to create a new TRACETM 700 project file based on building dimensional information from a CAD drawing. Since this tool is a favorite of many USACE District mechanical engineers, it would be worth testing the gbXML import feature from project BIM files.

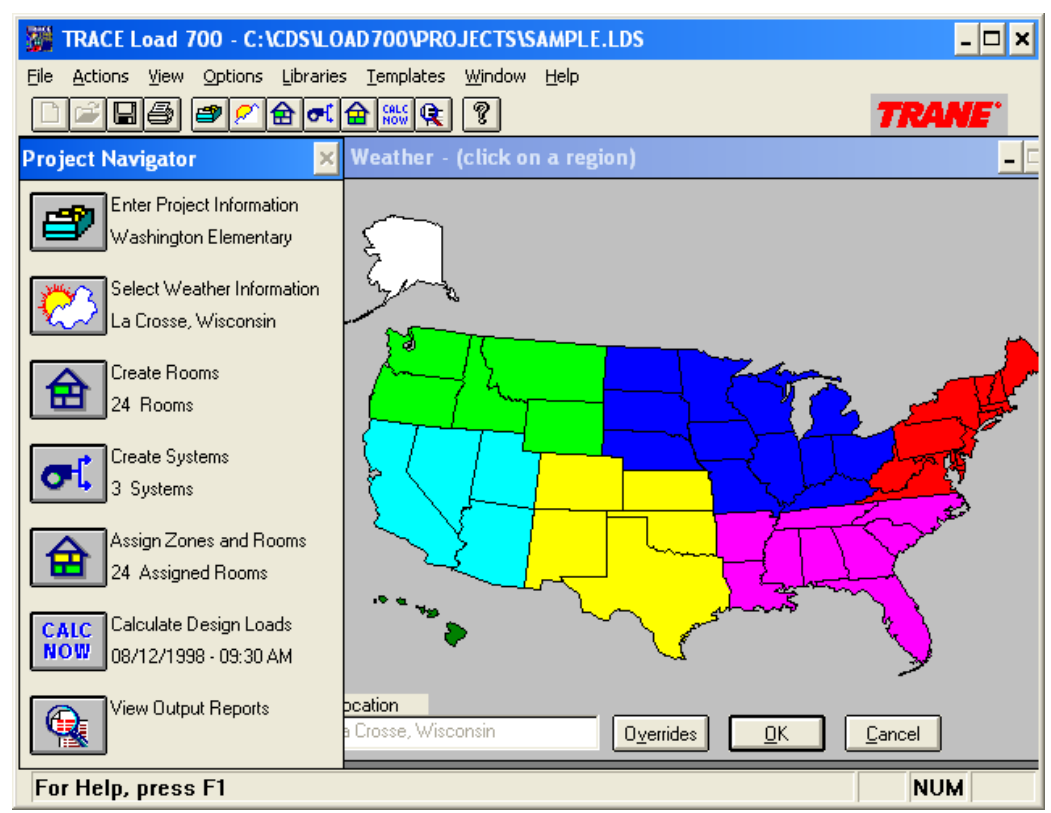

Figure B6. Energy analysis using Trane TRACETM 700.

(See comments on gbXML export and Trane TRACETM 700 at http://forums.augi.com/showthread.php?t=52135. 


\section{Appendix C: Partial Vendor List}

\begin{tabular}{|c|c|c|}
\hline Product & Cost & Recommended BIM Software \\
\hline Green Building Studio & $\begin{array}{l}\text { \$755/Anual Subscription } \\
\$ 4,995 / 10 \text { Annual } \\
\text { Subscriptions }\end{array}$ & $\begin{array}{l}\text { Bentley Architecture v8i or } \\
\text { Revit MEP }\end{array}$ \\
\hline Trane Trace & $\begin{array}{l}\$ 1,995 \text { first copy }+ \\
\$ 995 / \text { Each Additional } \\
\$ 3,990 / \text { Site }\end{array}$ & \\
\hline $\begin{array}{l}\text { Bentley AECOsim Energy } \\
\text { Simulator }\end{array}$ & Not Available & Bentley Architecture v8i or later \\
\hline Carrier Hap & $\$ 1,495$ & \\
\hline Ecotect & $\begin{array}{l}\text { Not Available } \\
\text { Green Building Studio is free } \\
\text { when Ecotect is purchased }\end{array}$ & Revit MEP \\
\hline
\end{tabular}

\section{Green Building Studio}

The Autodesk ${ }^{\circledR}$ Green Building Studio ${ }^{\circledR}$ web-based energy analysis service can help architects and designers perform whole building analysis, optimize energy efficiency, and work toward carbon neutrality earlier in the design process. With faster, more accurate energy analysis of building design proposals, architects and designers can work with sustainability in mind earlier in the process, plan proactively, and build better.

Website: http://www.greenbuildinstudio.com

\section{$\underline{\text { Trane Trace }}$}

As a systems and services provider, Trane understands the challenges of designing the most efficient, lowest cost HVAC system solutions. TRACE 700 delivers Trane expertise in superior software built on industryaccepted practices, decades of applications experience and world-class support. TRACE 700 software is the benchmark complete load, system, energy and economic analysis program that compares the energy and economic impact of such building alternatives as architectural features, HVAC systems, building utilization or scheduling and economic options. 


\section{$\underline{\text { AECOsim Energy Simulator }}$}

Bentley AECOsim Energy Simulator offers software for building performance design, simulation, and energy certification based on the EnergyPlus analysis engine to help predict a building's real-world performance as well as provide required compliance checking and documentation, such as those mandated by the US Green Building Council's LEED program.

Website: http://www.bentley.com/en-US/Products/

\section{Carrier Hap}

HAP is a dual function program for load estimating and system sizing for commercial buildings and hour-by-hour energy and operating cost analysis. Thermal loads are calculated using the ASHRAE-endorsed Transfer Function load method. Operating costs are computed based on energy use and demand charges. A wide range of tabular and graphical outputs is available.

Website: http://www.carrier.com

\section{$\underline{\text { Ecotect }}$}

ECOTECT is a complete building design and environmental analysis tool that covers the full range of simulation and analysis functions required to truly understand how a building design will operate and perform. It finally allows designers to work easily in 3D and apply all the tools necessary for an energy efficient and sustainable future.

Website: http://ecotect.com

\section{gbXML Schema}

The Green Building XML schema, referred to as "gbXML", was developed to facilitate the transfer of building information stored in CAD building information models, enabling integrated interoperability between building design models and a wide variety of engineering analysis tools and models available today. Today, gbXML has the industry support and wide adoption by the leading CAD vendors, Autodesk, Graphisoft, and Bentley. With the development of export and import capabilities in several major engineering modeling tools, gbXML has become a defacto industry standard 
schema. Its use dramatically streamlines the transfer of building information to and from engineering models, eliminating the need for time consuming plan take-offs. This removes a significant cost barrier to designing resource efficient buildings and specifying associated equipment. It enables building design teams to truly collaborate and realized the potential benefits of Building Information Modeling.

Website: http://www.gbxml.org/ 


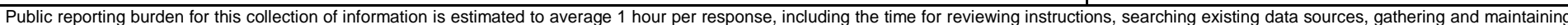

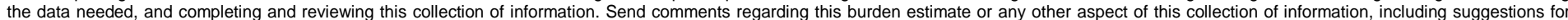

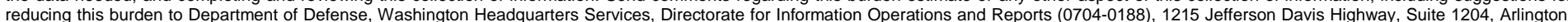

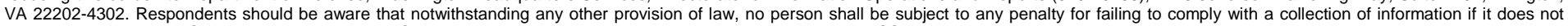
display a currently valid OMB control number. PLEASE DO NOT RETURN YOUR FORM TO THE ABOVE ADDRESS.

\section{REPORT DATE (DD-MM-YYYY) \\ November 2011}

4. TITLE AND SUBTITLE

Early Design Energy Analysis Using Building Information Modeling Technology

\section{AUTHOR(S)}

Annette L. Stumpf, Hyunjoo Kim, and Elisabeth M. Jenicek

\section{DATES COVERED (From - To)}

5a. CONTRACT NUMBER

5b. GRANT NUMBER

5c. PROGRAM ELEMENT NUMBER

ITTP

5d. PROJECT NUMBER

FY09-46

5e. TASK NUMBER

\section{5f. WORK UNIT NUMBER}

8. PERFORMING ORGANIZATION REPORT
NUMBER

ERDC/CERL TR-11-41

Construction Engineering Research Laboratory

P.O. Box 9005

Champaign, IL 61826-9005

\section{SPONSORING I MONITORING AGENCY NAME(S) AND ADDRESS(ES)}

Office of the Assistant Chief of Staff for Installation Management (ACSIM)

Facilities Branch (DAIM-ODF)

2511 Jefferson Davis Highway

Arlington, VA 22202

10. SPONSOR/MONITOR'S ACRONYM(S)

ACSIM

11. SPONSOR/MONITOR'S REPORT NUMBER(S)

\section{DISTRIBUTION / AVAILABILITY STATEMENT}

Approved for public release; distribution is unlimited.

\section{SUPPLEMENTARY NOTES}

\section{ABSTRACT}

With the advent of Military Construction (MILCON) Transformation, the responsibility for conducting energy modeling late in the design process falls solely on the Design/Build contractor or their consultants. This research utilized Building Information Modeling (BIM) for energy analysis during the conceptual design phase. Most building energy analyses are conducted later in the design process by energy analysts. This report describes a process of exploring different energy saving alternatives in early design using 3DCAD (computer-aided design)/BIM technology. This project investigated the feasibility of exporting a gbXML file from a BIM model for use in Green Building Studio, a computer-based energy analysis tool. The goal was to assess the applicability of this technology during a planning or early design charrette in order to identify energy saving measures equal to or exceeding the 30\% energy-saving requirement over the ASHRAE baseline. This type of tool could potentially be used early in the project life cycle to evaluate alternative energy design schemas as part of an integrated whole-building design process.

\section{SUBJECT TERMS}

Building Information Modeling (BIM), computer-aided design (CAD), military construction (MILCON), energy modeling, energy conservation, sustainability

\begin{tabular}{|l|l|l|l|l|l|}
\hline \multicolumn{2}{|l|}{ 16. SECURITY CLASSIFICATION OF: } & $\begin{array}{l}\text { 17. LIMITATION } \\
\text { OF ABSTRACT }\end{array}$ & $\begin{array}{l}\text { 18. NUMBER } \\
\text { OF PAGES }\end{array}$ & $\begin{array}{l}\text { 19a. NAME OF RESPONSIBLE } \\
\text { PERSON }\end{array}$ \\
\cline { 1 - 2 } $\begin{array}{c}\text { a. REPORT } \\
\text { Unclassified }\end{array}$ & $\begin{array}{c}\text { b. ABSTRACT } \\
\text { Unclassified }\end{array}$ & $\begin{array}{c}\text { c. THIS PAGE } \\
\text { Unclassified }\end{array}$ & & 90 & $\begin{array}{l}\text { 19b. TELEPHONE NUMBER (include } \\
\text { areade) }\end{array}$ \\
\end{tabular}

